\title{
Supramolecular Iridium(III) Assemblies
}

\author{
Diego Rota Martir ${ }^{a}$ and Eli Zysman-Colman ${ }^{a *}$
}

${ }^{a}$ Organic Semiconductor Centre, EaStCHEM School of Chemistry, University of St Andrews, St Andrews, Fife, KY16 9ST, UK, Fax: +44-1334 463808; Tel: +44-1334 463826; E-mail: eli.zysman-colman@st-andrews.ac.uk;

URL: http://www.zysman-colman.com

\begin{abstract}
Iridium(III) complexes exhibit remarkable photophysical properties such as high photoluminescence quantum yields, wide color tunability and high chemical stability. They have featured prominently in diverse applications such as sensing, bio-imaging, photoredox catalysis, solar fuels and solid-state lighting. In the vast majority of these reports the iridium complex is mononuclear in nature. The use of iridium complexes as components of selfassembled systems has garnered increasing attention and this review aims to comprehensively document the advances made in this area. Special emphasis will be devoted to describing the photophysical properties and applications of such photo-active supramolecular materials. Soft materials such as soft salts, liquid crystals, gels, colloids incorporating iridium are described as are hydrogen bonding- and $\pi-\pi$ staking-directed assemblies, coordination-driven selfassembled materials such as coordination polymers and metal organic frameworks, macrocycles, capsules and cages. Finally, guest Ir(III) complexes encapsulated within the cavities of cage-type structures are presented.
\end{abstract}

\section{Contents}

1. Introduction

2. Soft Materials

2.1 Soft salts

2.2 Liquid crystals

2.3 Luminescent gels 


\subsection{Colloidal structures}

2.5 Hydrogen bonding- and $\pi$ - $\pi$-directing supramolecular networks

3. Coordination-driven self-assembly

3.1 Coordination polymers, metal-organic frameworks and discrete structures

3.2 Macrocycles, capsules and cages

4. Encapsulation of Ir(III) chromophores

5. Conclusions

Acknowledgments

References

\section{Introduction}

The term molecular self-assembly applies to pathways that produce a final product directly and spontaneously when the correct components are mixed under appropriate conditions.[1] Self-assembly plays an integral role in the structure and function of biological systems[2-4] and it is implicated in a variety of functional materials. [5] In Nature self-assembly is generally based on numerous hydrogen bounding, electrostatic, van der Waals, and other weak inter- and intra-molecular interaction working synergistically to assemble, for example, secondary and tertiary structures of proteins, which then provide well-defined local environments to mediate biochemical transformations.[6] Similarly, in natural photosynthesis organisms optimize solar energy conversion through the self-organized assembly of photofunctional chromophores.[7, 8] Over the last two decades, molecular self-assembly has played a key role in the construction of a variety of elegant and intricate synthetic nanostructures, including molecular crystals and liquid crystals,[9, 10] colloids[11] and micelles,[12] gels,[13, 14] polymers[15, 16] and nanoscale structures of high symmetry, such as 3D-frameworks,[17] metal-organic polygons and polyhedra.[18, 19] As the properties of these materials highly depend both on the nature of their components and the interactions between them, the explicit manipulation of the building blocks and the non-covalent forces that hold the constituents together has promoted the evolution of functional properties, which have been exploited in numerous advanced 
technologies. For example, liquid crystals have found application as anisotropic organic semiconductors in organic field effect transistors (OFETs), Organic Light-Emitting Diodes (OLEDs) and Organic Photovoltaic devices (OPVs).[9, 10, 20] Due to their large surface area and biocompatibility, colloids and micelles are very important for water purification, cleansing action of soap and food formulation.[21, 22] Hydrogels and polymers are key components in materials for medicine, food science and cosmetics.[23-25] Nanostructured materials such as molecular crystals, frameworks or 3D-polyhedral structures exhibit interesting optical, magnetic and catalytic properties, which have been rapidly exploited in diverse applications such as in catalysis, magnetic devices and gas purification.[26-28]

In recent years, there has been an increasing interest in the construction of photoactive supramolecular assemblies through the incorporation of luminescent building blocks.[29-32] This immediately generates possibilities for assembling in very close proximity a high concentration of chromophoric units through non-covalent interactions, thereby achieving photophysical properties that are difficult to obtain in conventional molecular materials. Besides modulating the optoelectronic properties of the emissive compounds as a function of the assembly, their organization into ordered structures can also radically change the physical properties of the bulk materials.[33] As a result, nanomaterials that exhibit both fascinating physical and photoactive properties have been one of the main areas of interest in supramolecular chemistry in recent years.[29, 34, 35]

Cyclometalated iridium(III) complexes exhibit efficient phosphorescence, unprecedented facile emission color tunability across the visible spectrum, and high chemical and thermal stability.[36-40] They have thus found use in myriad applications such as in sensing,[41, 42] bio-imaging,[43] photoredox catalysis,[44] solar fuels[45, 46] and in electroluminescent 
devices.[47, 48] The use of iridium complexes as luminescent components for self-assembly has also become increasingly popular. This review article provides an exhaustive summary on the development of photoactive self-assembled materials based on iridium(III) complexes, giving special emphasis to their photophysical properties, and highlighting their applications. Depending on the nature of the ligands, iridium(III) complexes can be cationic, neutral and anionic. The vast majority of cationic iridium(III) complexes possess the general motif $\left[\operatorname{Ir}\left(\mathrm{C}^{\wedge} \mathrm{N}\right)_{2}\left(\mathrm{~N}^{\wedge} \mathrm{N}\right)\right]^{+}$, where $\mathrm{C}^{\wedge} \mathrm{N}$ is a cyclometalating ligand such as 2-phenylpyridinato (ppy) and $\mathrm{N}^{\wedge} \mathrm{N}$ is a neutral ancillary ligand such as 2,2 '-bipyridine (bpy). Homoleptic neutral iridium complexes possess the general formula $\left[\operatorname{Ir}\left(\mathrm{C}^{\wedge} \mathrm{N}\right)_{3}\right]$ and are frequently studied as their facial geometric isomer. Heteroleptic neutral complexes generally possess the structural motif $\left[\operatorname{Ir}\left(\mathrm{C}^{\wedge} \mathrm{N}\right)_{2}(\mathrm{X})\right]$, where $\mathrm{X}$ is an anionic bidentate ligand such as acetylacetonates, oxazolines or thiazolines whereas, negatively charged cyclometalated iridium(III) complexes typically possess the composition $\left[\operatorname{Ir}\left(\mathrm{C}^{\wedge} \mathrm{N}\right)_{2}(\mathrm{Y})_{2}\right]^{-}$, where $\mathrm{Y}$ is typically an anionic monodentate ligand such as $\mathrm{CN}^{-}, \mathrm{NCS}^{-}$and $\mathrm{NCO}^{-}$.

We begin by describing iridium-based soft materials such as ion-paired iridium complexes commonly known as soft-salts, liquid crystals, supramolecular gels, colloidal structures and assemblies developed through H-bonding and $\pi$ - $\pi$-stacking interactions. Next, we turn our attention to describing luminescent iridium-based coordination polymers, metal-organic frameworks (MOFs) and discrete structures, followed by an overview of luminescent Ir-based macrocycles, capsules and cages. The last chapter of this review highlights the emerging field of dynamic encapsulation of mononuclear iridium complexes into the cavities of 3D MOFs and cages. In this chapter, emphasis will be placed in describing the changes of the luminescent properties of the guest iridium complexes due to their physical and optoelectronic interactions with the host materials. It is worth noting that a number of studies involving luminescent Ir(III) 
complexes covalently assembled within multinuclear dyads, triads and arrays,[49-51] or covalently linked onto polymeric structures[52-54] have been reported. As these systems have been extensively described elsewhere, they are not included within the present review.

\section{Soft materials}

Molecular aggregation induced by non-covalent interactions between $\operatorname{Ir}(\mathrm{III})$ chromophores can have tremendous impact on the properties of materials. Desirable photophysical properties such as emission tuning, enhanced photoluminescence quantum yield, longer excited state lifetimes, and energy and electron transfer processes can be achieved by controlling the aggregation and organization of Ir(III) emitters in soft materials.

\subsection{Soft salts}

The term "soft salt" describes ionic materials that are composed of two or more organometallic components characterized by complementary charges and assembled into complex salts through Coulombic interactions. The majority of the reported soft salts incorporating iridium have consisted of a cationic iridium complex married with an anionic iridium complex.

The first examples of iridium soft salts were reported in 2010 by Thompson and coworkers[55] (Figure 1) and De Cola and co-workers[56] (Figure 2a) who assembled via salt metathesis reactions blue- and green-emitting anionic $\operatorname{Ir}(\mathrm{III})$ complexes with yellow- and orange-emitting cationic iridium complexes. 


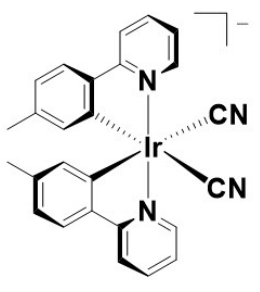

$1 \mathrm{a}$

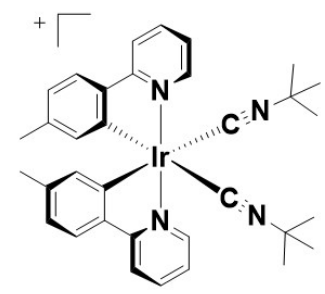

S1

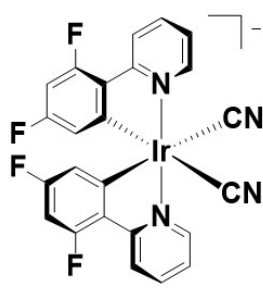

$2 \mathbf{a}$

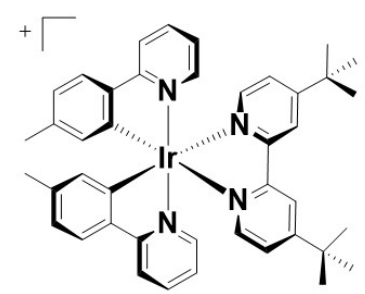

S2

$2 b$

Figure 1. Chemical structure of soft salt S1 (left) and S2 (right).

Soft salt S1 was prepared by assembling the anionic green-emitting $\operatorname{Ir}(\mathrm{III})$ complex $\mathrm{Na}\left[\operatorname{Ir}(\mathrm{mppyH})_{2}(\mathrm{CN})_{2}\right], \quad \mathrm{Na1a}$ with the cationic yellow-emitting $\operatorname{Ir}(\mathrm{III})$ complex $\left[\operatorname{Ir}(\mathrm{mppyH})_{2}(\mathrm{CNdt})_{2}\right] \mathrm{Cl}, \mathbf{1 b C l}(\mathrm{mppyH}$ is $2-(p$-tolyl)pyridine and $\mathrm{CNdt}$ is 2 -methyl- $N$ methylydynepropan-2-aminium), while $\mathbf{S 2}$ contains the anionic blue-emitting $\operatorname{Ir}(\mathrm{III})$ complex $\mathrm{Na}\left[\operatorname{Ir}(\mathrm{dFppy})_{2}(\mathrm{CN})_{2}\right], \mathrm{Na2a}$ (dFppyH is 4,6-difluorophenylpyridine) with the cationic orangeemitting $\operatorname{Ir}(\mathrm{III})$ complex $\left[\operatorname{Ir}(\mathrm{mppyH})_{2}(\mathrm{dtbubpy})\right] \mathrm{Cl}, \mathbf{2 b C l}$ (dtbubpy is 4,4'-di-tert-butyl-2,2'bipyridine) (Figure 1). In degassed $\mathrm{MeCN}$ the complexes $\mathrm{Na} \mathbf{1} \mathbf{a}$ and $\mathbf{1 b C l}$ exhibited vibronic ligand-centered $\left({ }^{3} \mathrm{LC}\right)$ emission profiles, respectively, at $\lambda_{\mathrm{PL}}=472 \mathrm{~nm}$ and $\lambda_{\mathrm{PL}}=458 \mathrm{~nm}$ with photoluminescence quantum yield of $\Phi_{\mathrm{PL}}=70 \%$ and $\Phi_{\mathrm{PL}}=38 \%$, and photoluminescence lifetimes of $\tau_{\mathrm{PL}}=4.0 \mu$ s and $\tau_{\mathrm{PL}}=36.7 \mu$ s. Similarly, complex Na2a exhibited a vibronic ${ }^{3} \mathrm{LC}$ emission at $\lambda_{\mathrm{PL}}=448 \mathrm{~nm}$ with a $\Phi_{\mathrm{PL}}$ of $70 \%$ and a $\tau_{\mathrm{PL}}=4.1 \mu \mathrm{s}$, while complex $2 \mathbf{b C l}$ showed a broad mixed metal-to-ligand and ligand-to-ligand charge transfer $\left({ }^{3} \mathrm{MLCT} /{ }^{3} \mathrm{LLCT}\right)$ emission centered at $\lambda_{\mathrm{PL}}=586 \mathrm{~nm}$ with a lower $\Phi_{\mathrm{PL}}$ of $21 \%$ and a shorter $\tau_{\mathrm{PL}}$ of $0.43 \mu \mathrm{s}$. The photoluminescence spectra of the soft salts $\mathbf{S} 1$ and $\mathbf{S} 2$ exhibited a concentration dependence, which impacted the degree of emission quenching of the anion by the cation via Dexter energy transfer. Taking $\mathbf{S} 2$ as an example, at a relatively low concentration of $10^{-5} \mathrm{M}$ its luminescence profile was dominated by the emission at $\lambda_{\mathrm{PL}}=448 \mathrm{~nm}$, characteristic of the blue-emitting anion 2a. This high-energy emission gradually decreased as a function of increasing concentration of $\mathbf{S 2}$ from $10^{-5} \mathrm{M}$ to $10^{-3} \mathrm{M}$ and, at a concentration greater than $10^{-3} \mathrm{M}$, only the 
orange emission exhibited by the cation $\mathbf{2 b}$ at $\lambda_{\mathrm{PL}}=586 \mathrm{~nm}$ was observed. Based on a bimolecular quenching model, a quenching rate constant $\mathrm{k}_{\mathrm{q}}$ of $1.71 \times 10^{10} \mathrm{M}^{-1} \mathrm{~s}^{-1}$, close to the diffusion limit in acetonitrile $\left(2 \times 10^{10} \mathrm{M}^{-1} \mathrm{~s}^{-1}\right)$, was calculated.

Similarly, De Cola and co-workers assembled the green-emitting anionic Ir(III) complex of composition $\mathrm{NBu}_{4}\left[\operatorname{Ir}(\mathrm{ppy})_{2}(\mathrm{CN})_{2}\right], \mathrm{NBu}_{4} 3 \mathbf{3 a}$, with the yellow-emitting cationic $\operatorname{Ir}(\mathrm{III})$ complex $\left[\operatorname{Ir}(\mathrm{dFppy})_{2}(\mathrm{bpy})\right] \mathrm{Cl}, \mathbf{3 b C l}(\mathbf{S 3}$, Figure 2), and the blue-emitting anionic $\operatorname{Ir}(\mathrm{III})$ complex K2a with the orange-emitting cationic $\operatorname{Ir}(\mathrm{III})$ complex $\left[\operatorname{Ir}(\mathrm{ppy})_{2}(\mathrm{bpy})\right] \mathrm{Cl}, \mathbf{4 b C l}(\mathbf{S 4}$, Figure $\mathbf{2 a})$.

a)
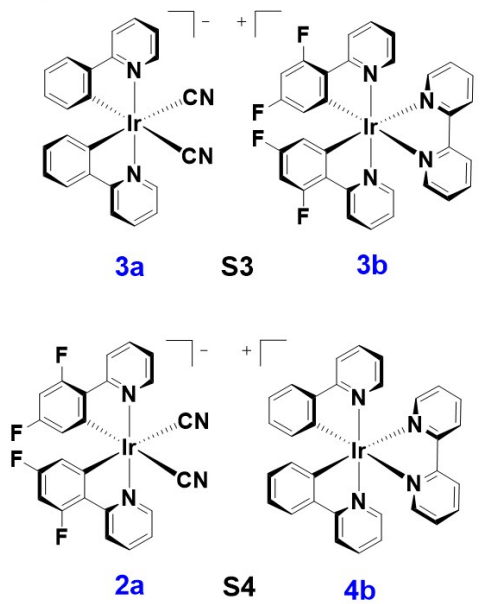

b)

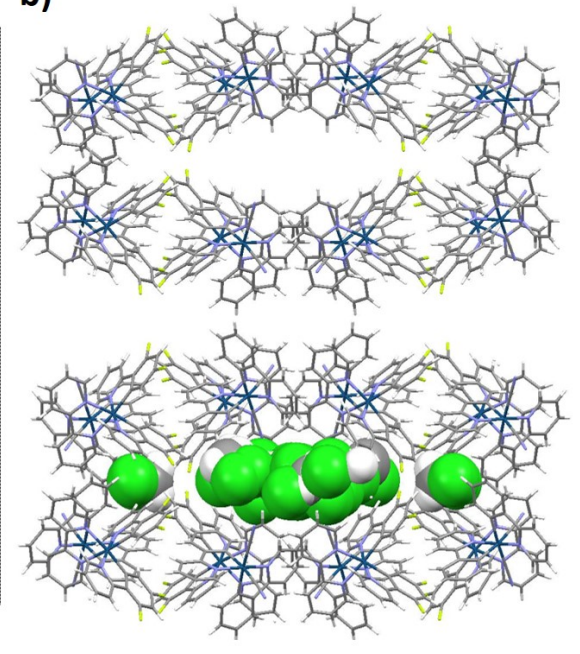

c)
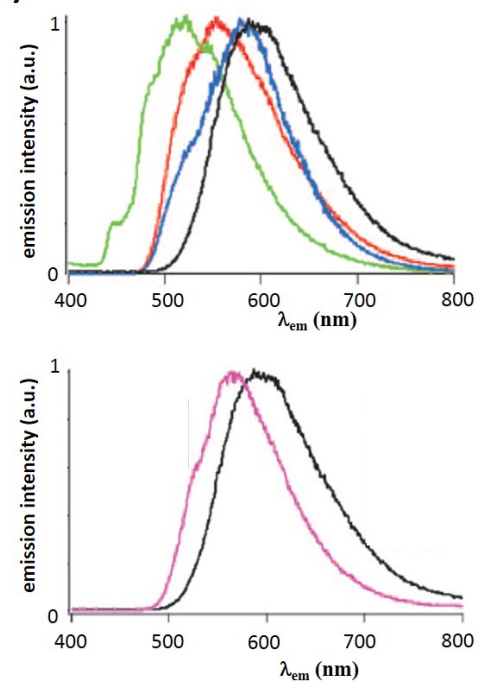

Figure 2. a) Chemical structures of complex salts $\mathbf{S 3}$ (top) and $\mathbf{S 4}$ (bottom). b) crystal packing of salt S3 highlighting the channel running along the crystallographic $c$ axis (top) and illustration of the dichloromethane solvent molecules (space-filling representation) inside the channel and pockets of $\mathbf{S 3}$ (bottom). The remaining solvent molecules are omitted for clarity. c) top: normalized emission spectra of dried $\mathbf{S 4}$ (black line), $\mathbf{S 4}$ with toluene intercalated (blue line), complexes $\mathbf{2 a}$ (red line) and $\mathbf{4 b}$ (green line); bottom: normalized emission spectra of $\mathbf{S 4}$ (black line) and S4 intercalating anthraquinone (pink line). Part c) is adapted with permission. Copyright 2010, Wiley-VCH.[56] 
The X-ray single crystal structure of $\mathbf{S 4}$ showed that this soft salt forms a 3D porous network where small solvent molecules such as dichloromethane, amyl acetate, ethyl acetate, diethyl ether, toluene or anthraquinone could be easily intercalated (Figure 2b). The emission properties of the single crystals of the microcrystalline salts $\mathbf{S 3}$ and $\mathbf{S 4}$ were investigated both under vacuum in the absence of guest molecule inclusion and after loading guest molecules into their networks. In degassed DCM, complex $\mathrm{NBu}_{4} 3 \mathrm{a}$ emitted yellow light with a $\lambda_{\mathrm{PL}}$ at 564 $\mathrm{nm}$ while $3 \mathrm{bCl}$ emitted in the blue-green with a $\lambda_{\mathrm{PL}}$ at $502 \mathrm{~nm}$. The emission of the crystal of S3 in its dry form exhibited a red-shifted emission at $\lambda_{\mathrm{PL}}=591 \mathrm{~nm}$. Analogously, the dried crystal of S4 exhibited a red-shifted emission at $\lambda_{\mathrm{PL}}=596 \mathrm{~nm}$ compared to the emission of both K2a and 4bCl, which exhibited, respectively, $\lambda_{\mathrm{PL}}=554 \mathrm{~nm}$ and $\lambda_{\mathrm{PL}}=460 \mathrm{~nm}$. The red-shifted emission of both $\mathbf{S 3}$ and $\mathbf{S 4}$ compared to the corresponding mononuclear complexes were attributed to strong $\pi-\pi$ interactions between the $\mathrm{C}^{\wedge} \mathrm{N}$ ligands of complementary iridium complexes of opposite charge present in the crystal networks, promoting Dexter energy transfer from the high energy anionic Ir donors $\mathbf{3 a}$ and $\mathbf{2 a}$ to the low energy cationic Ir acceptors $\mathbf{3 b}$ and $\mathbf{4 b}$, and additionally promoting exciplex formation and emission from correspondingly lower-energy excited states. Importantly, the emission properties of the crystals $\mathbf{S 3}$ and $\mathbf{S 4}$ could be efficiently modulated by trapping guest molecules within their porous networks. For example, the intercalation of toluene or anthraquinone into $\mathbf{S 4}$ led to blue-shifted emission of the soft-salt, respectively, at $\lambda_{\mathrm{PL}}=590 \mathrm{~nm}$ and $\lambda_{\max }=580 \mathrm{~nm}$, compared to the dried crystal. An enhanced emission was observed when toluene was absorbed into $\mathbf{S 4}$ due to the disruption of the $\pi-\pi$ interactions whereas the emission was quenched when anthraquinone was intercalated within the crystal of $\mathbf{S 4}$ as a function of the photoinduced electron transfer from the $\mathbf{S 4}$ donor to the anthraquinone acceptor (Figure $\mathbf{2 c}$ ). 
Our group reported[57] the first example of a three component heterometallic ion-pair assembly, S5 (Figure 3) involving two equivalents of complex $\mathrm{NBu}_{4} \mathbf{3 a}$ (Figure 2) associated with the red-emitting $\left[\mathrm{Ru}(\mathrm{dtbubpy})_{3}\right] \mathrm{Cl}_{2} \mathbf{5} \mathbf{b C l} \mathrm{Cl}_{2}$ (Figure 3a). Upon photoexcitation into the ruthenium complex ${ }^{1} \mathrm{MLCT}$ absorption band in $\mathrm{MeCN}, \mathbf{5} \mathbf{b C l} \mathrm{l}_{2}$ exhibited the characteristic broad ${ }^{3}$ MLCT emission centered at $\lambda_{\mathrm{PL}}=630 \mathrm{~nm}$, which is complementary in color compared to the ${ }^{3} \mathrm{LC}$ emission exhibited by complex $\mathrm{NBu}_{4} \mathbf{3 a}\left(\lambda_{\mathrm{PL}}=477 \mathrm{~nm}\right.$ in degassed MeCN). Soft salt $\mathbf{S 5}$ nicely illustrates how the emission properties can be modulated upon changes in concentration and medium. At low concentration, the emission of $\mathbf{S 5}$ is dominated by the structured ${ }^{3} \mathrm{LC}$ emission of 3a. As the concentration increases, due to increased efficiency of the Förster energy transfer from the anionic $\operatorname{Ir}(\mathrm{III})$ donor to the cationic $\mathrm{Ru}(\mathrm{II})$ acceptor, the emission profile of $\mathbf{S 5}$ resembles increasingly that of the lower-energy emission of the Ru(II) complex $\mathbf{5 b}$ (Figure 3b). In contrast to the emission behavior observed for $\mathbf{S 3}$ and $\mathbf{S 4}$, the emission of $\mathbf{S 5}$ did not involve either excimers or exciplexes. Further, as a function of the solvent polarity, the electrostatic interaction of the cation and anion could be modulated and therefore the magnitude of the energy transfer between the two. Solvents of high polarity, such as DMSO, MeOH or EtOH, solvated strongly the ions, leading to their weak association, poor energy transfer and an emission dominated by 3a. Less polar solvents such as DCM or MeCN promoted the formation of intimate ion pairs, resulting in shorter distance between the Ir and Ru ions and more efficient energy transfer, and an emission profile that resembles that of $\mathbf{5 b}$. 


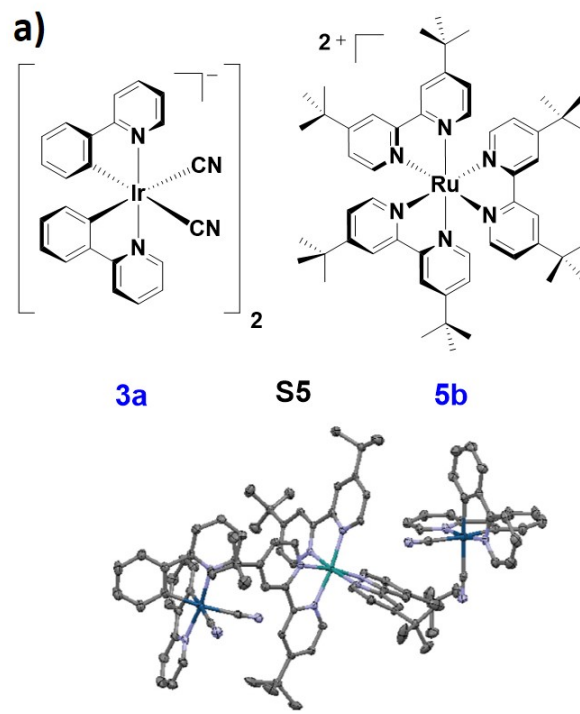

b)

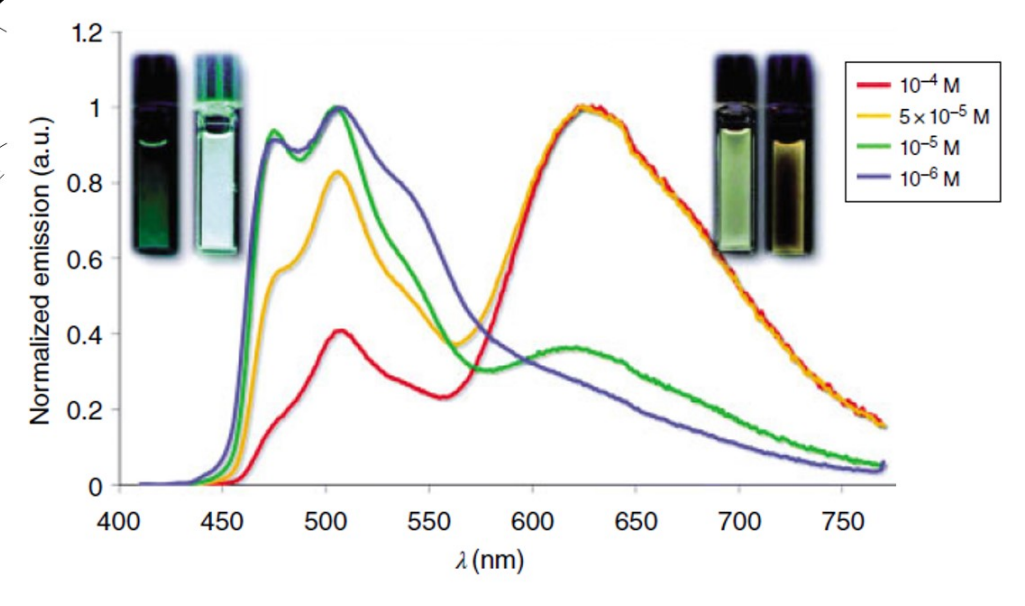

Figure 3. a) Chemical structure of the soft salt $\mathbf{S 5}$ with its single crystal $\mathrm{x}$-ray structure; b) normalized emission spectra of $\mathbf{S 5}$ recorded in deaerated $\mathrm{MeCN}$ at $298 \mathrm{~K}$ at different concentrations $\left(\lambda_{\text {exc }}=390 \mathrm{~nm}\right)$. Insets are images of MeCN solutions of S5 at different concentrations. Image b) is adapted from ref [57] with permission from The Royal Society of Chemistry.

Soft salt S5 exhibited a significantly enhanced ECL (electrochemiluminescence) signal at similar energy to $\mathbf{5 b}$.[58] This observation is rather unusual considering that for the vast majority of multichromophoric species, the ECL signals could be addressed at different potentials and thus produce multiple emissive readouts.[59-61] The ECL efficiency of S5 was determined to be $2.51 \%$, which is intermediate between the ECL efficiencies of the ionic components 3a (2.83\%) and $\mathbf{5 b}(2.14 \%)$. The higher ECL efficiency for $\mathbf{S 5}$ compared to $\mathbf{5 b}$ is due to the $[\mathrm{Ir}]^{-}-[\mathrm{Ru}]^{+}$annihilation process, where $[\mathrm{Ir}]^{-}$acts as a co-reactant and thus reduces the energy required to emit light from the excited $[\mathrm{Ru}]^{*}$.

Godbert and co-workers[62] synthetized green-emitting anionic Ir complexes bearing an unsual bidentate orotate dianion as the ancillary ligand $\left(\mathrm{NBu}_{4} \mathbf{4 a}\right.$ and $\mathrm{NBu}_{4} \mathbf{4 b}$ in Figure $\left.\mathbf{4 a}\right)$. 
These complexes exhibited high photoluminescence quantum yields of $\Phi_{\mathrm{PL}}=69 \%$ and $\Phi_{\mathrm{PL}}=$ $58 \%$, respectively, with emission maxima, respectively, at $530 \mathrm{~nm}$ and $536 \mathrm{~nm}$. When $\mathrm{NBu}_{4} \mathbf{4 a}$ and $\mathrm{NBu}_{4} \mathbf{4 b}$ were respectively assembled with the cationic complex $\left[\operatorname{Ir}(\mathrm{ppy})_{2}(\mathrm{py}-\mathrm{am})\right] \mathrm{Cl}(\mathbf{6} \mathbf{b C l}$ in Figure 4a, py-am is 2-pycolylamine), which itself shows an emission at $\lambda_{\mathrm{PL}}=490 \mathrm{~nm}$ with a $\Phi_{\mathrm{PL}}$ of 52\%, highly emissive soft salts, S6a and S6b (Figure 4a) were obtained. S6a and S6b are unusual examples of soft salts in which the cation $(\mathbf{6 b})$ is the donor unit, while the anions (4a and $\mathbf{4 b}$ ) are the acceptors. The emission of S6a and S6b involved contributions from both ions with $\lambda_{\mathrm{PL}}$, respectively, at $480,525 \mathrm{~nm}$ and $486,532 \mathrm{~nm}$ and high $\Phi_{\mathrm{PL}}$ values of $81 \%$ and $83 \%$, respectively.

a)

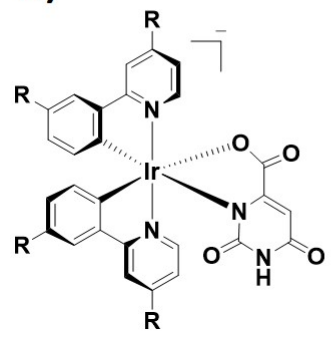

R: $\mathbf{H}, \mathbf{4 a}$

R: $\mathrm{CH}_{3}, 4 \mathrm{~b}$

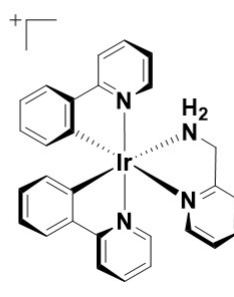

$6 b$

S6a

S6b

b)
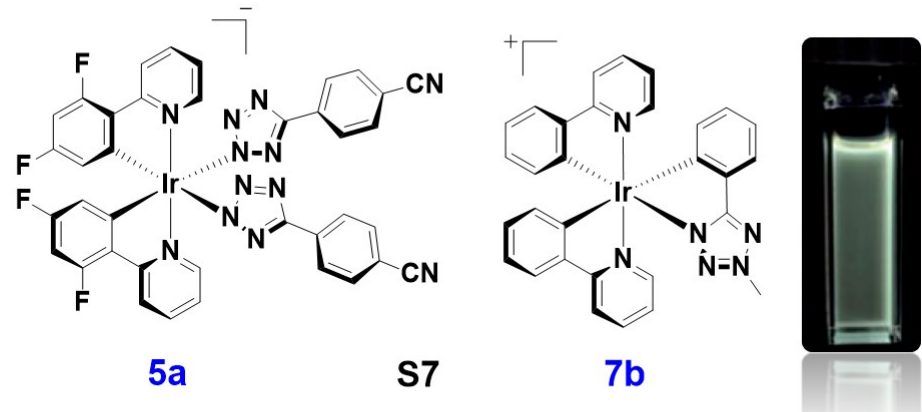

Figure 4. a) chemical structure of soft salts $\mathbf{S 6 a}$ and $\mathbf{S 6 b}$ and b) chemical structure of the white-emitting soft salt $\mathbf{S 7}$. Inset is image of air-equilibrate DCM solution of $\mathbf{S 7}$. The inset image is adapted from ref [63] with permission from The Royal Society of Chemistry.

A white-emitting soft salt was obtained by Stagni and co-workers[63] by assembling the blue-emitting anionic $\mathrm{Ir}(\mathrm{III})$ complex $\mathrm{NBu}_{4} 5 \mathbf{5}$ (Figure 4b), bearing $\mathrm{dFppy}$ as $\mathrm{C}^{\wedge} \mathrm{N}$ ligands and 4-benzonitrile tetrazolate as ancillary ligands, with the red-emitting $\left[\operatorname{Ir}(\mathrm{ppy})_{2}(\mathrm{ptz}-\mathrm{Me})\right] \mathrm{Cl}$ complex (ptz-Me is 5-methyl-2-phenyltetrazole) (7bCl, Figure 4b). In aerated DCM, complex $\mathrm{NBu}_{4} \mathbf{5 a}$ exhibited a structured emission profile typical of emission from a ${ }^{3} \mathrm{LC} /{ }^{3} \mathrm{MLCT}$ state with $\lambda_{\mathrm{PL}}$ at $462 \mathrm{~nm}$ and $492 \mathrm{~nm}$ and a $\Phi_{\mathrm{PL}}$ of $3.3 \%$. Complex $7 \mathbf{b C l}$, by contrast, exhibited a broad emission profile with $\lambda_{\mathrm{PL}}=686 \mathrm{~nm}$ and a $\Phi_{\mathrm{PL}}$ of $2.7 \%$. As both the anionic and cationic 
complexes $\mathbf{5 a}$ and $\mathbf{7 b}$ contributed almost equally to the emission of $\mathbf{S 7}$ in aerated DCM, and energy transfer between the two ions played a minor role, an almost pure white-light (CIE: $\mathrm{x}=$ $0.3288, \mathrm{y}=0.3284)$ with $\lambda_{\mathrm{PL}}$ at $460 \mathrm{~nm}, 490 \mathrm{~nm}$ and $680 \mathrm{~nm}$ and a $\Phi_{\mathrm{PL}}$ of $2.8 \%$ was emitted by the assembly. The poor energy transfer in $\mathbf{S 7}$ is probably due to the presence of the bulky 4benzonitrile tetrazolate in $\mathbf{5 a}$ that restricts its interaction with the cation $\mathbf{7 b}$.

In the context of electroluminescence devices, neutral Ir complexes have been extensively used in Organic Light-Emitting Diodes (OLEDs),[64-66] whereas cationic $\operatorname{Ir}(\mathrm{III})$ complexes have been explored more explicitly as emitters in Light-Emitting Electrochemical Cells (LEECs).[47, 67] Covalently linked dinuclear iridium complexes have been scarcely investigated as emitters in solid-state lighting, with only one example available for use in LEECs[68] and few for OLEDs.[69-75] However, iridium-based soft salts have demonstrated reasonable performance as emitter materials in OLEDs. The main advantage of using soft salts in lighting devices relies on the capacity to introduce two phosphorescent centers in one complex ion, while controlling the intermolecular separation of the two metal centers through non-covalent interactions. The first examples of iridium soft salts used in OLEDs were reported by Thompson and co-workers.[55] Notably, OLEDs fabricated by using S2 (Figure 1) as the emitting material exhibited an external efficiency, EQE, of $4.7 \%$ and a luminance of over 7428 $\mathrm{cd} \cdot \mathrm{m}^{2}\left(\lambda_{\mathrm{PL}}=586 \mathrm{~nm}\right)$. The good performance of the OLED could be directly linked to the suitable alignment of the HOMO-LUMO levels of the two ionic components of the soft salt. Unfortunately, the relatively low $\Phi_{\mathrm{PL}}$ of $18 \%$ exhibited by $\mathbf{S 2}$ in thin films limited the efficiency of the device. When $\mathbf{S 2}$ was used as the emitter in a single-layer LEEC, the device failed to turn on under voltages ranging from $2.5 \mathrm{~V}$ to $7 \mathrm{~V}$, a result of the poor ionic mobility of the ions of $\mathbf{S 2}$. 
a)

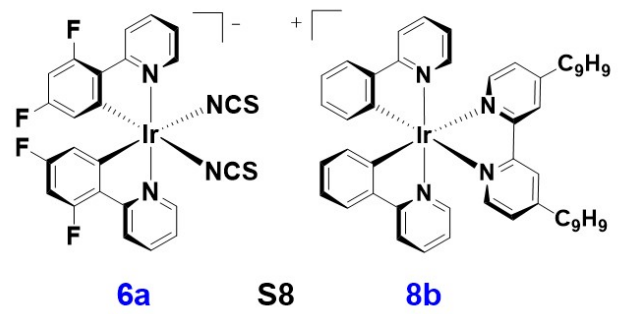

b)

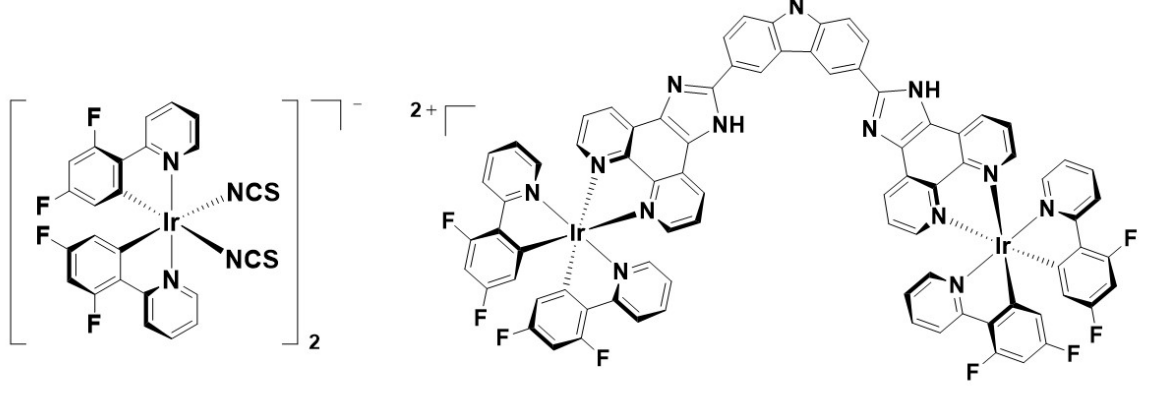

$7 a$

S9

$9 b$

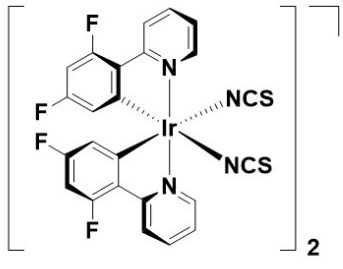

$7 a$
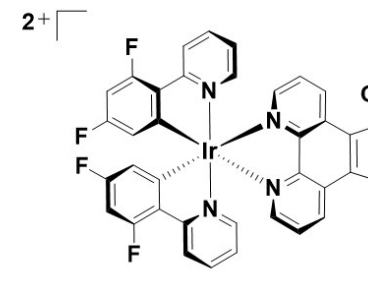

S10

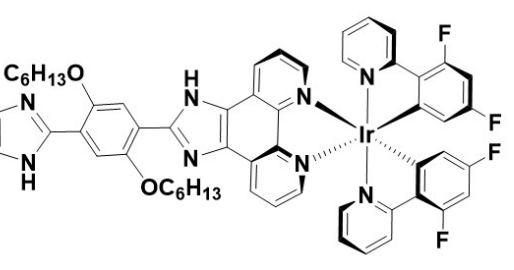

$10 \mathrm{~b}$

Figure 5. Chemical structures of iridium soft salts used in OLEDs. a) $\mathbf{S 8}$ and b) $\mathbf{S 9}$ (top) and S10 (bottom).

Dumur, Mayer and co-workers[76] also explored the use of a soft salt emitter in OLEDs, the composition of which consisted of the anionic $\mathrm{NBu}_{4}\left[\operatorname{Ir}(\mathrm{dFppy})_{2}(\mathrm{NCS})_{2}\right], \mathrm{NBu}_{4} \mathbf{6 a}$, with the cationic complex $\left[\operatorname{Ir}(\mathrm{ppy})_{2}(\right.$ bpy-non) $] \mathrm{PF}_{6} \mathbf{8 b P F}_{6}$ (Figure 5a, bpy-non is 4,4'-dinonyl-2,2'bipyridine). The nonyl chains were introduced to $\mathbf{8 b P F}$ to enhance the solubility of the resultant S8 in organic solvents and thus improve the thin film morphology in solutionprocessed devices. Soft salt $\mathbf{S 8}$ exhibited luminescence centered at approximately $550 \mathrm{~nm}$ in DCM solution, thin film and in electroluminescent devices. The OLEDs fabricated with $\mathbf{S 8}$ as 
the emitting material exhibited a low external quantum efficiency of $0.66 \%$ and a luminance of $1114 \mathrm{~cd} \cdot \mathrm{m}^{-2}\left(\lambda_{\mathrm{EL}}=553 \mathrm{~nm}\right)$.

Two iridium soft salts based on ion-paired dinuclear cationic, and mononuclear anionic complexes were reported by Mayer and co-workers[77] and investigated as emitting materials in OLEDs (Figure 5b). The unit bridging the two iridium centers in the dinuclear cationic complexes consisted either of a carbazole derivative for $9 \mathbf{b P F}_{6}$ or a phenylene group in the case of $10 \mathrm{bPF}_{6}$. Both dinuclear complexes $9 \mathrm{bPF}_{6}$ and $\mathbf{1 0 b P F}_{6}$ exhibited low $\Phi_{\mathrm{PL}}$ in degassed DCM of $9.1 \%$ and $15.0 \%$, respectively, attributed to intramolecular quenching between the two iridium luminophores. As the phenylene bridge favored the communication between the two iridium centers, the electroluminescence performance using $\mathbf{S 1 0}$ was poorer than that using $\mathbf{S 9}$ with respective maximum peak current efficiencies of 0.06 and $0.44 \mathrm{~cd} \cdot \mathrm{A}^{-1}$ and maximum brightness of 101 and $1022 \mathrm{~cd} \cdot \mathrm{m}^{-2}$.

Intracellular $\mathrm{pH}$ is a crucial parameter associated with cellular behavior and pathological conditions such as cell proliferation, apoptosis, drug resistance, enzymatic activity and ion transport.[78] Abnormal cellular $\mathrm{pH}$ is an indicator of inappropriate cellular function, which is associated with many diseases such as stroke, cancer, and Alzheimers.[79] It is thus pivotal to monitor $\mathrm{pH}$ alteration in biological cells and tissues to understand physiological and pathological processes.[80] In this context, Wong, Zhao and co-workers[81] recently illustrated that soft salts can also be rationally designed to act as efficient probes for lifetime imaging of intracellular $\mathrm{pH}$. Indeed, they designed the soft salt S11 (Figure 6a) formed by the assembly of the cationic complex $\mathbf{1 1 b C l}$, bearing a qpy (qpy $=4,4^{\prime}: 2^{\prime}, 2^{\prime \prime}: 4^{\prime \prime}, 4^{\prime \prime \prime}$-quaterpyridine) as the ancillary ligand, with the anionic complex $\mathrm{NBu}_{4} \mathbf{2 a}$ (Figure 1). Specifically, complex 
$\mathbf{1 1 b C l}$ is $\mathrm{pH}$ sensitive as the protonation or deprotonation of its distal pyridine units gives rise to changes in the emission of $\mathbf{S 1 1}$, which can be easily detected by both steady-state and timeresolved luminescence spectroscopy. The cationic complex $\mathbf{1 1 b C l}$ showed a broad orange-red emission in deareated $\mathrm{MeCN}$ centered at $\lambda_{\mathrm{PL}}=625 \mathrm{~nm}$, which decreased dramatically in intensity with decreasing $\mathrm{pH}$ (Figure 6b). By contrast, the structured blue-emission exhibited by the anionic counterpart $\mathrm{NBu}_{4} \mathbf{2 a}\left(\lambda_{\mathrm{PL}}=451,475 \mathrm{~nm}\right)$ was not affected by changes in $\mathrm{pH}$.

a)
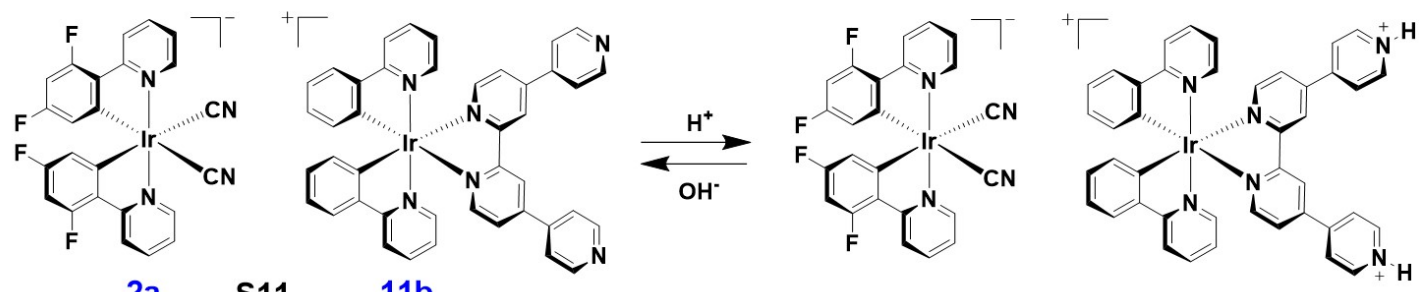

$2 a \quad 511$ $11 \mathrm{~b}$

b)

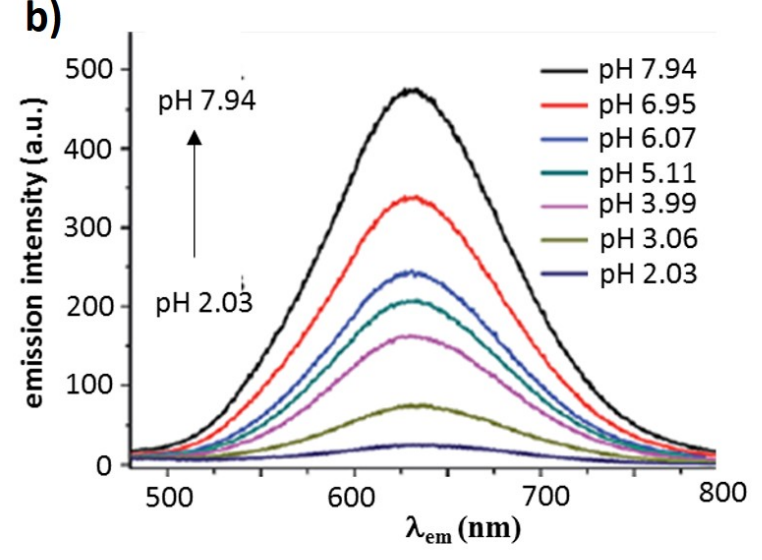

c)

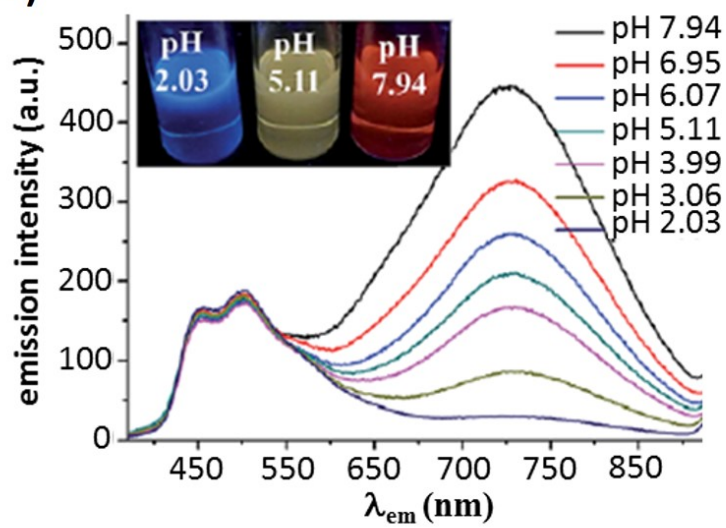

d) $\mathrm{pH}$

3.98

5.02

6.08

7.01

8.01

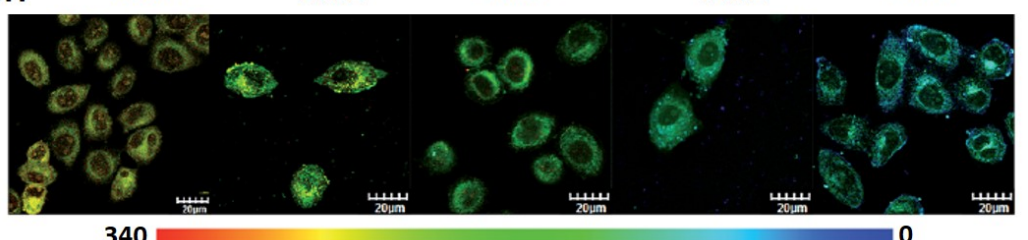

Average lifetime (ns)

Figure 6. a) Design concept of the ratiometric design probe and chemicals structures of $\mathbf{2 a}$,

$\mathbf{1 1 b}$ and soft salt S11. b) changes in the phosphorescence emission spectra of $\mathbf{1 1 b}\left(2.0 \times 10^{-5}\right.$ $\mathrm{M})$ in the $\mathrm{pH}$ range of $2.03-7.94 \mathrm{in} \mathrm{MeCN/buffer}(1: 9, \mathrm{v} / \mathrm{v})$. c) changes in the phosphorescence emission spectra of $\mathbf{S 1 1}\left(2.0 \times 10^{-5} \mathrm{M}\right)$ in the $\mathrm{pH}$ range of $2.03-7.94$ in MeCN/buffer $(1: 9$, v/v). d) phosphorescence lifetime images of $\mathbf{S 1 1}$ in living Hep-G2 cells (incubated at $37^{\circ} \mathrm{C}$ for 
1h) at different $\mathrm{pH}$ values. Images b), c) and d) are adapted from Ref. [81] with permission from The Royal Society of Chemistry.

The phosphorescence spectral changes of $\mathbf{S 1 1}$ at different $\mathrm{pH}$ values are illustrated in Figure 6c. Enhanced phosphorescence at $\lambda_{\mathrm{PL}}=625 \mathrm{~nm}$ was observed at basic $\mathrm{pH}$, while at acidic $\mathrm{pH}$ the emission of $\mathbf{1 1 b}$ was quenched due to the protonation of the qpy ligand. Thus, at basic $\mathrm{pH}$ the emission of $\mathbf{S 1 1}$ was dominated by the orange emission of $\mathbf{1 1 b}$, the result of efficient energy transfer from 2a, while at acidic $\mathrm{pH}$ the emission of $\mathbf{S 1 1}$ was dominated by the structured blue emission of the donor anion. Such a change in phosphorescence from blue to orange with increasing $\mathrm{pH}$ values was also detected using confocal luminescence microscopy after incubation of S11 in living HepG-2 cells (Figure 6d).

Similarly, Zhao and co-workers[82] used an ion-paired iridium complex (S12, Figure 7a), composed of a cationic complex functionalised with $\alpha, \beta$-unsaturated ketone moieties $\left(\mathbf{1 2 b P F}_{6}\right)$, and the anionic complex $\mathrm{NBu}_{4} \mathbf{3 a}$ (Figure $\mathbf{2 a}$ ), for ratiometric and time-resolved luminescence sensing and imaging of intracellular biothiols cysteine and homocysteine. These analytes were chosen as they participate in the process of cellular growth in living cells. The sensing capacity of $\mathbf{S 1 2}$ towards thiol analytes is due to their rapid Michael addition with the $\alpha, \beta$-unsaturated ketone moieties of $\mathbf{1 2 b}$ thereby promoting a strong enhancement of the emission of the cation acceptor at $\lambda_{\mathrm{PL}}=560 \mathrm{~nm}$, while only slightly influencing the photophysics of the donor complex at $\lambda_{\mathrm{PL}}=485,505 \mathrm{~nm}$ (Figure $\left.7 \mathbf{b}, \mathbf{c}\right)$. 

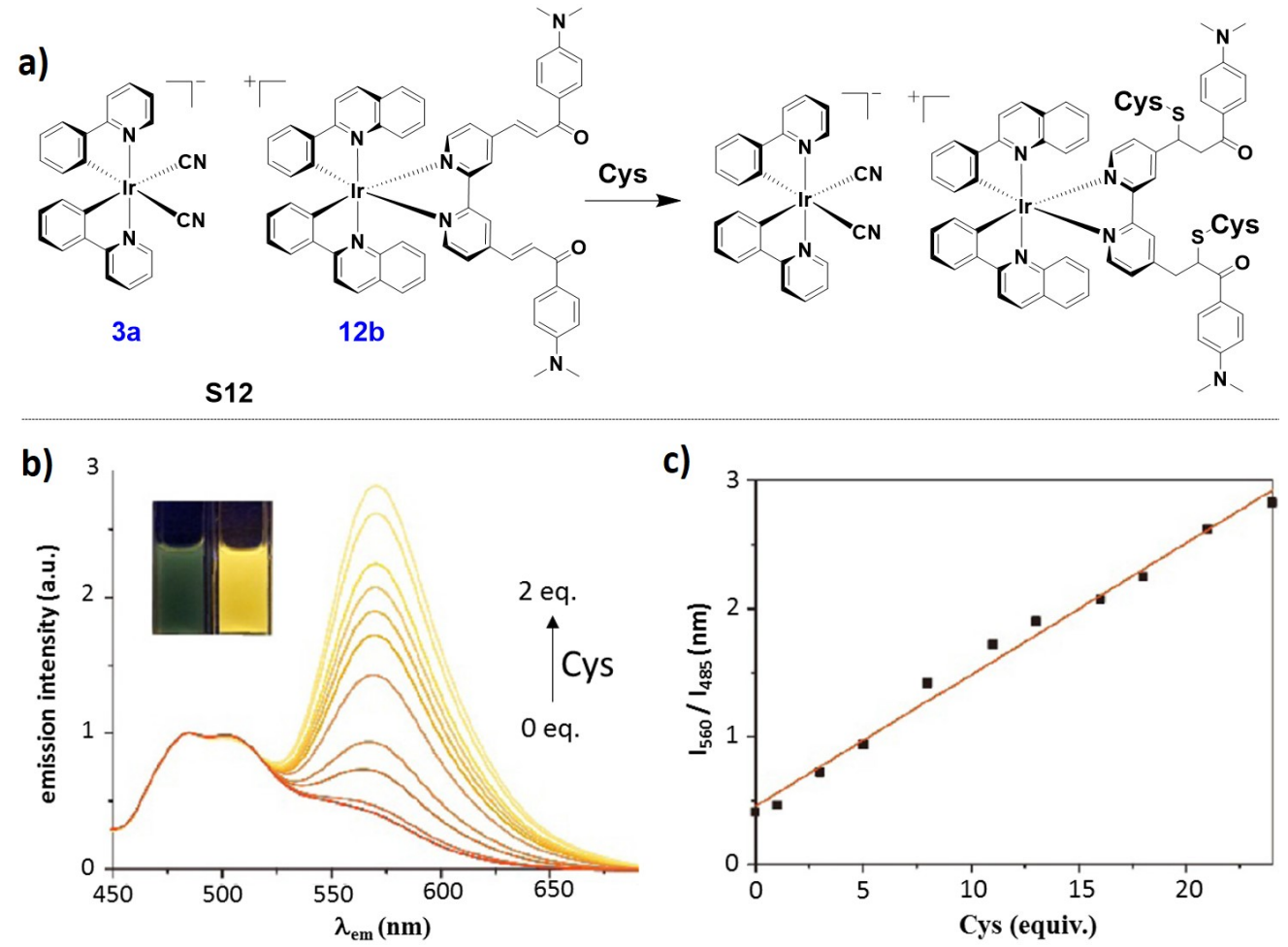

Figure 7. a) chemical structures of 3a, 12b and soft salt S12 and sensing mechanism of S12. b) changes in phosphorescence emission spectra of $\mathbf{S 1 2}$ in $\mathrm{MeCN} / \mathrm{H}_{2} \mathrm{O}(3: 2, \mathrm{v} / \mathrm{v})$ with various amount of cysteine added (from 0 to 2 equivalents). Insets are images of $\mathbf{S 1 2}$ without cysteine (left) and with two equivalent of cysteine (right). c) titration curve plotted with emission intensity at $560 \mathrm{~nm}$ over that at $485 \mathrm{~nm}$ as a function of cysteine equivalents. Images b) and c) are adapted from Ref. [82] - published by OSA publishing.

Schanze and co-workers[83] reported an ion-paired assembly between the anionic poly(phenyleneethynylene) electrolyte $\left(\mathrm{PPESO}_{3}{ }^{-}\right.$) and the cationic $\mathrm{Ir}(\mathrm{III})$ complex $\mathbf{4 b C l}$ (Figure 2a). Upon excitation of $\mathbf{4 b}-\mathrm{PPESO}_{3}$ in methanol at $355 \mathrm{~nm}$, the emission of $\mathrm{PPESO}_{3}{ }^{-}$at $\lambda_{\mathrm{PL}}=$ $450 \mathrm{~nm}$ was completely quenched as a result of Dexter energy transfer from $\mathrm{PPESO}_{3}{ }^{-}$to $\mathbf{4 b}$ with a calculated quenching constant $\left(\mathrm{k}_{\mathrm{q}}\right)$ of around $10^{5} \mathrm{M}^{-1}$. A weak phosphorescence from $\mathbf{4 b}$ was observed at $\lambda_{\mathrm{PL}}=610 \mathrm{~nm}$. Subsequent to the Dexter energy transfer, ultra-fast back-transfer from the triplet state of $\mathbf{4 b}$ located at $2.25 \mathrm{eV}$ to the triplet state of $\mathrm{PPESO}_{3}^{-}$located between 
$2.0-2.2 \mathrm{eV}$ was detected by transient absorption spectroscopy. By contrast, back-energy transfer was not observed when $\mathrm{PPESO}_{3}{ }^{-}$was assembled with the $\operatorname{Ir}(\mathrm{III})$ complex of composition $\left[\operatorname{Ir}(\mathrm{hqx})_{2}(\mathrm{bpy})\right] \mathrm{Cl}$ (hqx is 2,3-diphenylquinoxaline), which possesses a triplet state at $1.96 \mathrm{eV}$, which is too low in energy to sensitize the formation of the triplet state of $\mathrm{PPESO}_{3}{ }^{-}$ . This study demonstrates that $\operatorname{Ir}(\mathrm{III})$ complexes with appropriate triplet energy can serve to sensitize the triplet state in conjugated polymers.

\subsection{Liquid crystals}

Liquid crystals (LC) are considered as the "fourth state of matter" as their properties are intermediate between those of crystalline solids and those of liquids. Most liquid crystals are neutral organic compounds.[10] However, ionic liquid crystals can also be formed by incorporating anions and cations into the molecule of the LC.[84] Ionic metallomesogens, for instance, are liquid crystals based on transition metal complexes.[85] The driving force for the formation of metallomesogens are the interactions, generally van der Waals, between the anisometric molecules promoting high self-organization of the materials into rod-like, disc-like or nematic columnar phases.[9, 10] Early examples of LC iridium complexes took advantage of the square-planar geometry or iridium(I) metal centers. Complex LC1 (Figure 8) is a dinuclear complex bearing a mesomorphic ligand that, due to its elongated shape, displayed a smectic phase at higher temperature (between $142{ }^{\circ} \mathrm{C}$ and $169{ }^{\circ} \mathrm{C}$ ) compared to related mononuclear complexes (between $104{ }^{\circ} \mathrm{C}$ and $128{ }^{\circ} \mathrm{C}$ ) of the composition of $\left[\operatorname{IrCl}(\mathrm{CO})_{2} \mathrm{~L}\right]$, where $\mathrm{L}$ are 4-stilbazole or 4-styrylpyridine derivatives bearing long alkoxy chains.[86, 87] LC2 (Figure 8) is based on an iridium dicarbonyl $\beta$-ketonate functionalized with alkoxy chains that crystallized with a strict antiparallel arrangement of the Ir centers to produce onedimensional chains that displayed disordered columnar hexagonal phases $\left(\mathrm{Col}_{\mathrm{hd}}\right) \cdot[88,89]$ 
Interestingly, for $n=3,4,5$, the complexes were liquid crystalline already at $0{ }^{\circ} \mathrm{C}$ and remained so up to $130{ }^{\circ} \mathrm{C}$.

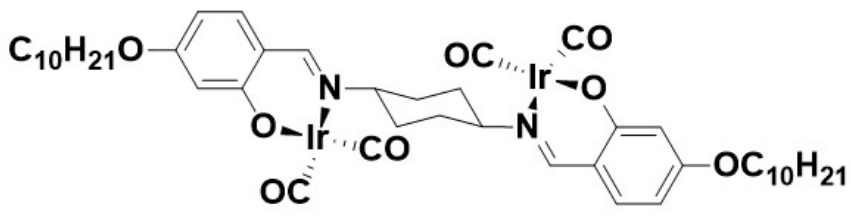

LC1

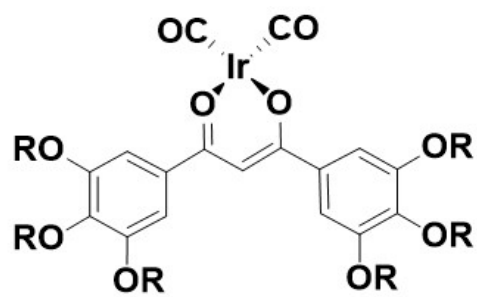

LC2

Figure 8. Chemical structure of LC1 (left) and LC2 (right).

The first example of a LC based on a luminescent cyclometalated $\operatorname{Ir}(\mathrm{III})$ complex (LC3, Figure 9) was reported by Ghedini and co-workers.[90] LC3 is the cationic complex $\left[\operatorname{Ir}(\mathrm{ppy})_{2}(\mathrm{bpy}-\mathrm{C} 8)\right] \mathrm{PF}_{6}$ bearing a bipyridine functionalized at the 4,4 '-position with $[3,4,5$ (trioctyloxy)benzoyloxymethyl] units as the ancillary ligand. This complex exhibited a monotropic columnar hexagonal phase when the sample was cooled rapidly $\left(>10{ }^{\circ} \mathrm{C} / \mathrm{min}\right)$, and this mesophase was stable within the temperature range of $120{ }^{\circ} \mathrm{C}-20{ }^{\circ} \mathrm{C}$. Upon subsequent heating, crystallization was observed at $94{ }^{\circ} \mathrm{C}$ and isotropization occurred at $184{ }^{\circ} \mathrm{C}$. When the sample was slowly cooled, only the crystalline phase was observed. Interestingly, the different phases exhibited different emission properties. In deaerated DCM LC3 exhibited an orangered emission at $\lambda_{\mathrm{PL}}=600 \mathrm{~nm}$ with a $\Phi_{\mathrm{PL}}$ of $12 \%$ and an emission lifetime, $\tau_{\mathrm{PL}}$, of $320 \mathrm{~ns}$, corresponding to a mixed ${ }^{3} \mathrm{LLCT} /{ }^{3} \mathrm{MLCT}$ transition (LLCT $=$ ligand-to-ligand charge transfer). Unlike the modest $\Phi_{\mathrm{PL}}$ of $\mathbf{L C 3}$ in solution, enhanced luminescence was detected in the two condensed phases. The emission of the liquid-crystalline and crystalline phases were both blueshifted, respectively, at $\lambda_{\mathrm{PL}}=560 \mathrm{~nm}$ and $520 \mathrm{~nm}$, with significantly higher $\Phi_{\mathrm{PL}}$ of $39 \%$ and 48\%, respectively, compared to those observed in DCM (Figure 9). The blue shifts accompanied by the enhanced emission intensities exhibited by $\mathbf{L C 3}$ on moving from solution to the liquid-crystalline phase and finally to the crystalline solid are due to the reduced 
aggregation quenching phenomena and the increasing molecular rigidity present in the condensed phases.

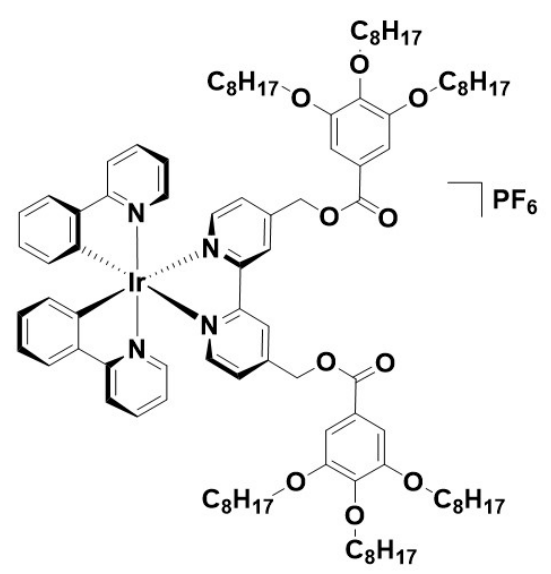

LC3

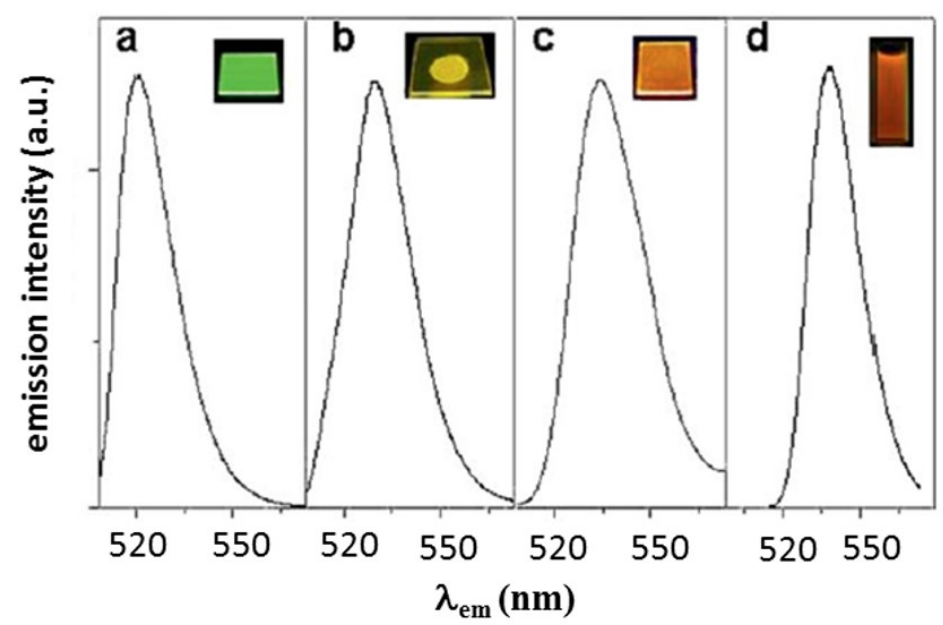

Figure 9. Chemical structure of $\mathbf{L C 3}$ (left) and its emission spectra (right) collected from a) crystalline film (green), b) mesophase film (yellow), c) amorphous film (orange-red) and d) DCM solution. Insets are images of samples under UV illumination. Images a), b), c) and d) are adapted with permission. Copyright 2010, Wiley-VCH.[90]

Bruce, Williams and co-workers[91] used cyclometalated $\operatorname{Ir}(\mathrm{III})$ complexes bearing anisotropic polycatenar 2,5-diphenylpyridine ligands to prepare the liquid crystalline complexes LC4-LC9 illustrated in Figure 10. Complex LC4 was formed by cleavage of the corresponding $\mu$-dichloro-bridged iridium dimers with dimethyl sulfoxide. Complex LC4 showed both lamellar and columnar rectangular phases. However, LC4 exhibited a weak emission at $\lambda_{\mathrm{PL}}=580 \mathrm{~nm}$ with a low $\Phi_{\mathrm{PL}}$ of $0.5 \%$ in degassed DCM and lacked chemical stability. The subsequent reaction of $\mathbf{L C 4}$ with $\mathrm{AgPF}_{6}$ in $\mathrm{MeCN}$ yielded $\mathbf{L C 5}$, which was found to be slightly more emissive and more stable than LC4. LC5 exhibited a columnar mesophase between $145{ }^{\circ} \mathrm{C}$ and $163{ }^{\circ} \mathrm{C}$, and emission in degassed DCM at $\lambda_{\mathrm{PL}}$ of $520 \mathrm{~nm}$, with a $\Phi_{\mathrm{PL}}$ of $1.3 \%$ and a $\tau_{\mathrm{PL}}$ of $1750 \mathrm{~ns}$. In search as additional luminescent iridium-based LCs, attention then turned to neutral complexes bearing acetylacetonate (acac) as the ancillary ligand. 
Complexes LC6 and LC7 were not liquid crystalline. It was indeed discovered that three polycatenar chains on each of the $\mathrm{C}^{\wedge} \mathrm{N}$ ligands were necessary to confer liquid crystallinity upon the complexes. Thus, LC8 was both LC in nature and emissive, exhibiting a columnar hexagonal phase between $31{ }^{\circ} \mathrm{C}$ and $66{ }^{\circ} \mathrm{C}$ and emission at $\lambda_{\mathrm{PL}}=582 \mathrm{~nm}$ with a $\Phi_{\mathrm{PL}}$ of $9.1 \%$; no emission lifetime was reported. The $\mu$-dichloro-bridged iridium dimer LC9 (Figure 10) also exhibited a columnar liquid crystal phase from room temperature to $75^{\circ} \mathrm{C}$. This iridium dimer was, however, weakly emissive at $\lambda_{\mathrm{PL}}=570 \mathrm{~nm}$, exhibiting a low $\Phi_{\mathrm{PL}}$ of $0.8 \%$ accompanied by a relatively long $\tau_{\mathrm{PL}}$ of $5.1 \mu \mathrm{s}$.
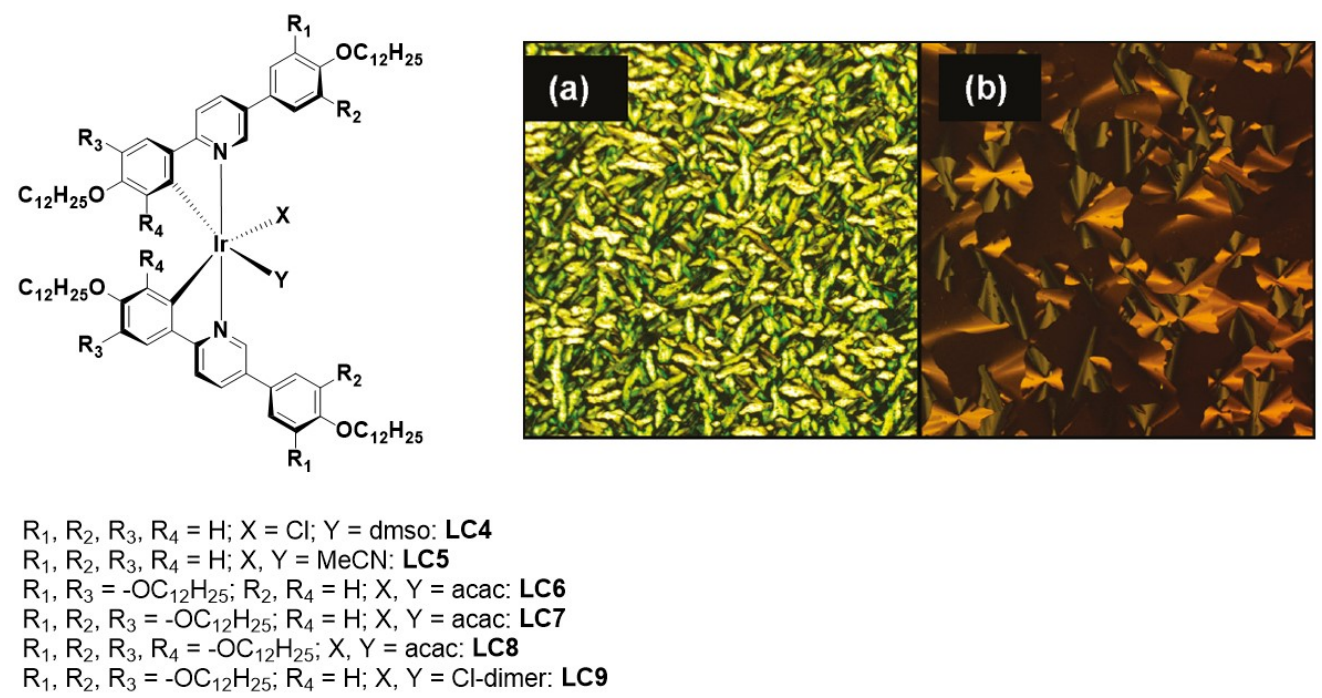

Figure 10. Chemical structure of the LC molecular complexes and optical texture of complexes (a) LC5 (155 ${ }^{\circ} \mathrm{C}$ on cooling) and (b) LC9 (43 ${ }^{\circ} \mathrm{C}$ on cooling). Images a) and b) are adapted with permission from Ref. [91]. Copyright 2011, American Chemical Society.

In a subsequent work[92] by the same authors, a series of dinuclear $\operatorname{Ir}(\mathrm{III})$ complexes were prepared based on ppy derivatives functionalized with four, five and six polycatenar chains as cyclometalating ligands, and 1,1,2,2-tetraacetylethane (tae) acting as both the ancillary and bridging ligand to connect two iridium centers (Figure 11a). LC10, LC11, LC12 and LC13 were all similarly mesomorphic, showing a columnar hexagonal mesophase with a fern-like feature. Considering that the corresponding mononuclear acac complexes LC6 and LC7 were 
not mesomorphic in nature, the bridging tae ligand changes the geometries of the molecules, making them more disc-like and inducing mesomorphism in the same manner as the bridging chlorides did in LC9. However, unlike LC9, complexes LC10, LC11, LC12 and LC13 were all very emissive in DCM solution at room temperature, all exhibiting similar orange luminescence between $578 \mathrm{~nm}$ and $588 \mathrm{~nm}$ with $\Phi_{\mathrm{PL}}$ of approximately $50 \%$ and $\tau_{\mathrm{PL}}$ of around 4.0 $\mu \mathrm{s}$. As the two iridium centers in all of the dinuclear complexes are asymmetric, two diastereomeric forms, i.e. meso-form with $\Lambda$-, $\Delta$-stereochemistry, and racemate-form with $\Delta, \Delta-$ and $\Lambda, \Lambda$-stereochemistry, can be obtained. For $\mu$-dichloro-bridged iridium dimers only the racemic form is generally obtained because of steric hindrance. However, as the tae bridging ligand keeps the iridium centers more distant compared to the chloro bridging ligands, the formation of both diastereomers (meso and racemic) was observed for complexes LC10, LC11, LC12 and LC13. In the case of complex LC11, the two racemates were separated by column chromatography into the enantiopure analogs without identifying their respective absolute configuration. Despite both isomers exhibiting identical emission properties $\left(\lambda_{\mathrm{PL}}=\right.$ $558,663 \mathrm{~nm}, \Phi_{\mathrm{PL}}=43 \%$ ) and columnar hexagonal phases (Figure 11b), their isomorphic temperature ranges differed from $79-126{ }^{\circ} \mathrm{C}$ for one isomer to $63-95{ }^{\circ} \mathrm{C}$ for the other.

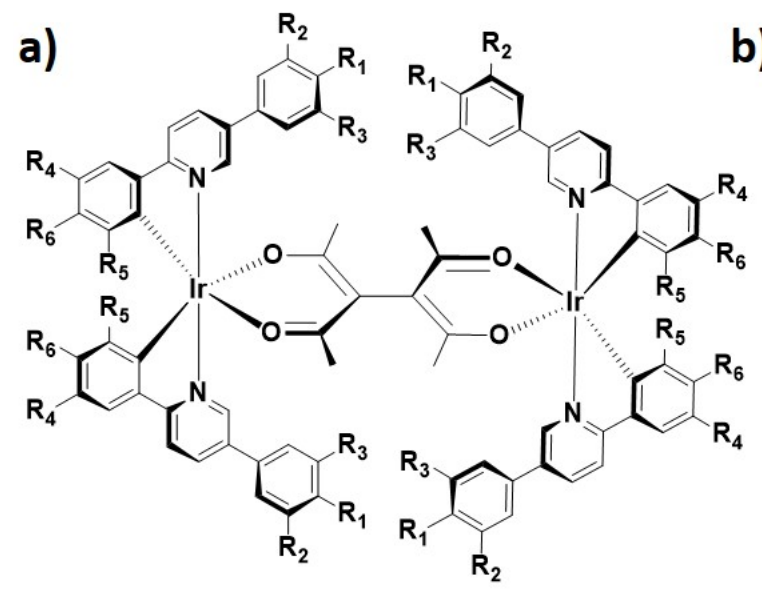

$\mathrm{R}_{1}, \mathrm{R}_{2}, \mathrm{R}_{4}, \mathrm{R}_{6}=-\mathrm{OC}_{12} \mathrm{H}_{25} ; \mathrm{R}_{3}, \mathrm{R}_{5}=\mathrm{H}: \mathrm{LC} 10$

$\mathrm{R}_{1}, \mathrm{R}_{2}, \mathrm{R}_{3}, \mathrm{R}_{4}, \mathrm{R}_{6}=-\mathrm{OC}_{12} \mathrm{H}_{25} ; \mathrm{R}_{5}=\mathrm{H}: \mathrm{LC} 11$

$\mathrm{R}_{1}, \mathrm{R}_{2}, \mathrm{R}_{3}, \mathrm{R}_{4}, \mathrm{R}_{5}, \mathrm{R}_{6}=-\mathrm{OC}_{12} \mathrm{H}_{25}: \mathrm{LC} 12$

$\mathrm{R}_{1}, \mathrm{R}_{4}, \mathrm{R}_{5}, \mathrm{R}_{6}=-\mathrm{OC}_{12} \mathrm{H}_{25} ; \mathrm{R}_{2}, \mathrm{R}_{3}=\mathrm{H}: \mathrm{LC} 13$
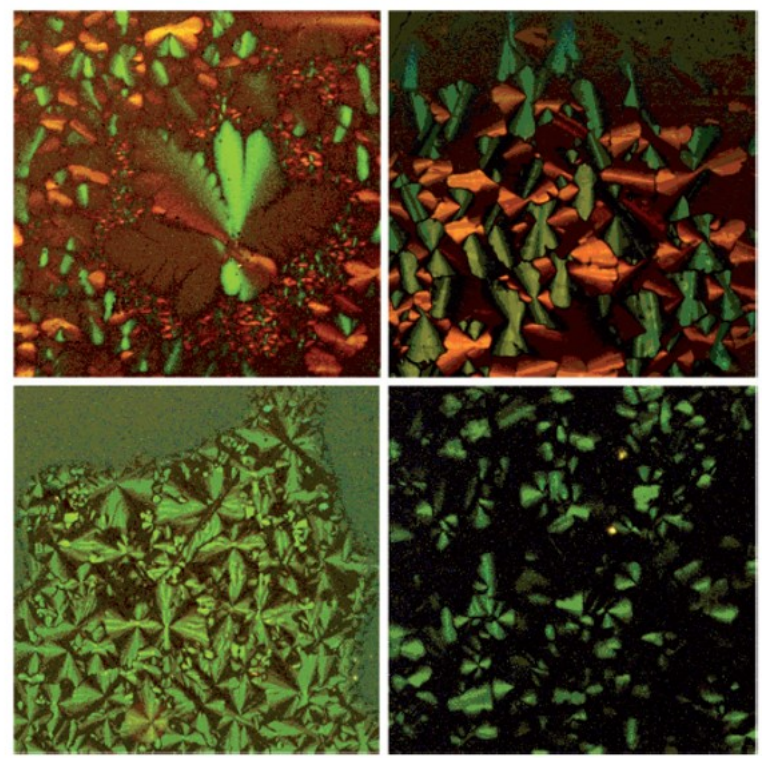
Figure 11. a) Chemical structures of LC10, LC11, LC12 and LC13. b) optical micrograph (on cooling) of complexes: $\mathbf{L C 1 1}$ isomer $1,100{ }^{\circ} \mathrm{C}$ (top-left); $\mathbf{L C 1 1}$ isomer $2,60^{\circ} \mathrm{C}$ (top-right); LC11 isomer $1,100{ }^{\circ} \mathrm{C}$ (top-left); $\mathbf{L C 1 0}$ racemate, $85^{\circ} \mathrm{C}$ (bottom-left); $\mathbf{L C 1 3}, 133{ }^{\circ} \mathrm{C}$ (bottomright). Image b) is adapted with permission. Copyright 2012, Wiley-VCH.[92]

Baranoff and co-workers[93] recently reported a modular approach to the design of mesomorphic phosphorescent iridium complexes. In their design, rod-shaped difluorobiphenyl cyclohexyl mesogenic groups were grafted onto the non-chromophoric acac ligand of the core structure $\left[\operatorname{Ir}\left(\mathrm{C}^{\wedge} \mathrm{N}\right)_{2}(\right.$ acac) $]$ in complexes LC14, LC15, LC16 and LC17 (Figure 12). The $\mathrm{C}^{\wedge} \mathrm{N}$ ligands (ppy and dFppy) dictated the photophysical properties of the complexes while the mesogenic units of the functionalized acac ligands controlled the mesomorphic properties of the materials.

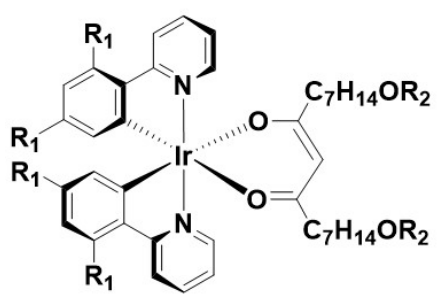

$\mathrm{R}_{1}=\mathrm{H}:$ LC14

$\mathrm{R}_{1}=\mathrm{F}: \mathrm{LC} 15$

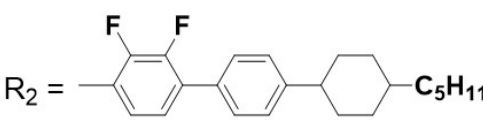

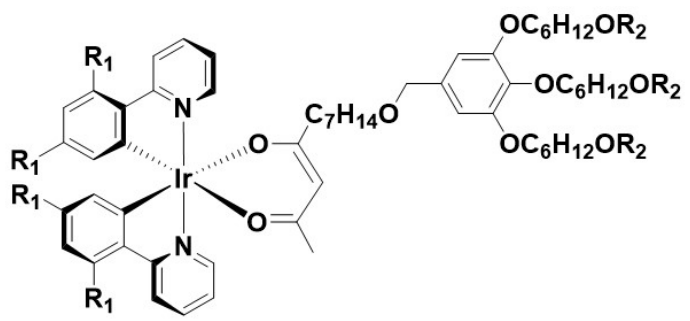

$\mathrm{R}_{1}=\mathrm{H}: \mathrm{LC} 16$

$\mathrm{R}_{1}=\mathrm{F}: \mathrm{LC} 17$

Figure 12. Chemical structures of LC14, LC15, LC16 and LC17.

In degassed DCM solution, the complexes LC14 and LC16 bearing $\mathrm{dFppy} \mathrm{C}^{\wedge} \mathrm{N}$ ligands exhibited sky-blue emissions centered at $\lambda_{\mathrm{PL}}=482 \mathrm{~nm}$, with $\Phi_{\mathrm{PL}}$ of $64 \%$ and $65 \%$ and $\tau_{\mathrm{PL}}=1.2$ $\mu$ s and $1.0 \mu$ s, respectively. LC15 and LC17 bearing ppy as the $\mathrm{C}^{\wedge} \mathrm{N}$ ligands, showed redshifted emission compared to the previous two LCs centered at $\lambda_{\mathrm{PL}}=517 \mathrm{~nm}$, with $\Phi_{\mathrm{PL}}$ of $51 \%$ 
and $45 \%$ and $\tau_{\mathrm{PL}}=1.4 \mu \mathrm{s}$ and $1.6 \mu \mathrm{s}$, respectively. As the functionalization of the acac ligand had little effect on the emission properties of the complexes in solution, the photophysical properties of LC14, LC15, LC16 and LC17 were very similar to those exhibited by the corresponding reference complexes $\left[\operatorname{Ir}(\mathrm{ppy})_{2}(\mathrm{acac})\right]$ and $\left[\operatorname{Ir}(\mathrm{dFppy})_{2}(\mathrm{acac})\right]$. Each of LC14, LC15, LC16 and LC17 exhibited a smectic A mesophase with melting points between $150{ }^{\circ} \mathrm{C}$ and $170{ }^{\circ} \mathrm{C}$. However, due to the unsymmetrical nature of $\mathbf{L C 1 6}$ and $\mathbf{L C 1 7}$, the mesophase of these two complexes were found to be enantiotropic.

Kozhevnikov, Bruce and co-workers[94] recently reported the luminescent and mesomorphic properties of a series of metal complexes ( $\mathrm{Zn}(\mathrm{II}), \mathrm{Co}(\mathrm{III}), \mathrm{Rh}(\mathrm{III}), \mathrm{Ir}(\mathrm{III}), \mathrm{Eu}(\mathrm{III})$ and $\mathrm{Dy}(\mathrm{III}))$ based on the mesomorphic ligand 5,5"-di(3,4,5-trialkoxyphenyl)terpyridine. Among this series of liquid crystals, the Ir(III) LCs, LC18 and LC19 (Figure 13), exhibited enantiotropic columnar mesophases $\left(\mathrm{Col}_{\mathrm{h}}\right)$ at temperatures higher than $140{ }^{\circ} \mathrm{C}$ that were dependent on the 5,5"-di(3,4,5-trialkoxyphenyl)terpyridine ligand, with little influence of the iridium metal center.

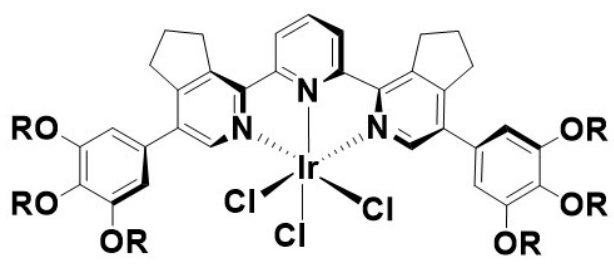

$R:-C_{12} \mathrm{H}_{25}$, LC18

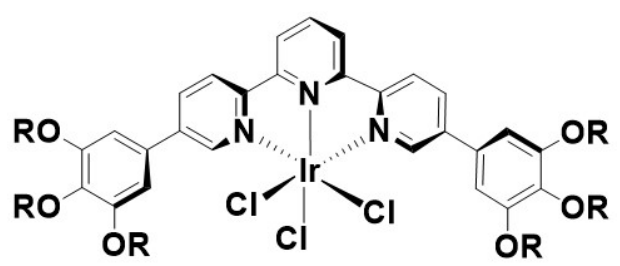

R: $-\mathrm{C}_{12} \mathrm{H}_{25}$, LC19

Figure 13. Chemical structures of LC18 and LC19.

In degassed hexane LC18 and LC19 exhibited broad ${ }^{3}$ MLCT emissions, respectively, at 621 and $622 \mathrm{~nm}$, with $\Phi_{\mathrm{PL}}$ of $40 \%$ and $8 \%$ and $\tau_{\mathrm{PL}}$ of 1.5 and $1.2 \mu \mathrm{s}$. The higher $\Phi_{\mathrm{PL}}$ of $\mathbf{L C 1 8}$ compared to LC19 is attributed to the presence of the fused cyclopentane rings on the 
terpyridine ligand, which increased the rigidity of the $\operatorname{Ir}(\mathrm{III})$ complex thereby reducing nonradiative decay pathways. In neat thin films at $298 \mathrm{~K} \mathrm{LC18}$ emitted at $\lambda_{\mathrm{PL}}=619 \mathrm{~nm}$ while complex LC19 was found to be non-emissive. For LC18, the thin film photophysics were unchanged up to $100{ }^{\circ} \mathrm{C}$ while a $36 \mathrm{~nm}$ bathochromic shift was observed from $100{ }^{\circ} \mathrm{C}$ to 176 ${ }^{\circ} \mathrm{C}\left(\lambda_{\text {exc }}=375 \mathrm{~nm}\right)$. This high temperature bathochromic shift was attributed to the reorganisation of LC18 upon entering the liquid crystal phase and generating an excimer-like emission. Excimer emission was also observed for Pt(II) liquid crystals bearing the 5,5"$\operatorname{di}(3,4,5$-trialkoxyphenyl)terpyridine ligand scaffold.[95]

\subsection{Luminescent gels}

Macroscopically, gels consist of viscoelastic solid-like materials comprised of an elastic cross-linked network and a solvent trapped within the 3D matrix of the gel network by physical or chemical forces.[96,97] Traditional gel chemistry is dominated by polymers formed through covalent bonds. Of more recent interest are fibrous gel networks, called "supramolecular gels", that can be constructed from small molecules that are interlinked through non-covalent interactions such as hydrogen bonding, $\pi-\pi$ interactions, metal coordination or host-guest inclusion.[98] Gels have been used in diverse applications such as tissue engineering and wound healing, drug delivery, templating self-assembled morphologies, molecular electronics and sensing. $[14,99]$ Metal introduction in gel networks has been motivated as a way of tuning their properties with examples of gels containing metallo-porphyrins, ferrocene, platinum, ruthenium, gold and copper complexes having been described in the literature.[100] In this section of the review we summarize the recent developments in phosphorescent gels based on cyclometalated $\operatorname{Ir}(\mathrm{III})$ complexes. 
By combining the blue-emitting 1,8-naphtalimide-based gelator G1 with the orange-emitting iridium complex G2 (Figure 14a), Yi and co-workers[101] reported a white-emitting twocomponents supramolecular gel. G1 exhibited an excellent ability to gelate a series of polar or apolar organic solvents (e.g., cyclohexane, ethyl acetate, acetonitrile, acetone, methanol, propanol and dimethyl sulfoxide). Scanning electron microscopy (SEM) images of the xerogels of $\mathbf{G 1}$ showed the formation of interweaving fibers (Figure 14b). G1 could also efficiently form gel networks in acetonitrile in the presence of the iridium complex $\mathbf{G 2}$ in a molar ratio G1:G2 = 3:1. This xerogel had almost the same fiber framework as that of the neat G1 xerogel, with the iridium complex G2 assembled into nanoparticles of $20-50 \mathrm{~nm}$ dispersed into the gel fibers. G1 exhibited a blue fluorescence at $\lambda_{\mathrm{PL}}=430 \mathrm{~nm}$ with a $\Phi_{\mathrm{PL}}$ of $26.7 \%$ in $\mathrm{MeCN}$, while after gelation its emission was slightly red-shifted at $\lambda_{\mathrm{PL}}=440 \mathrm{~nm}$. The iridium complex $\mathbf{G} 2$, on the other hand, exhibited a structured orange emission at $\lambda_{\mathrm{PL}}=533,570 \mathrm{~nm}$ with a $\Phi_{\mathrm{PL}}$ of 2.2\%. Upon photoexcitation of $\mathbf{G 1}$ in $\mathrm{MeCN}$, inefficient energy transfer (with efficiency of approximately $0.5-5 \%$ ) to the iridium complex $\mathbf{G 2}$ was promoted. However, due to the close proximity of the chromophores $\mathbf{G 1}$ and $\mathbf{G 2}$ in the gel fibers, the efficiency of the energy transfer increased up to $60-70 \%$, leading to white light emission from the gel network of composition G1:G2 = 3:1 (CIE coordinates, $\mathrm{x}:$ 0.31, y: 0.39, Figure 14c).

It had previously been reported that Ir(III) complexes functionalized with carbonyl units can react with cysteine to give non-emissive complexes.[102] Addition of cysteine to complex G2 in $\mathrm{MeCN}$ resulted in a red-shift of the emission of the iridium complex from $533 \mathrm{~nm}$ to $579 \mathrm{~nm}$ with a dramatic decrease in intensity due to the formation of the thiazolidine species. When cysteine (from 0 to 40 equiv.) was added to the white-emitting gel G1:G2, the gradual quenching of the orange emission of $\mathbf{G 2}$ gave rise to a pronounced color change of the gel from 
white to blue. As a result, the emission properties exhibited by gel G1:G2 can be exploited for the detection of cysteine.

a)

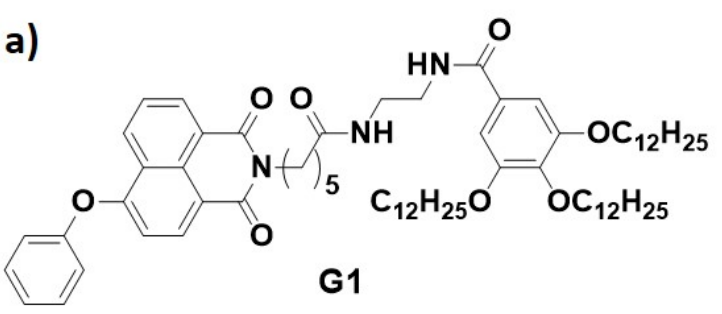

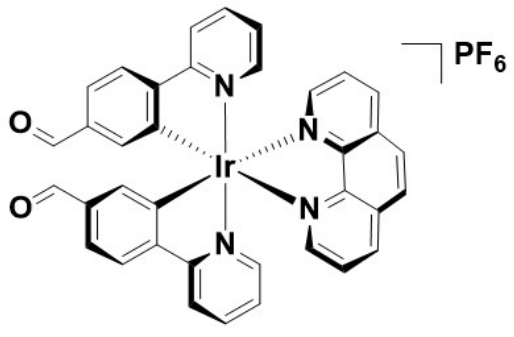

G2

b)
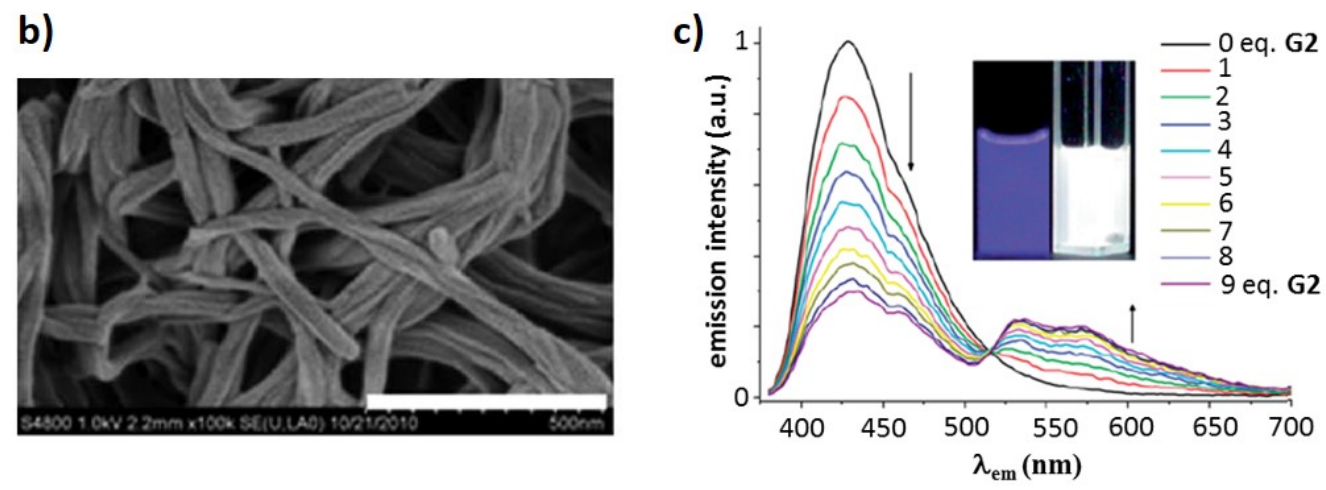

Figure 14. a) chemical structures of gelator G1 (left) and the iridium complex G2 (right). b) SEM images of xerogel G1 in acetonitrile at 298 K. c) Emission spectral changes of G1 as a result of the addition of $\mathbf{G 2}$ from 0.1 to 9 equivalents. Insets are images of the blue emitting G1 and white emitting gel G1:G2. Images b) and c) are adapted from Ref. [101] with permission from The Royal Society of Chemistry.

Szerb, Donnio and co-workers[103] reported that cationic Ir(III) complexes of composition $\left[\operatorname{Ir}(\mathrm{ppy})_{2}(\mathrm{bpy})\right]^{+} \mathrm{X}^{-}$spontaneously self-assembled into ordered aqueous gel phases when containing aliphatic carboxylate counterions, $\mathrm{X}^{-}$, of the type of $\mathrm{RCO}_{2}^{-}\left(\mathrm{R}^{-} \mathrm{CH}_{3}, \mathrm{C}_{2} \mathrm{H}_{5}, \mathrm{C}_{5} \mathrm{H}_{11}\right.$, $\mathrm{C}_{7} \mathrm{H}_{15}$, Figure 15a). When dissolved in water at a concentration of $2.5 \mathrm{wt} \%$, complexes $\mathbf{G 3}, \mathbf{G 4}$ and G5 formed gel networks (Figure 15b), exhibiting similar blue-shifted emissions, respectively, at $\lambda_{\mathrm{PL}}=540 \mathrm{~nm}, \lambda_{\mathrm{PL}}=538 \mathrm{~nm}$ and $\lambda_{\mathrm{PL}}=536 \mathrm{~nm}$ with modestly higher $\Phi_{\mathrm{PL}}$ of $15 \%, 15 \%$ and $17 \%$ compared to the corresponding isotropic solutions at lower concentration (1 wt $\%$ in degassed aqueous solution, G3: $\lambda_{\mathrm{PL}}=564 \mathrm{~nm}, \Phi_{\mathrm{PL}}: 9 \%, \mathbf{G 4}: \lambda_{\mathrm{PL}}=554 \mathrm{~nm}, \Phi_{\mathrm{PL}}:$ 
$11 \%$, G5: $\left.\lambda_{\mathrm{PL}}=540 \mathrm{~nm}, \Phi_{\mathrm{PL}}: 16 \%\right)$. By contrast, due to the long $\mathrm{C}_{7} \mathrm{H}_{15}$ aliphatic chain present on the counterion of G6, the complex was found to be poorly soluble in water and it formed only turbid suspensions when dissolved in aqueous solution. The aggregation process of G3G5 into gels was investigated by wide- and small-angle x-ray scattering (WAXS and SAXS) and small-angle neutron scattering (SANS) measurements. At concentrations higher than 1.8 wt $\%$, the gelification of G3-G5 occurred with close packing of supramolecular columns, sheathed in their solvation shells into 2D-rectangular lattices surrounded by their counterions. The overall organization of the gels G3-G5 is classified as a lamellar-columnar phase (Figure 15c).

a)

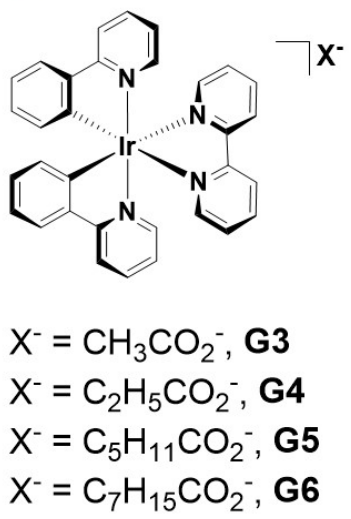

b)

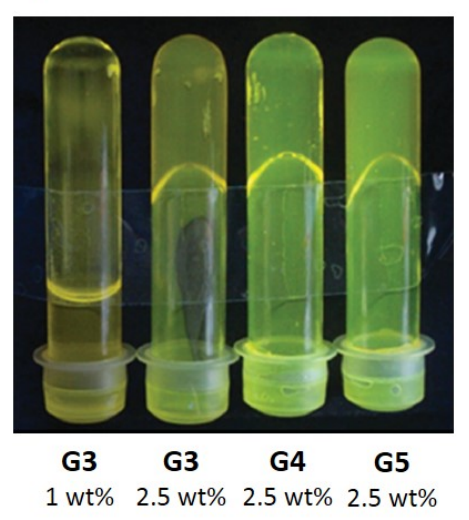

c)

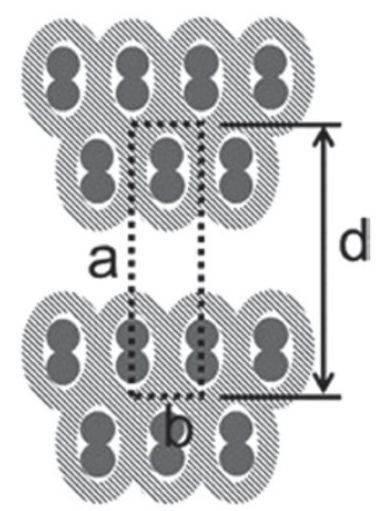

Figure 15. a) Chemical structures of complexes G3-G6; b) images from left to right of anisotropic solution of $\mathbf{G 3}$ at concentration of 1 wt $\%$, gel of G3, G4 and G5 at concentration of $2.5 \mathrm{wt} \%$; c) schematic representation of the proposed organization of the $\operatorname{Ir}(\mathrm{III})$ complexes in the gel phase. Strand (solid gray) associated laterally into double rows incorporating water and counterions (dashed gray). Images b) and c) are adapted with permission. Copyright 2013, Wiley-VCH.[103] 
The quasi-spherical shape of octahedral Ir(III) complexes is intrinsically unfavorable for face-to-face stacking and linearly polarized emission and therefore the number of emissive Ir(III) liquid crystals and gels reported to date are still limited. This contrasts, for example, with cyclometalated $\mathrm{Pt}(\mathrm{II})$ complexes that have square planar geometries and interact through both $\pi-\pi$ and Pt-Pt bounding interactions, thus exhibiting good alignment with high polarization ratio.[104, 105] As a result, the number of reports of luminescent liquid crystals and gels to date based on $\operatorname{Ir}(\mathrm{III})$ complexes are much fewer in number than those based on $\mathrm{Pt}(\mathrm{II})$ chromophores.

\subsection{Surfactant-based structures}

The term surfactant defines molecules soluble in both organic solvents and water. They generally consist of a polar headgroup and an apolar tail that confer amphiphilic behavior to the systems.[21] One of the characteristic feature of surfactants is their ability to self-assemble, under certain conditions, into well-define aggregate structures such as micelles, colloids or highly symmetric volume phases through amphiphilic interactions.[106] Recent advances in nanoscience and colloidal technology have strongly driven the development of colloidal structures with integrated multifunctional properties.[11] In this context, iridium-based surfactants, when opportunely designed, have shown the ability to self-assemble into colloidal structures, giving rise to amphiphilic networks with enhanced photophysical properties.

De Cola and co-workers[107] reported the first examples of iridium and ruthenium metallosurfactants assembled in micellar systems. Both the $\operatorname{Ir}(\mathrm{III})$ complex MS1 $\left[\operatorname{Ir}(\mathrm{dFppy})_{2}(\right.$ alkbpy) $] \mathrm{Cl}$ and the $\mathrm{Ru}(\mathrm{II})$ complex $\mathrm{MS2}\left[\mathrm{Ru}(\mathrm{bpy})_{2}(\right.$ alk-bpy)$] 2 \mathrm{Cl}$ (Figure 16a) contain a 2,2'bipyridine ligand functionalized at the 4,4'-positions with seventeen methylene units (alk-bpy) 
as the hydrophobic part of the structure. The photophysical properties of MS1 and MS2 in water below their critical micelle concentrations (CMC), respectively, of $5 \mu \mathrm{M}$ and $3 \mu \mathrm{M}$, resembled those of the reference complexes $\left[\operatorname{Ir}(\mathrm{dFppy})_{2}(\mathrm{bpy})\right] \mathrm{Cl}, \mathbf{3 b}$ (Figure 2) and $\left[\mathrm{Ru}(\mathrm{bpy})_{3}\right] \mathrm{Cl}_{2}$. MS1 exhibited, as a monomeric species, a broad emission at $\lambda_{\mathrm{PL}}=635 \mathrm{~nm}$ with a $\Phi_{\mathrm{PL}}$ of $3.0 \%$ and a $\tau_{\mathrm{PL}}$ of $360 \mathrm{~ns}$. At a concentration of $0.15 \mathrm{mM}$ (above the CMC limit), the emission intensity of MS1 was almost unchanged $\left(\Phi_{\mathrm{PL}}=3.3 \%\right)$ but its emission lifetime became bi-exponential in nature, with a short component due to the non-aggregated form of $\tau_{\mathrm{PL}}$ $=400 \mathrm{~ns}$, and a longer component of $\tau_{\mathrm{PL}}=860 \mathrm{~ns}$ that arises from the self-assembled species. Similarly, the emission intensity of MS2 at a concentration of $0.01 \mathrm{mM}$ was slightly enhanced $\left(\Phi_{\mathrm{PL}}=4.5 \%\right)$ with longer bi-exponential lifetime decay components of $\tau_{\mathrm{PL}}=175 \mathrm{~ns}$ and $475 \mathrm{~ns}$ compared to the emission properties of $\mathbf{M S 2}$ in its monomeric form $\left(\Phi_{\mathrm{PL}}=2.5 \%, \tau_{\mathrm{PL}}=160 \mathrm{~ns}\right)$. The enhanced emissions with long lifetime components in both MS1 and MS2 observed at concentrations higher than their CMC are attributed to their micellar aggregation that reduce the non-radiative vibrational modes of the complexes as a function of their closer packing. When MS1 and MS2 were mixed in a 1:1 ratio at $0.025 \mathrm{mM}$ each, the complexes aggregated into mixed micellar system, and when excited at $350 \mathrm{~nm}$, only the characteristic emission of the ruthenium complex MS2 was observed at $645 \mathrm{~nm}$. Thus, efficient Förster energy (ET) transfer from the iridium donor to the ruthenium acceptor was promoted in the assembled mix micelles (Figure 16b); ET was not observed when the two complexes were mixed at a concentration below their CMC. 
a)

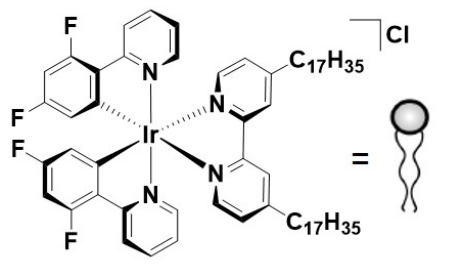

MS1

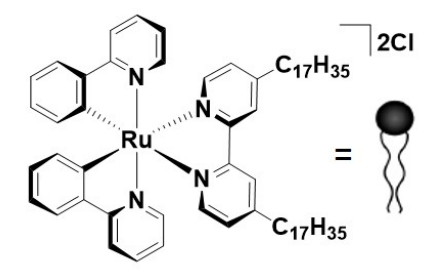

MS2 b)

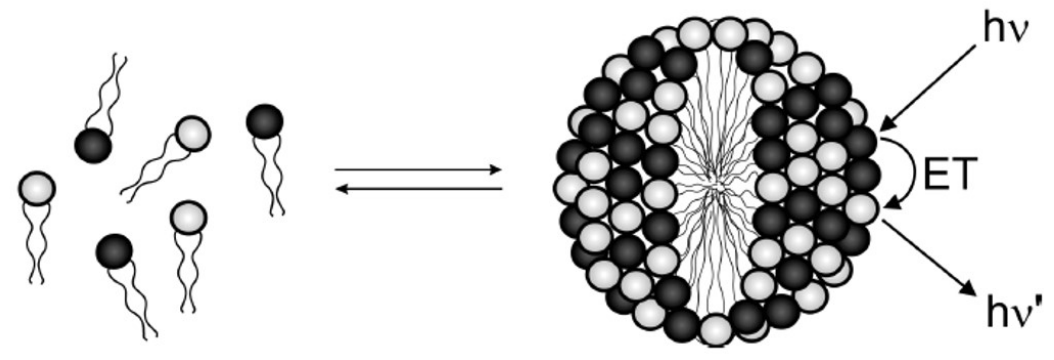

Figure 16. a) Chemical structure of the metallo-surfactants MS1 and MS2. b) selfaggregation of MS1 and MS2 into mix micelle and schematic illustration of ET from donor Ir to acceptor $\mathrm{Ru}$. Image b) is adapted with permission from Ref. [107]. Copyright 2008, American Chemical Society.

The Ir(III) complex MS3 (Figure 17a) was designed similarly to MS1, to have a polar charged iridium head and long aliphatic tail appended to the ligands with the complex of composition $\left[\operatorname{Ir}(\mathrm{ppy})_{2}\left(\mathrm{~N}^{\wedge} \mathrm{N}\right)\right] \mathrm{PF}_{6}$, where $\mathrm{N}^{\wedge} \mathrm{N}$ is $2,2^{\prime}$-bipyridine functionalized with six apolar long aliphatic chains, bis-[4,4'-bis(3,4,5-trydodecyloxybenzoyloxymethyl)-2,2'bipyridyl)].[108] As observed for MS1, MS3 exhibited high tendency to aggregate in water through interactions between the hydrophobic chains, resulting in a blue-shifted emission at $\lambda_{\mathrm{PL}}=565 \mathrm{~nm}$ with higher $\Phi_{\mathrm{PL}}$ of $25.6 \%$ and longer bi-exponential emission decays of $210 \mathrm{~ns}$, $700 \mathrm{~ns}$ compared to the emission exhibited in THF, where no aggregation was observed $\left(\lambda_{\mathrm{PL}}=\right.$ $\left.605 \mathrm{~nm}, \Phi_{\mathrm{PL}}=4.5 \%, \tau_{\mathrm{PL}}=113 \mathrm{~ns}\right)$.

In contrast to MS1 and MS3 that consist of a neutral hydrophobic tail attached to the ancillary ligand and a cationic Ir(III) complex as the headgroup, MS4 and MS5 (Figure 17b) are characterized by a reverse design strategy where the $\operatorname{Ir}(\mathrm{III})$ core is neutral of composition of 
$\left[\operatorname{Ir}(\mathrm{ppy})_{2}(\right.$ alk-pic)], and the picolinate ligand (alk-pic) is substituted with long alkyl chains bearing a terminal mono-anionic sulfate group and sodium as counter cation.[109] At a low concentration of $0.01 \mathrm{mM}$ in water, complexes MS4 and MS5 both exhibited weak emission centered respectively at $\lambda_{\mathrm{PL}}=650 \mathrm{~nm}$ and $\lambda_{\mathrm{PL}}=646 \mathrm{~nm}$ with $\Phi_{\mathrm{PL}}<0.1 \%$ accompanied by very short emission lifetimes $\tau_{\mathrm{PL}}<20 \mathrm{~ns}$. At higher concentrations between $1 \mathrm{mM}$ and $0.1 \mathrm{mM}$ both MS4 and MS5 showed at first good solubility in water giving clear solutions, followed by a visible formation of colloidal samples within $2 \mathrm{~h}$. Compared to the mononuclear species, the colloidal samples of MS4 and MS5 exhibited enhanced and blue-shifted emissions, respectively, at $\lambda_{\mathrm{PL}}=509 \mathrm{~nm}$ and $\lambda_{\mathrm{PL}}=531 \mathrm{~nm}$ with $\Phi_{\mathrm{PL}}$ of ca. $1 \%$ and bi-exponential $\tau_{\mathrm{PL}}$ of $111 \mathrm{~ns}$ and $261 \mathrm{~ns}$ for MS4 and $24 \mathrm{~ns}$ and $87 \mathrm{~ns}$ for MS5. The size, morphology and stability of the aggregates were determined by dynamic light scattering (DLS) and scanning electron microscopy (SEM), both of which evidenced the formation of particles with average radii of $300-1300 \mathrm{~nm}$. In addition, Zeta potential analyses showed that MS4 and MS5 at a concentration of $1.9 \mathrm{mM}$ both have highly negative surfaces towards the water phase (-37 and $-57 \mathrm{mV}$, respectively). Therefore, the surfactant molecules gave rise to aggregates where the neutral and hydrophobic iridium complexes were preferentially inside the colloidal structure while the anionic sulfate moieties faced the solvent. Consequently, the protection of the iridium chromophores inside the colloidal systems accounted for the enhanced emission properties of MS4 and MS5 observed at high concentration. 
a)

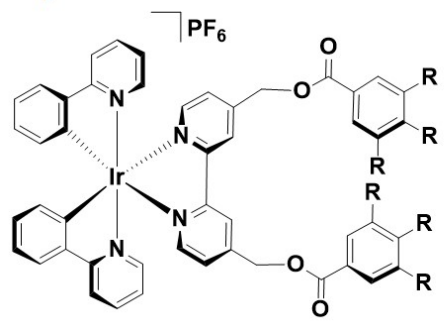

R: $\mathrm{OC}_{12} \mathrm{H}_{25}, \mathbf{M S 3}$ b)

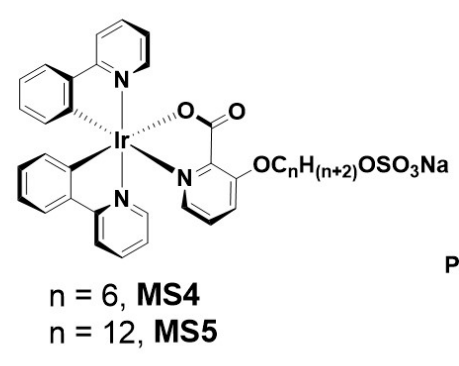

c)

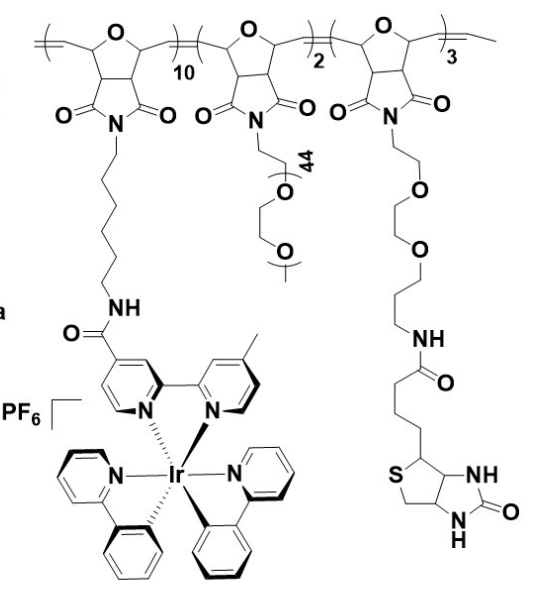

MS6

Figure 17. a) Chemical structures of a) MS3; b) MS4 and MS5 and c) copolymer MS6.

Luminescent mesoporous silicas were prepared by assembling the neutral iridium complex $f a c-\left[\operatorname{Ir}(\mathrm{ppy})_{3}\right]$ with two structure-directing agents (SDA), the cationic cetyltrimethyl ammonium bromide (CTAB) and the non-ionic poly(ethylene glycol)-block-poly(propylene glycol)-block-poly(ethylene glycol) (P123).[110] The Ir(III) complex was firstly trapped into the micelles formed by the SDAs. The micelles were then used as templates to form mesoporous silicas. XRD and nitrogen sorption measurements provided evidence for the preferential inclusion of the $\operatorname{Ir}(\mathrm{III})$ luminophore into the hydrophobic channels of the mesostructures, without any substantial changes in the hexagonal symmetry of the silica. The resulting hybrid material showed a blue-shifted iridium-based emission at $\lambda_{\mathrm{PL}}=509 \mathrm{~nm}$ with higher $\Phi_{\mathrm{PL}}$ of $72 \%$ and longer bi-exponential $\tau_{\mathrm{PL}}$ of $576 \mathrm{~ns}$ and $1077 \mathrm{~ns}$ compared to the emission observed for $f a c$ - $\left[\operatorname{Ir}(\text { ppy })_{3}\right]$ as a pristine powder $\left(\lambda_{\mathrm{PL}}=534 \mathrm{~nm}, \Phi_{\mathrm{PL}}=12 \%, \tau_{\mathrm{PL}}=38\right.$ ns) where aggregation-caused quenching is prevalent. 
Phosphorescent materials based on templated synthesis of mesoporous silica using micellar solution of the $\operatorname{Ir}(\mathrm{III})$ metallosurfactant $\left[\operatorname{Ir}(\mathrm{dFptrBz})_{2}(\mathrm{ppy}-\mathrm{hd})\right] \mathrm{Cl}$ (dFptrBz is 1-benzyl-4-(2,4difluorophenyl)-1H-1,2,3-triazole and bpy-hd is 4,4'-diheptadecyl-2,2'-bipyridine), MS7 in CTAB were also investigated by Stucchi de Camargo, De Cola and co-workers[111] (Figure 18). MS7 exhibited a broad emission at approximately $\lambda_{\mathrm{PL}}=500 \mathrm{~nm}$ with a $\Phi_{\mathrm{PL}}$ of $85 \%$ and a $\tau_{\mathrm{PL}}=1043 \mathrm{~ns}$ in degassed EtOH-H $\mathrm{H}_{2} \mathrm{O}(1: 1 \mathrm{v} / \mathrm{v})$ at a concentration of $10^{-5} \mathrm{M}$. Micellar solutions of MS7:CTAB (1:8000 ratio) also exhibited a broad emission at $\lambda_{\mathrm{PL}}=500 \mathrm{~nm}$ with lower $\Phi_{\mathrm{PL}}$ of $42 \%$ and a $\tau_{\mathrm{PL}}=1040 \mathrm{~ns}$. Due to the rigidification of the system and/or more restricted access of oxygen inside the pores of the host silica material, MS7:TEOS exhibited an emission at $\lambda_{\mathrm{PL}}$ $=460,500 \mathrm{~nm}$ with a $\Phi_{\mathrm{PL}}$ of $45 \%$ and significantly longer bi-exponential lifetime of $\tau_{\mathrm{PL}}=1037$ ns, 4200 ns compared to the micellar solution MS7:CTAB.

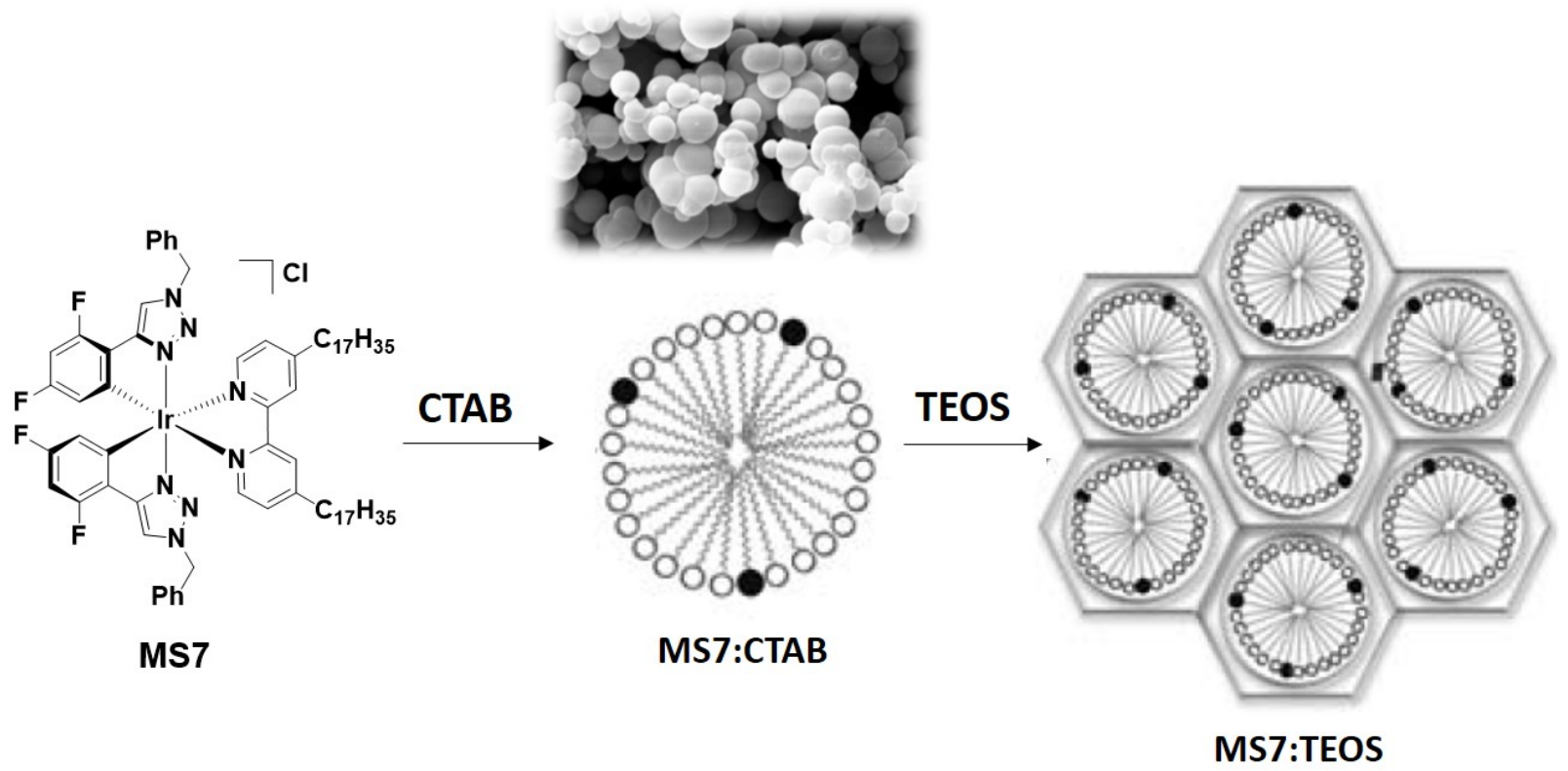

Figure 18. Chemical structure of MS7 and representation of the micellar system MS7:CTAB and the silica material MS7:TEOS. Inset is a SEM micrograph image of MS7:CTAB (1:1500 ratio). Adapted from Ref. [111] with permission from The Royal Society of Chemistry. 
A different type of micellar system was reported by Mauzeroll, Sleiman and coworkers.[112] Through a ring-opening metathesis polymerization (ROMP), a tri-block polymer, MS6 (Figure 17c) containing an iridium complex with a core structure of composition of $\left[\operatorname{Ir}(\mathrm{ppy})_{2}(\mathrm{bpy})\right]^{+}$as the luminescent unit, oligoethylene glycol, and biotin as biorecognition unit for binding streptavidin (Figure 17c) was prepared. As the $\operatorname{Ir}(\mathrm{III})$ blocks are hydrophobic and the PEG-based block is water soluble, the self-assembly of the polymer into a micellar system was possible upon addition of water to an acetonitrile solution of the polymer. Atomic force microscopy (AFM) evidenced the formation of nanoparticles with an average diameter of $20-50 \mathrm{~nm}$, where the iridium complexes were located in the core of the micelles, while the biotin recognition units were situated at the surface. As observed for MS1-MS5, the emission of the iridium complex in MS6 was blue-shifted at $\lambda_{\mathrm{PL}}=562 \mathrm{~nm}$ with slightly higher $\Phi_{\mathrm{PL}}$ of $34 \%$ compared to its monomeric emission in $\mathrm{MeCN}\left(\lambda_{\mathrm{PL}}=579 \mathrm{~nm}, \Phi_{\mathrm{PL}}=28 \%\right)$. Copolymer MS6 was used for bio-detection[113] and for electrogenerated chemiluminescence.[112]

Two examples of supramolecular polymers incorporating $\operatorname{Ir}(\mathrm{III})$ core structures $\left[\operatorname{Ir}\left(\mathrm{C}^{\wedge} \mathrm{N}\right)_{2}(\right.$ pic $\left.)\right][114]$ and $\left[\operatorname{Ir}\left(\mathrm{dFC}^{\wedge} \mathrm{N}\right)_{2}(\right.$ pic $\left.)\right][115]$ (pic is a picolinate ligand, and $\mathrm{C}^{\wedge} \mathrm{N}$ and $\mathrm{dFC}^{\wedge} \mathrm{N}$ are 2-phenylpyridinato- and 2-(2,4-difluorophenyl)pyridinato- derived cyclometalating ligands) used in OLEDs were reported by Huang, Zhu and co-workers. These systems take advantage of the efficient non-bonding assembly between both the bis(dibenzo-24-crown-8)functionalized Ir(III) complexes-based monomers with the bis(dibenzylammonium)-tethered co-monomer. The formation of the polymeric assemblies was evidenced by ${ }^{1} \mathrm{H}$ NMR spectroscopy and viscosity measurements. Atomic Force Microscopy (AFM) measurements revealed that the assemblies exhibited a high tendency to form homogeneous and good film morphologies. The supramolecular polymer incorporating the complex $\left[\operatorname{Ir}\left(\mathrm{C}^{\wedge} \mathrm{N}\right)_{2}(\mathrm{pic})\right]$ 
exhibited in neat film a structured emission at $\lambda_{\mathrm{PL}}=416,562,604 \mathrm{~nm}$ with a $\Phi_{\mathrm{PL}}$ of $17 \%$. OLEDs fabricated with this polymer showed a turn-on voltage of $6.6 \mathrm{~V}$, a luminous efficiency of $14.6 \mathrm{~cd} \cdot \mathrm{A}^{-1}$ at a luminance of $450 \mathrm{~cd} \cdot \mathrm{m}^{-2}$ and an $\mathrm{EQE}_{\max }$ of $6.9 \%$. The polymer incorporating the complex $\left[\operatorname{Ir}\left(\mathrm{dFC}^{\wedge} \mathrm{N}\right)_{2}(\right.$ pic $\left.)\right]$ exhibited in neat film sky-blue structured phosphorescence with $\lambda_{\mathrm{PL}}=476,497 \mathrm{~nm}$ and a high $\Phi_{\mathrm{PL}}$ of $78 \%$. OLEDs fabricated with this polymer showed a turn-on voltage of $5.6 \mathrm{~V}$, luminous efficiency of $6.89 \mathrm{~cd} \cdot \mathrm{A}^{-1}$ at a current density of $2.1 \mathrm{~mA} \cdot \mathrm{cm}^{-1}$ and an $\mathrm{EQE}_{\max }$ of $3.96 \%$.

\subsection{Hydrogen bonding- and $\pi$ - $\pi$-directing supramolecular networks}

Hydrogen bonding and aromatic $\pi$ - $\pi$-stacking interactions are particularly powerful building motifs employed in crystal engineering. Relevant examples of hydrogen bondingdirecting supramolecular assembly of iridium(III) chromophore were reported by Talarico, Ghedini and co-workers[116] (Figure 19). The $\operatorname{Ir}(\mathrm{III})$ complexes $\left[\operatorname{Ir}(\mathrm{ppy})_{2}(\mathrm{en})\right] \mathrm{X}(\mathrm{en}=$ ethylenediamine), with $\mathrm{X}^{-}: \mathrm{ClO}_{4}^{-}(\mathbf{H 1}), \mathrm{PF}_{6}^{-}(\mathbf{H} 2), \mathrm{Cl}^{-}(\mathbf{H 3})$ and $\mathrm{BH}_{4}^{-}(\mathbf{H} 4)$, assembled into different supramolecular networks depending on the nature of the counterions and the crystallization conditions. Two different types of crystalline materials classified as "nonchanneled" and "channeled" were obtained. Non-channeled structures primarily involved intermolecular interactions between the $\mathrm{NH}_{2}$ functionalities of the en ligand and the counterions (Figure 19a). These types of frameworks were obtained from complexes H1 and $\mathbf{H} 2$ when crystallized through diffusion of $\mathrm{Et}_{2} \mathrm{O}$ into methanol solutions, and from $\mathbf{H 4}$ when crystallized through diffusion of water into an acetone solution. More interesting from a supramolecular point of view are the 3D-channeled networks exhibited by $\mathbf{H} 2$ and H3 when both crystallized through vapor diffusion of water into their methanol or acetone solutions, respectively. These 3D-networks assembled by multiple $\mathrm{N}-\mathrm{H} \cdots \mathrm{F}$ intermolecular 
interactions, that formed two types of hexagonal channels along the crystallographic $c$ axis (Figure 19b): (i) empty hydrophilic channels where $\mathrm{PF}_{6}^{-}$or $\mathrm{Cl}^{-}$ions and en ligands were projected inwards and (ii) hydrophobic channels, defined by the ppy ligand, accommodating templating solvent molecules. The complexes H1-H4 exhibited identical photophysical properties in deoxygenated acetone solution $\left(\lambda_{\mathrm{PL}}=502 \mathrm{~nm}, \Phi_{\mathrm{PL}}=68 \%, \tau_{\mathrm{PL}}\right.$ $=1.6 \mu \mathrm{s})$. In the crystalline state, on the other hand, their photophysical properties strongly depended upon their supramolecular organizations. Compared to the acetone emissions, non-channeled networks exhibited red-shifted emissions between $517 \mathrm{~nm}$ and $520 \mathrm{~nm}$ with lower $\Phi_{\mathrm{PL}}$ of proximately $20 \%$. Channeled networks also exhibited red-shifted emissions between $518 \mathrm{~nm}$ and $526 \mathrm{~nm}$, but the emissions of these crystals were weak with $\Phi_{\mathrm{PL}}$ ranging between 1 and 4\%. The high degrees of inter-chromic interactions in the crystal networks accounted for the red-shifted emissions and the low $\Phi_{\mathrm{PL}}$ observed for H1-H4 in their crystalline states. 


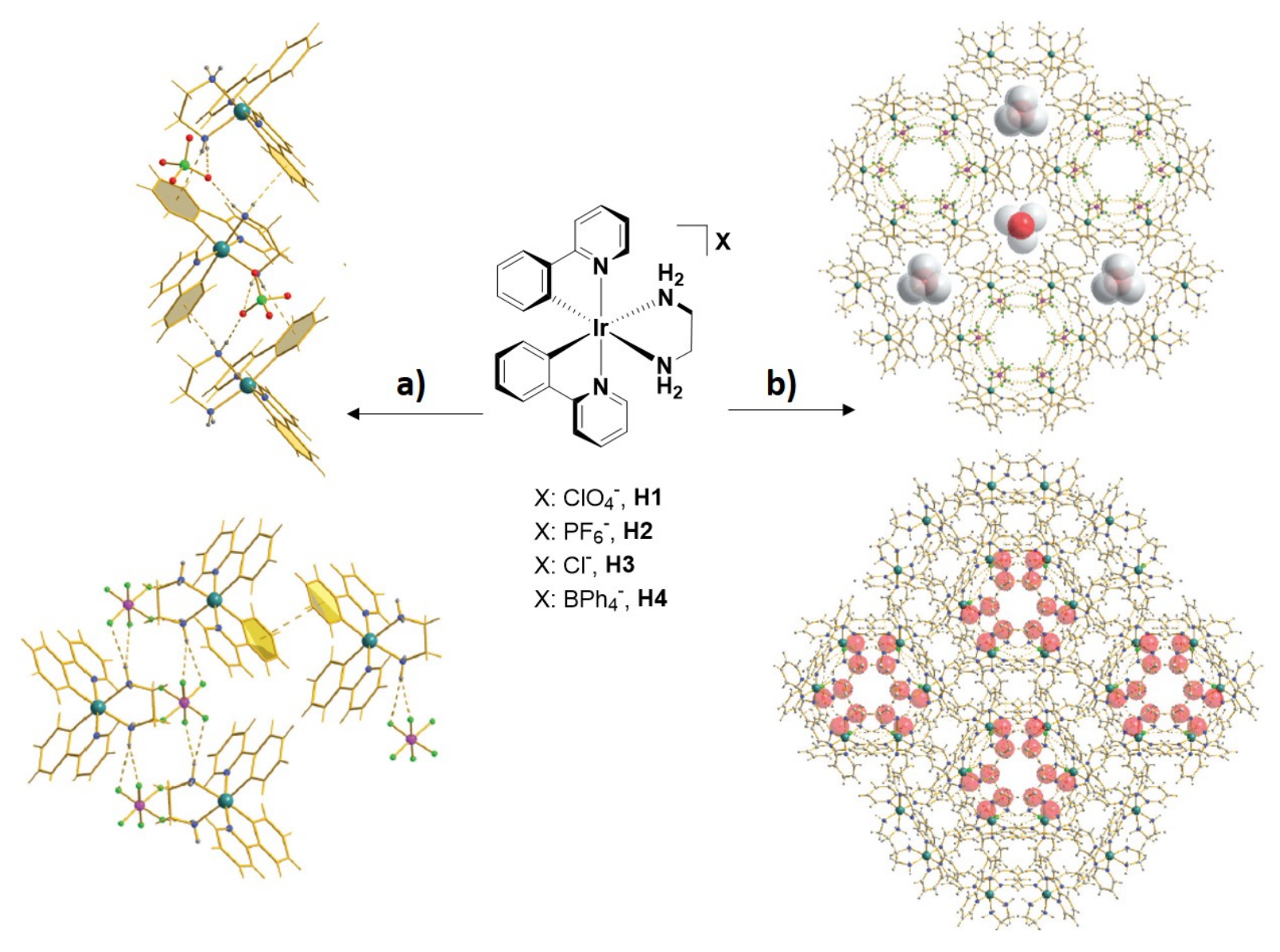

Figure 19. Chemical structure of the Iridium complexes H1-H4; a) illustration of the 1D motif in $\mathbf{H 1}$ along the c crystallographic axis (top) and $\mathbf{H 2}$ along the $a$ crystallographic axis (bottom). b) illustration of the crystal packing of $\mathbf{H 2}$ (top) and $\mathbf{H 3}$ (bottom) showing the channeled networks along the c crystallographic axis. van der Walls radii (red and white balls) for the crystallization solvent molecules are showed. Adapted from Ref. [116] with permission from The Royal Society of Chemistry.

Our group reported two iridium complexes of the composition of $\left[\operatorname{Ir}(\mathrm{dfphtl})_{2}(\mathrm{btl})\right] \mathrm{PF}_{6}(\mathbf{H 5})$ and $\left[\operatorname{Ir}(\mathrm{dfphtl})_{2}(\mathrm{btl})\right] \mathrm{Cl}$ (H6) (dfphtl is 1-benzyl-4-(2,4-difluorophenylato)-1H-1,2,3-triazole and btl is 1,1'-dibenzyl-4,4'-bi-1H-1,2,3-triazolyl) that exhibit the formation of 1D-networks dictated by the hydrogen bonding motifs involving the triazole units (Figure 20).[117, 118] Both $\mathbf{H 5}$ and $\mathbf{H 6}$ crystallized in the triclinic space group P $\overline{1}$ and exhibited similar H-bonding 
motifs. The btl ligands formed C-H hydrogen bonds to the anions $\mathrm{PF}_{6}^{-}$in $\mathrm{H5}$ and $\mathrm{Cl}^{-}$in $\mathbf{H 6}$ and a molecule of water, while the dfphtl triazole $\mathrm{C}-\mathrm{H}$ groups acted as $\mathrm{C}-\mathrm{H}$ hydrogen bond donors, forming $\mathrm{C}-\mathrm{N} \cdots \mathrm{N}$ bonds to one of the nitrogen atom of the btl ligand (Figure 20b). Complexes H5 and H6 were not photostable at room temperature neither in solution nor in the solid state.[117, 119] However, at $77 \mathrm{~K}$ in 2-MeTHF glass state $\mathbf{H 6}$ exhibited a weak emission at $\lambda_{\mathrm{PL}}$ $=393,419 \mathrm{~nm}$.

a)

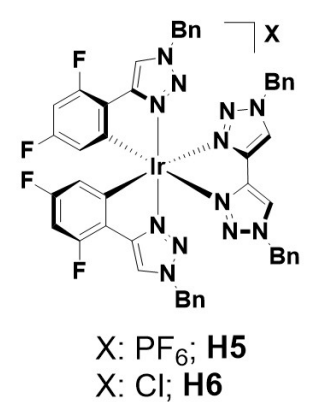

b)

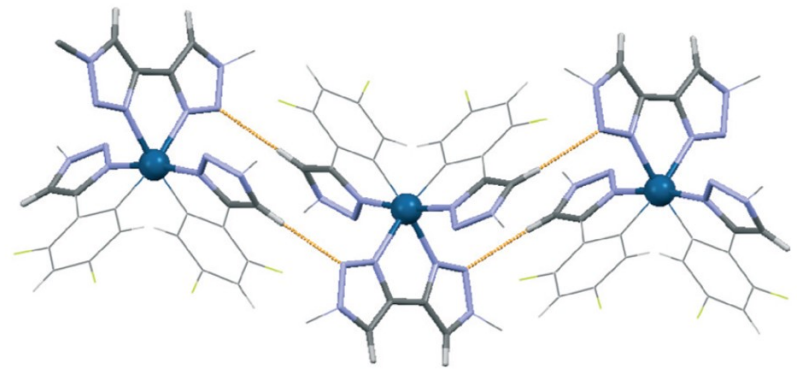

Figure 20. a) Chemical structures of complexes $\mathbf{H 5}$ and $\mathbf{H 6}$ and b) view of the X-ray structure of $\mathbf{H 5}$ showing the $\mathrm{C}-\mathrm{N} \cdots \mathrm{N}$ hydrogen bonds propagating parallel to the $c$ crystallographic axis. Image b) is adapted from Ref. [118] with permission from The Royal Society of Chemistry.

Holdt and co-workers have shown that homoleptic octahedral $\mathrm{Ni}(\mathrm{II})$ and $\mathrm{Fe}(\mathrm{III})$ complexes bearing the 1,12-diazaperylene (dap) ligand and $\mathrm{PF}_{6}^{-}$or $\mathrm{BF}_{4}^{-}$as the counterion in $\left[\mathrm{M}(\mathrm{dap})_{3}\right]^{2+}$ are able to form supramolecular assemblies in their crystalline state with honeycomb structures via $\pi-\pi$ stacking interaction.[120] Homoleptic tetrahedral $\mathrm{Cu}(\mathrm{I})$ complexes of 2,11-alkylated dap ligand are similarly able to form supramolecular columnar assemblies through $\pi$ $\pi$ interactions.[121] The work has been subsequently extended to investigate the self-assembly in the solid state of heteroleptic diazaperylene $\operatorname{Ir}(\mathrm{III})$ complexes $\left[\operatorname{Ir}\left(\mathrm{C}^{\wedge} \mathrm{N}\right)_{2}(\mathrm{dap})\right] \mathrm{PF}_{6}$ (where $\mathrm{C}^{\wedge} \mathrm{N}$ are isophenylisoquinoline, benzoquinoline, 1-phenylpyrazole and 2-(thiophen-2-yl)pyridine).[122] Among this family of complexes, $\left[\operatorname{Ir}(\mathrm{piq})_{2}(\mathrm{dap})\right] \mathrm{PF}_{6}$ (where piq is 
isophenylisoquinoline, H7) gave a three-dimensional assembly in the crystalline state (Figure 21a). Complex $\mathbf{H 7}$ indeed exhibited $\pi$ - $\pi$-stacking interactions involving both the dap and piq ligands, leading to the formation of rectangles consisting of four cationic complexes, assembled together through both $\pi-\pi$ and $\mathrm{CH}-\pi$ interactions (Figure 21b). This particular crystal packing gave rise channels of $6.4 \AA$ in height and $3.3 \AA$ in width along the crystallographic $c$ axis (Figure 21c). Complex $\mathbf{H 7}$ however was non emissive both in solution and in the crystalline state.

a)

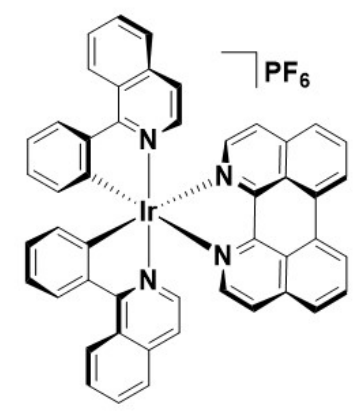

$\mathrm{H} 7$ b)

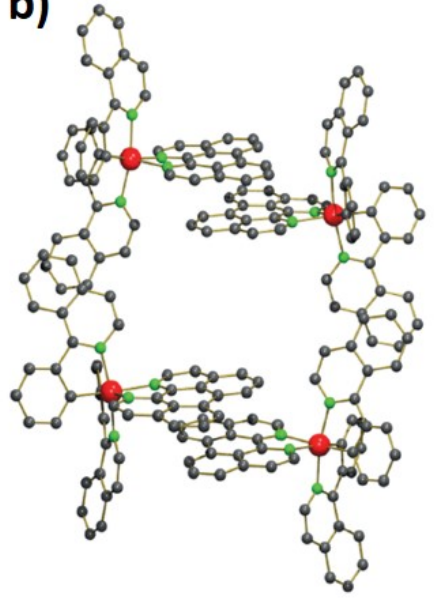

c)

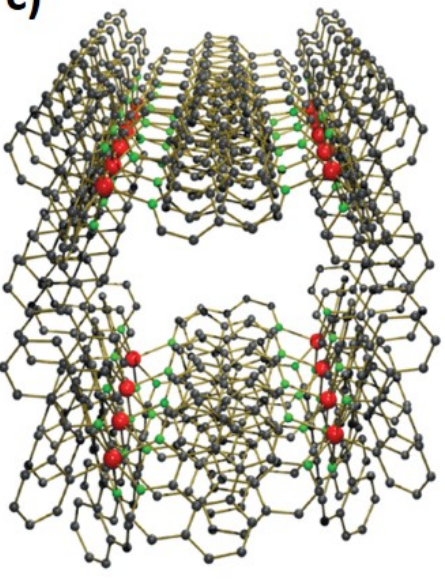

Figure 21. a) chemical structure of $\mathbf{H 7}$; b) illustration of the molecular rectangle exhibited by the $\mathrm{x}$-ray structure of $\mathbf{H 7}$ by $\pi-\pi$ stacking aggregation; c) illustration of the channels exhibited by the x-ray structure of $\mathbf{H 7}$. Hydrogen and counterions are omitted for clarity. Images b) and c) are adapted from Ref. [122] with permission from The Royal Society of Chemistry.

\section{Coordination-driven self-assembly}

Coordination-driven self-assembly, which is based on the formation of metal-ligand bonds, has proven to be a powerful method to prepare supramolecular well-defined nanostructures of varying shapes, sizes and functional properties, featuring considerable synthetic advantages 
such as facile and rapid construction of the final products and high yields.[123-125] In this section, we highlight the use of Ir(III) complexes as luminescent scaffolds in coordinationdriven self-assembly by describing the recent examples of luminescent coordination polymers, metal-organic frameworks (MOFs), discrete structures, capsules and cages.

\subsection{Coordination polymers, metal-organic frameworks and discrete structures}

Coordination polymers (CPs) and metal-organic frameworks (MOFs) are highly crystalline and porous materials constructed from metal ions or clusters usually bound to carboxylate or nitrogen capped organic linkers to form extended one-dimensional (1D), two-dimensional (2D) and three-dimensional (3D) networks.[17, 27, 126, 127] Because of the high surface area and structural tunability, $\operatorname{Ir}(\mathrm{III})$-based CPs and MOFs have been primarily used as functional materials for gas storage and purification, sensing and catalysis.

Lin and co-workers[128] reported the first examples of the incorporation of two $\operatorname{Ir}(\mathrm{III})$ complexes of the form of $f a c$-[ $\left.\operatorname{Ir}(\text { ppy-c) })_{3}\right]$ (ppy-c is 3-(pyridin-2-yl)benzoic acid in L1 and 4(pyridin-2-yl)benzoic acid in L2, Figure 22), into Zn-based coordination polymers. Reaction of $\mathrm{Zn}\left(\mathrm{NO}_{3}\right) \cdot 6 \mathrm{H}_{2} \mathrm{O}$ with $\mathbf{~} \mathbf{1}$ and $\mathbf{~} \mathbf{2}$ in $\mathrm{DMF} / \mathrm{H}_{2} \mathrm{O}$ at $90{ }^{\circ} \mathrm{C}$ for $24 \mathrm{~h}$ afforded, respectively, single

crystals of $\quad\left[\mathrm{Zn}_{4}\left(\mu_{4}-\mathrm{O}\right)(\mathbf{L 1})_{2}\right] \cdot 6 \mathrm{DMF} \cdot \mathrm{H}_{2} \mathrm{O}, \quad \mathbf{P 1} \quad$ (Figure 22a) and $\left[\mathrm{Zn}_{3}(\mathbf{L 2})_{2}(\mathrm{DMF})\left(\mathrm{H}_{2} \mathrm{O}\right)_{3}\right] \cdot 2 \mathrm{DMF} \cdot 3 \mathrm{H}_{2} \mathrm{O}, \mathbf{P 2}$ (Figure 22b). 


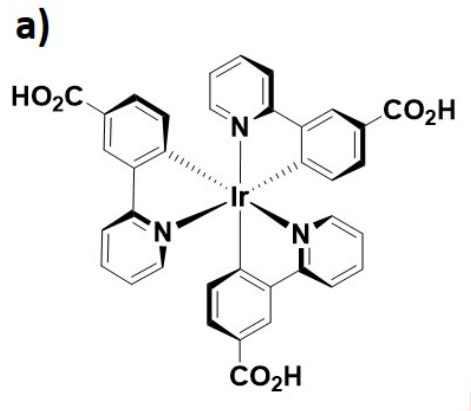

L1

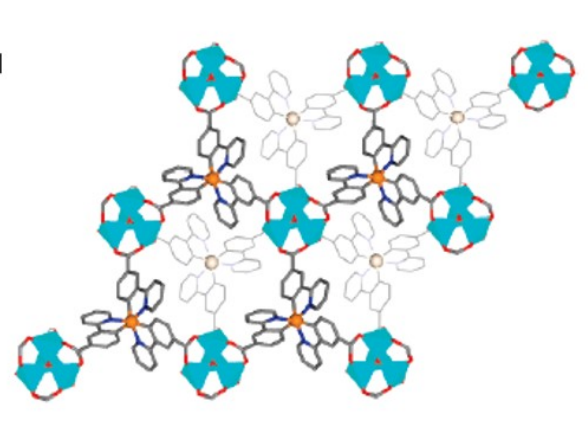

b)

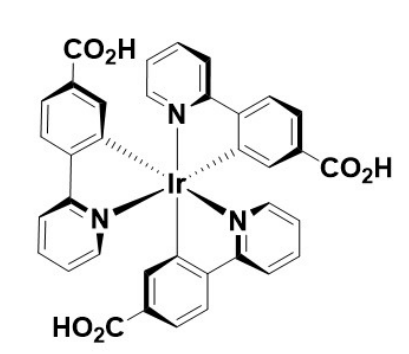

L2

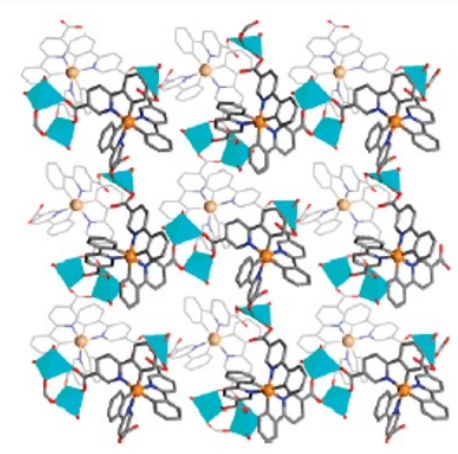

Figure 22. From left to right: a) chemical structure of metalloligand L1; a top view of the 2D bilayer of the X-ray structure of $\mathbf{P 1}$ and space-filling model of the x-ray structure of $\mathbf{P 1}$. b) chemical structure of metalloligand L2; a top view of the 2D bilayer of the x-ray structure of $\mathbf{P 2}$ and space-filling model of the x-ray structure of P2. Adapted with permission from Ref. [128]. Copyright 2010, American Chemical Society.

$\mathbf{P 1}$ crystallized in a trigonal $\mathrm{R} \overline{3}$ space group where the carboxylate groups from six adjacent L1 ligands coordinate to four $\mathrm{Zn}$ centers to form 2D-bilayers $\left[\mathrm{Zn}_{4}\left(\mu_{4}-\mathrm{O}\right)(\mathbf{L 1})_{2}\right]$. The crystal packing of the 2D layers along the crystallographic $c$ axis created open channels of dimensions of $7.9 \AA ̊ 4.3 \AA$ (Figure $22 \mathbf{a}$ ). By contrast, $\mathbf{P} 2$ crystallized in the triclinic $\mathrm{P} \overline{1}$ space group where both the carboxylate groups coordinate to the $\mathrm{Zn}$ to generate both mononuclear and dinuclear complexes where in the latter case three carboxylate groups bridge the two $\mathrm{Zn}$ centers, forming 2D-bilayers that packed along the $a$-axis. The largest channels of $\mathbf{P 2}$ were of $4 \AA \times 3 \AA$ run along the $b$-axis (Figure 22b). $\mathbf{P 1}$ exhibited high $\mathrm{N}_{2}$ uptake at $77 \mathrm{~K}$ and $\mathrm{CO}_{2}$ uptake at $273 \mathrm{~K}$. 
However, due to its smaller porosity no $\mathrm{N}_{2}$ or $\mathrm{CO}_{2}$ uptake was observed for $\mathbf{P 2}$. The solid-state emission of $\mathbf{P 1}$ was red-shifted at $\lambda_{\mathrm{PL}}=540 \mathrm{~nm}$ compared to that of $\mathbf{L 1}\left(\lambda_{\mathrm{PL}}=520 \mathrm{~nm}\right)$, while the emission of $\mathbf{P 2}$ was blue-shifted at $\lambda_{\mathrm{PL}}=550 \mathrm{~nm}$ compared to that of $\mathbf{L} \mathbf{2}\left(\lambda_{\mathrm{PL}}=575 \mathrm{~nm}\right)$ (Table 1). Both P1 and P2 were sensitive to $\mathrm{O}_{2}$ via the expected efficient and reversible luminescence quenching of the $\operatorname{Ir}(\mathrm{III})$ phosphors. When polymers $\mathbf{P 1}$ and $\mathbf{P 2}$ and metalloligands $\mathbf{L} \mathbf{1}$ and $\mathbf{L} \mathbf{2}$ were subjected to a gradual increase in $\mathrm{O}_{2}$ partial pressure (from 0.05 to $1.0 \mathrm{~atm}$ ), their luminescence intensity gradually decreased and, after addition of $1.0 \mathrm{~atm}$ of $\mathrm{O}_{2}$, the quenching efficiencies of P1, P2, L1 and L2 were, respectively, 59\% and 41\%, $16 \%$ and $8 \%$. As oxygen can be trapped within the pores of $\mathbf{P 1}$ and $\mathbf{P 2}$ and thus in persistent close contact with the Ir(III) luminophores, the emission quenching efficiencies of $\mathbf{P 1}$ and $\mathbf{P 2}$ were correspondingly higher than those of $\mathbf{L 1}$ and $\mathbf{L 2}$.

Four $\quad \mathrm{Ir}(\mathrm{III}) \quad$ coordination polymers $\quad\left[\mathrm{Zn}(\mathbf{L 3})_{2}\right] \cdot 3 \mathrm{DMF} \cdot 5 \mathrm{H}_{2} \mathrm{O} \quad(\mathbf{P 3 a})$, $\left[\mathrm{Cd}(\mathbf{L 3})_{2}\left(\mathrm{H}_{2} \mathrm{O}\right)_{2}\right] \cdot 3 \mathrm{DMF} \cdot 6 \mathrm{H}_{2} \mathrm{O} \quad(\mathbf{P 3 b}), \quad\left[\mathrm{Co}(\mathbf{L 3})_{2}\left(\mathrm{H}_{2} \mathrm{O}\right)_{2}\right] \cdot 2 \mathrm{DMF} \cdot 8 \mathrm{H}_{2} \mathrm{O} \quad(\mathbf{P 3 c}) \quad$ and $\left[\mathrm{Ni}(\mathbf{L 3})_{2}\left(\mathrm{H}_{2} \mathrm{O}\right)_{2}\right] \cdot 3 \mathrm{DMF} \cdot 6 \mathrm{H}_{2} \mathrm{O}(\mathbf{P 3 d})$ were formed by using $\left[\operatorname{Ir}(\mathrm{ppy})_{2}\left(\mathrm{H}_{2} \mathrm{dcbpy}\right)\right] \mathrm{PF}_{6}\left(\mathrm{H}_{2} \mathrm{dcbpy}\right.$ is 4,4'-dicarboxy-2,2'-bipyridine) as the bridging metalloligand (L3, Figure 23a) and $\mathrm{Zn}^{2+}$, $\mathrm{Cd}^{2+}, \mathrm{Co}^{2+}$ and $\mathrm{Ni}^{2+}$ as metal ions.[129] P3a exhibited an orthorhombic geometry (Pna2 1 space group) that consisted of $\mathbf{L} \mathbf{3}$ ligand coordinated to the $\mathrm{Zn}$ centre through the carboxylate groups in a 1:2 ratio, with DMF and water molecules trapped in the cavities of the extended structure in the solid state. This particular packing generated channels of rectangular shape (Figure $\mathbf{2 3 b}$ ). Similarly, polymers P3b, P3c, P3d, gave rise to 1D-chains with metal(II) ions in distorted orthorhombic geometries (Pnma space group) where $\mathrm{Cd}(\mathrm{II}), \mathrm{Co}(\mathrm{II})$ and $\mathrm{Ni}(\mathrm{II})$ were each, respectively, bound to six oxygen atoms, four of which were from four carboxylate groups of $\mathbf{L 3}$ and two of which were from water molecules (Figure 23b). P3a, P3b, P3c, P3d each 
exhibited CT emission from single crystals at $\lambda_{\mathrm{PL}}=613 \mathrm{~nm}, \lambda_{\mathrm{PL}}=595 \mathrm{~nm}, \lambda_{\mathrm{PL}}=587 \mathrm{~nm}$ and $\lambda_{\mathrm{PL}}=600 \mathrm{~nm}$, respectively with $\Phi_{\mathrm{PL}}$ values of $27.4 \%, 19.3 \%, 0.1 \%$ and $0.2 \%$, respectively $\left(\lambda_{\mathrm{PL}}\right.$ $=613 \mathrm{~nm}$ and $\Phi_{\mathrm{PL}}$ of $17.8 \%$ for $\mathbf{L 3}$ in the solid state, Table 1). As reported for P1 and P2, polymers P3a, P3b, P3c, P3d also exhibited reversible oxygen-sensing properties. Indeed, at 1 atm of $\mathrm{O}_{2}$ the emission quenching efficiencies from their single crystals were, respectively, 46\%, 74\%, 57\% and 52\%. The emission spectra and photos in Figure 23c show the emission quenching of P3b upon gradual addition of oxygen.

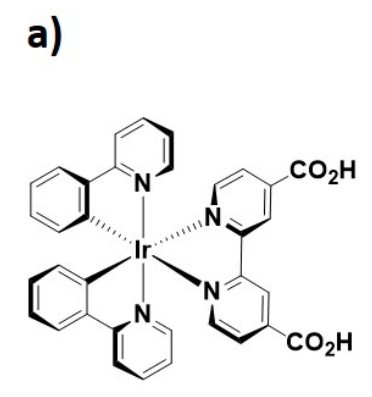

L3 b)

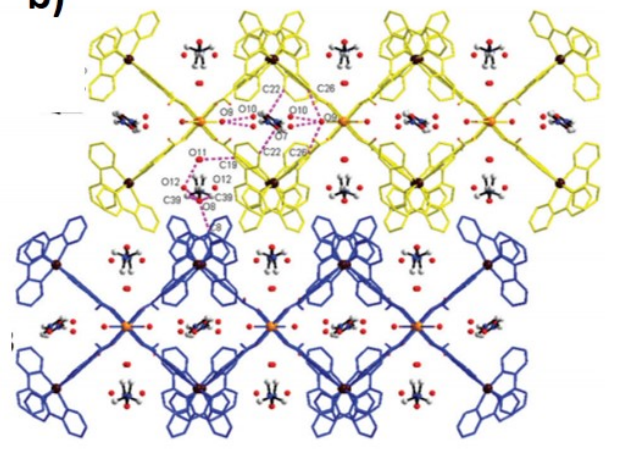

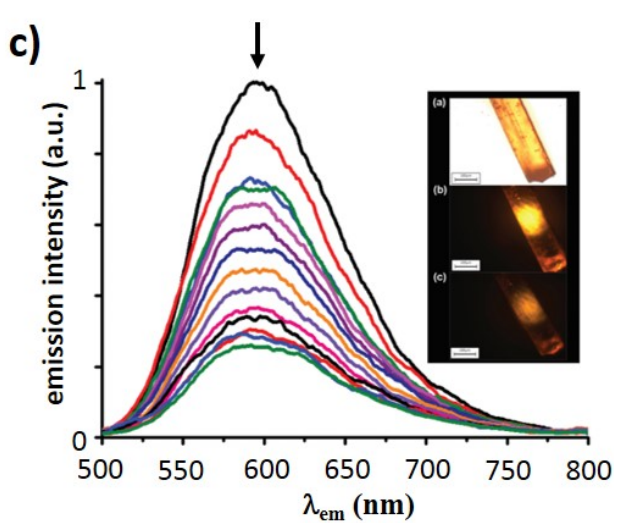

Figure 23. a) Chemical structure of $\mathbf{L 3}$; b) illustration of two layers (in yellow and blue) of the 3D cadmium-bridged structure of $\mathbf{P 3 b}$ with open channels. c) Emission quenching of P3b upon addition of an increased amount of $\mathrm{O}_{2}$. Insets are images of the emissions from the crystal P3b, with $100 \% \mathrm{~N}_{2}$, and with $100 \% \mathrm{O}_{2}$. Images b) and c) are adapted from Ref. [129] with permission from The Royal Society of Chemistry.

In a subsequent report, the same group developed an electrochemical method to produce the $\operatorname{Ir}(\mathrm{III})-\mathrm{Zn}(\mathrm{II})$ coordination polymer $\left[\mathrm{Zn}(\mathbf{L 3})_{2}\right] \cdot 3 \mathrm{DMF} \cdot 5 \mathrm{H}_{2} \mathrm{O}(\mathbf{P 3 a})$ with greater control over the crystal growing process. With this improved synthetic method, polymer P3a exhibited higher crystal stability and enhanced oxygen sensing performance.[130] Indeed, when electrochemically produced, P3a exhibited a high selectivity towards the absorption of $\mathrm{O}_{2}$ with an emission quenching efficiency as high as $95 \%$. Once oxygen was trapped within the pores 
of P3a, the gradual addition of glucose to the crystals of P3a restored its emission at $\lambda_{\mathrm{PL}}=596$ $\mathrm{nm}$ upon excitation at $405 \mathrm{~nm}$. As the consumption of oxygen due to the combustion reaction between glucose and $\mathrm{O}_{2}$ was linearly correlated to the reduction of the emission quenching of P3a, quantitative detection of glucose within the concentration range of $0.05-6.0 \mathrm{mM}$ was also possible.

Three luminescent coordination polymers were synthetized by assembling metalloligand $\mathbf{L 3}$ with $\mathrm{Mg}$ (II) ions, respectively, in $\mathrm{H}_{2} \mathrm{O}, \mathrm{DMF}$ and $\mathrm{DEF}$ (DEF is $\mathrm{N}, \mathrm{N}$-diethylformamide) to form $\left[\mathrm{Mg}(\mathbf{L 3})_{2}\right] \cdot 3.5 \mathrm{H}_{2} \mathrm{O} \quad(\mathbf{P 3 e}), \quad\left[\mathrm{Mg}(\mathbf{L 3})_{2}(\mathrm{DMF})_{2}\right] \cdot 3.5 \mathrm{H}_{2} \mathrm{O} \quad(\mathbf{P 3 f}) \quad$ and $\left[\mathrm{Mg}(\mathbf{L 3})_{2}(\mathrm{DEF})\left(\mathrm{H}_{2} \mathrm{O}\right)\right] \cdot 3 \mathrm{H}_{2} \mathrm{O}(\mathbf{P 3 g}) \cdot[131]$ Single crystal x-ray diffraction analyses revealed that the three coordination polymers were allomeric and formed similar 1D chain structures in which the Mg atoms coordinated in an octahedral geometry to four carboxylate oxygen atoms from four $\mathbf{L 3}$ ligands and two oxygen atoms from solvent molecules (Figure 24). Polymers P3e, P3f and P3g all exhibited in the solid state broad emission centered at $\lambda_{\mathrm{PL}}=544 \mathrm{~nm}, \lambda_{\mathrm{PL}}$ $=554 \mathrm{~nm}$ and $\lambda_{\mathrm{PL}}=570 \mathrm{~nm}$, respectively, with $\Phi_{\mathrm{PL}}$ of $14.6 \%, 18.1 \%$ and $2.4 \%$ and $\tau_{\mathrm{PL}}$ of 7.7 $\mu \mathrm{s}, 13.3 \mu \mathrm{s}$ and $7.7 \mu \mathrm{s}$, respectively (Table 1). Therefore, the different electron-donating abilities of the solvents, which increases in the order $\mathrm{H}_{2} \mathrm{O}<\mathrm{DMF}<\mathrm{DEF}$, exerted a strong influence on the emission energies of the polymers. 
a)

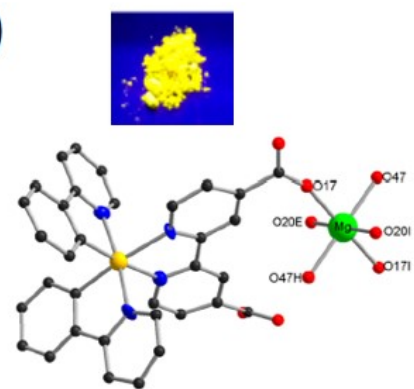

P3e

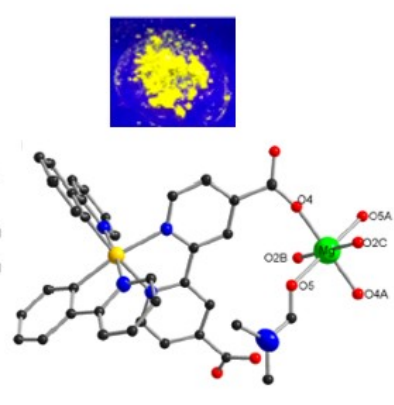

P3f

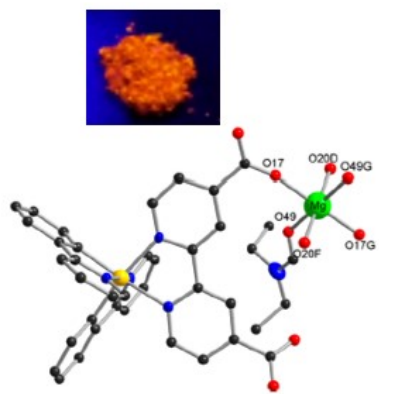

P3g

b)

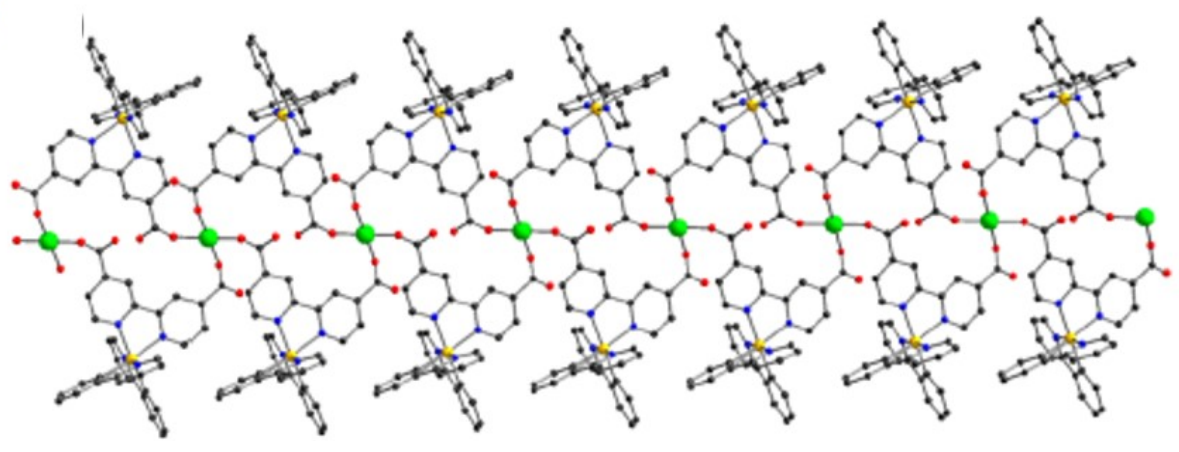

Figure 24. a) view of the coordination environments of the $\mathrm{Mg}(\mathrm{II})$ ions in P3e, P3f and P3g. Insets are images of the powder emissions upon UV irradiation. b) View of the 1D chains exhibited by the coordination polymers. Adapted with permission from Ref. [131]. Copyright 2016, American Chemical Society.

Metalloligand $\mathbf{L 3}$ was also used in heteronuclear $\operatorname{Ir}(\mathrm{III})-\mathrm{Ln}(\mathrm{III})$ coordination polymers as a light-harvesting antenna to sensitize $\mathrm{Ln}(\mathrm{III})$-based near-infrared (NIR) luminescence from $\mathrm{Gd}^{3+}, \mathrm{Yb}^{3+}, \mathrm{Er}^{3+}$ and $\mathrm{Nd}^{3+}$ ions.[132] The polymers Ir-Gd, Ir-Yb, Ir-Er and Ir-Nd are all isostructural and each crystallized in a triclinic $\mathrm{P} \overline{1}$ space group where one $\operatorname{Ln}(\mathrm{III})$ center is seven-coordinate by five carboxylate oxygen atoms from five $\mathbf{L 3}$ ligands and two hydroxylic groups from $\mathrm{NaOH}$ added to prepare to polymers, generating a pentagonal bipyramid coordination geometry. In the reference $\mathbf{I r - G d}$ polymer, as the $\mathrm{Gd}^{3+}$ ions cannot accept energy from the Ir excited state because of the absence of energy levels below $3200 \mathrm{~cm}^{-1}$, the solidstate emission of Ir-Gd showed the characteristic ${ }^{3} \mathrm{MLCT} /{ }^{3} \mathrm{LLCT}$ emission of the $\operatorname{Ir}(\mathrm{III})$ 
luminophore at $\lambda_{\mathrm{PL}}=610 \mathrm{~nm}$ with a $\tau_{\mathrm{PL}}$ of $8.1 \mu \mathrm{s}\left(\mathbf{L 3}\right.$ emits in the solid state at $\lambda_{\mathrm{PL}}=592 \mathrm{~nm}$ with a $\tau_{\mathrm{PL}}$ of $\left.7.8 \mu \mathrm{s}\right)$. For the other three luminescent polymers $\operatorname{Ir}-\mathbf{L n}(\mathrm{Ln}: \mathrm{Yb}, \mathrm{Er}, \mathrm{Nb})$, the Irbased emission centred at $610 \mathrm{~nm}$ was largely quenched, indicating that Dexter $\mathrm{d} \rightarrow \mathrm{f}$ energy transfer from the $\mathrm{Ir}(\mathrm{III})$ units to the $\mathrm{Ln}^{3+}$ ions was efficiently promoted. The fastest energy transfer rate was observed for the Ir-Nd polymer, with a calculated quenching rate constant $\left(k_{q}\right)$ of $6.8 \times 10^{6} \mathrm{~s}^{-1}$, while for Ir-Yb and Ir-Er, $k_{\mathrm{q}}$ of $5.0 \times 10^{5} \mathrm{~s}^{-1}$ and $6.0 \times 10^{6} \mathrm{~s}^{-1}$ were, respectively, obtained.

A related example of a $\operatorname{Ir}(\mathrm{III})-\mathrm{Ln}(\mathrm{III})$ discrete structure was reported by Zheng and coworkers[133] by microwave reaction between the iridium complex $\left[\operatorname{Ir}(\mathrm{ppy})_{2}(\mathrm{dppH})\right], \mathbf{L 4}(\mathrm{dppH}$ is 2-pyridyl phosphonic acid) and $\mathrm{Dy}\left(\mathrm{CF}_{3} \mathrm{SO}_{3}\right)_{3}$ in $\mathrm{MeOH}$ at $100{ }^{\circ} \mathrm{C}$. The composition of the resultant structure, $\mathbf{P 4}$, was identified to be $\left.\left[\mathrm{Dy}(\mathbf{L 4})_{6}\right]\left(\mathrm{CF}_{3} \mathrm{SO}_{3}\right)\right] \cdot 8 \mathrm{H}_{2} \mathrm{O}$ by x-ray diffraction (Figure 25). The assembly $\mathbf{P 4}$ exhibited a broad emission in the solid state centred at $\lambda_{\mathrm{PL}}=531$ $\mathrm{nm}$, which is slightly blue-shifted compared to the emission in the solid-state of the iridium complex $\mathbf{L} 4\left(\lambda_{\mathrm{PL}}=538 \mathrm{~nm}\right)$ (Table 1). Given that the emission of the $\operatorname{Ir}(\mathrm{III})$ complex was not quenched, energy transfer from Ir(III) to Dy(III) did not take place. P4 exhibited field-induced slow magnetization relaxation originating from both the $\operatorname{Ir}(\mathrm{III})$ and Dy(III) components.

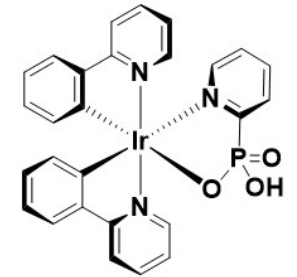

L4

\section{$\operatorname{Dy}\left(\mathrm{CF}_{3} \mathrm{SO}_{3}\right)_{3}$}

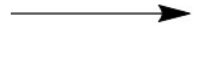

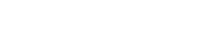

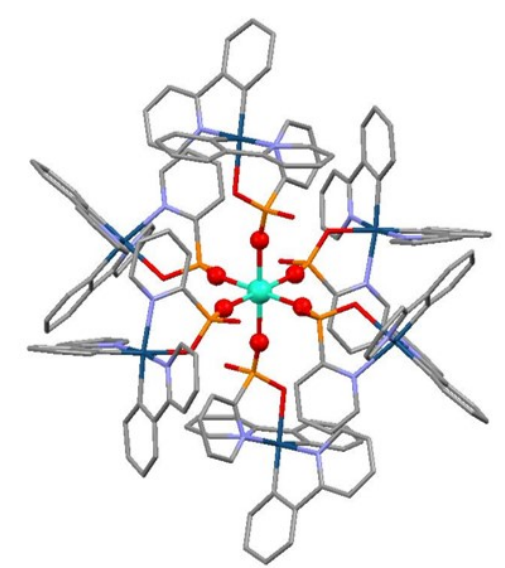

P4 
Figure 25. Chemical structure of complex $\mathbf{L} 4$ and X-ray structure of the $\operatorname{Ir}(\mathrm{III})-\mathrm{Dy}(\mathrm{III})$ assembly P4. The red balls illustrate the octahedral coordination around the Dy ion (in lightblue).

Crystallisation of PPN3a (Figure 2a, PPN is bis(triphenylphosphine) iminium cation) in the presence of excess of the $\mathrm{Ln}$ ions $\mathrm{Gd}, \mathrm{Nd}$, Eu led to the formation of assemblies based on IrCN-Ln bonding, which generated in the solid state either $\operatorname{Ir}_{2} \mathrm{Ln}_{2}(\mu-\mathrm{CN})_{4}$ square assemblies or linear trinuclear species with Ir-CN-Ln-NC-Ir cores.[134] In the Ir-Eu and Ir-Nd assemblies the vibronic emission of PPN3a in the solid state at $\lambda_{\mathrm{PL}}=484,507 \mathrm{~nm}$ was substantially quenched due to energy transfer to the lower-lying f-f states on these Ln ions. By contrast, similar to that observed for the Ir-Gd polymer previously described, [132] in the $\operatorname{Ir}_{2} \operatorname{Gd}_{2}(\mu-C N)_{4}$ complex the Gd cannot accept the energy from the Ir chromophore and therefore no energy transfer was promoted.

A heterogeneous coordination polymer, $\mathbf{P 3} \mathbf{h}$, based on the assembly between metalloligand L3 and $\mathrm{Y}^{3+}$ ions (Figure 26) was used as a catalyst for the photochemical reduction of $\mathrm{CO}_{2}$.[135] Similar to the $\operatorname{Ir}(\mathrm{III})-\mathrm{Ln}(\mathrm{III})$ polymers previously described, $\mathbf{P 3 h}$ crystallizes in a triclinic $\mathrm{P} \overline{1}$ space group where the $\mathrm{Y}$ atom is seven-coordinate with a coordination sphere consisting of five carboxylate oxygen atoms from five $\mathbf{L 3}$ ligands and two hydroxyl groups from $\mathrm{NaOH}$ added to prepare the polymers, generating a pentagonal bipyramid coordination geometry (Figure 26a). The neighboring Y centers are alternatively linked via two hydroxide ions from $\mathrm{NaOH}$ and two carboxylate groups from two $\mathbf{L 3}$ ligands, giving rise to a 1D$\left[\mathrm{Y}(\mathrm{OH})_{2}\left(\mathrm{CO}_{2}\right)_{2}\right]_{\infty}$ chain structure (Figure 26b). Neighboring chain structures pack together through non-bonding Ir $\cdots$ Y interactions, forming the 3D supramolecular frameworks illustrated in Figure 26c. Energy transfer from the Ir to Y centers was not possible due to the mismatching 
of their respective energy levels. Indeed, P3h displayed in the crystal state a strong Ir-based emission centered at $\lambda_{\mathrm{PL}}=592 \mathrm{~nm}$, with a bi-exponential emission decay with the longest component of $\tau_{\mathrm{PL}}=29.0 \mu$ s (Table 1). The emission decay of P3h was found to be almost four times longer than that exhibited by $\mathbf{L 3}\left(\tau_{\mathrm{PL}}=7.8 \mu \mathrm{s}\right)$. P3h exhibited remarkable photocatalytic activity for $\mathrm{CO}_{2}$ reduction under visible-light irradiation $\left(\lambda_{\text {exc }}=475 \mathrm{~nm}\right)$. The quantum yield of $\mathrm{HCOO}^{-}$production was $1.2 \%$ with a high turnover frequency (TF) of $118.8 \mu \mathrm{mol}$ (g of cat. $)^{-1}$ $\mathrm{h}^{-1}$.

a)

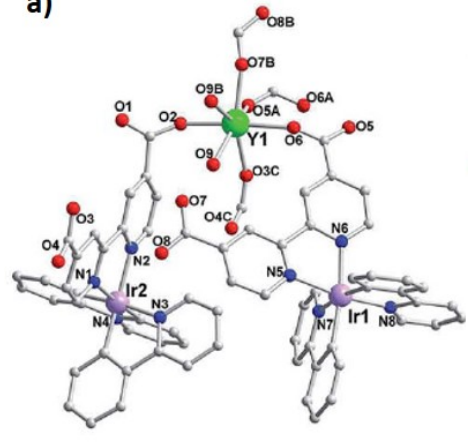

b)

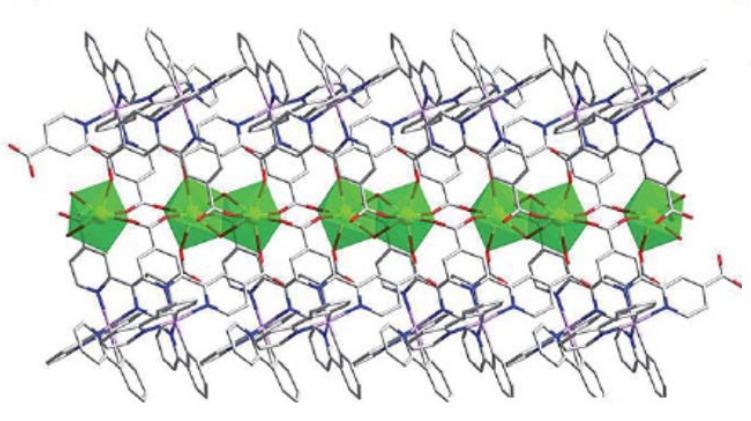

c)

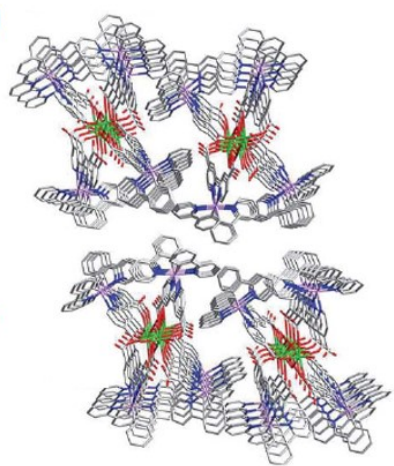

Figure 26. X-ray structure of P3h illustrating: a) pentagonal bipyramid coordination geometry of the Y(III) ions; b) view of 1D-chain structures and $\mathbf{c}$ ) view of 3D networks. Adapted from Ref. [135] with permission from The Royal Society of Chemistry.

The detection of nitroaromatic explosives on ppm scale is evidently of great importance for national security and defence. Luo and co-workers reported a highly luminescent heteronuclear MOF of composition [Zn(L3) $)_{2} \cdot 3 \mathrm{DMF} \cdot 5 \mathrm{H}_{2} \mathrm{O}$ (MOF1).[136] MOF1 crystallized in the noncentrosymmetric space group Pna2 $2_{1}$ where the $\mathrm{Zn}$ centre adopts a tetrahedral geometry coordinated to four carboxylate $\mathrm{O}$ atoms from four $\mathbf{L} \mathbf{3}$ ligands thereby forming a 3D porous network. MOF1 exhibited an Ir-based emission that was red-shifted at $\lambda_{\mathrm{PL}}=602 \mathrm{~nm}$ with an enhanced $\Phi_{\mathrm{PL}}$ of $23.6 \%$ and a longer $\tau_{\mathrm{PL}}$ of $14.3 \mu$ s compared to that observed for $\mathbf{L 3}$ (Table $\mathbf{1}$ ). 
Similar to the behavior of polymers P3a, P3b, P3c and P3e, P3f and P3g, the enhanced emission of MOF1 compared to $\mathbf{L 3}$ is attribute to the enhanced rigidity and symmetry experienced by the Ir(III) luminophores in the coordination frameworks, which reduces nonradiative decay modes. MOF1 exhibited good sensing abilities towards nitroaromatic compounds. Remarkably, when aromatic compounds with high nitro content such as TNT (trinitrotoluene) were diffused into the crystal at a concentration of $625 \mathrm{ppm}$, the emission of MOF1 was quenched by $60 \%-70 \%$ via electron transfer from the $\operatorname{Ir}(\mathrm{III})$ luminophores to the nitroaromatic acceptors.

Lin and co-workers[137] successfully incorporated three iridium-based water-oxidation catalysts, $\left[\operatorname{Ir}\left(\mathrm{Cp}^{*}\right)(\mathrm{dcppy}) \mathrm{Cl}\right](\mathbf{L 5}),\left[\operatorname{Ir}\left(\mathrm{Cp}^{*}\right)(\mathrm{dcbpy}) \mathrm{Cl}\right] \mathrm{Cl}(\mathbf{L 6})$ and $\left[\operatorname{Ir}(\mathrm{dcbpy})_{2}\left(\mathrm{OH}_{2}\right)_{2}\right] \mathrm{OTf}$ (L7) (Figure 27a) (where Cp* is pentamethylcyclopentadienyl, dcppy is 2-phenylpyridine-5,4'dicarboxylic acid, dcbpy is 2,2'-bipyridine-5,5'-dicarboxylic acid and OTf is trifluoromethyl sulfonate) into the octahedral $\mathrm{Zr}_{6} \mathrm{O}_{4}(\mathrm{OH})_{4}(\mathrm{bpdc})_{6}$ framework UiO-67 (bpdc is parabiphenyldicarboxylate), forming, respectively, MOF2, MOF3 and MOF4 (Figure 27a). When these materials were tested as photocatalysts for water oxidation by using cerium ammonium nitrate (CAN) as the oxidant, turnover frequencies (TOFs) of 4.8, 1.9 and $0.4 \mathrm{~h}^{-1}$ for MOF2, MOF3 and MOF4 were, respectively, reported. Higher TOFs of 7.5 and $94.5 \mathrm{~h}^{-1}$ were, however, observed when the $\operatorname{Ir}(\mathrm{III})$ complexes bearing elongated linear bridging ligands $\mathbf{L 8}$ and L9 (Figure 27b) were, respectively, incorporated into the octahedral zirconium frameworks (MOF5 and MOF6).[138] The higher TOFs of MOF5 and MOF6 compared to MOF2-MOF4 were attributed to the extended networks generated with wider channel sizes where the hydrated $\mathrm{Ce}^{4+}$ ions can freely diffuse without steric hindrance, thus promoting overall higher catalytic efficiency. 
a)

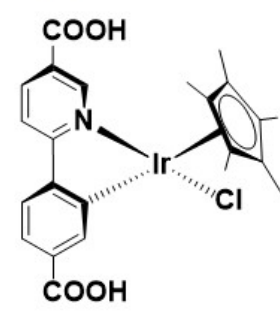

L5

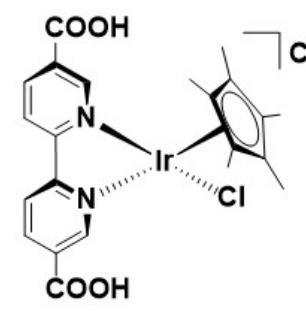

L6

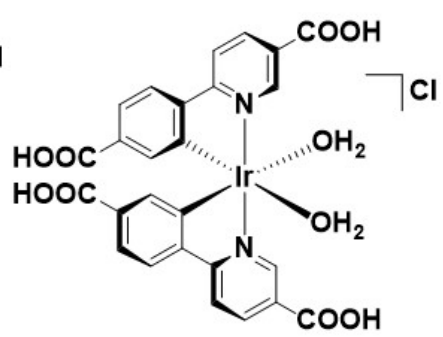

L7

b)

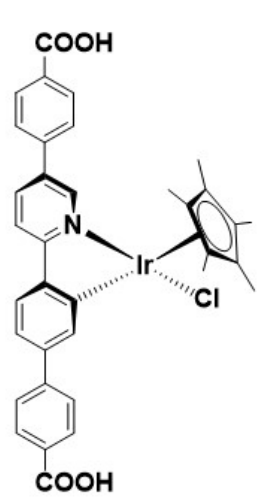

L8

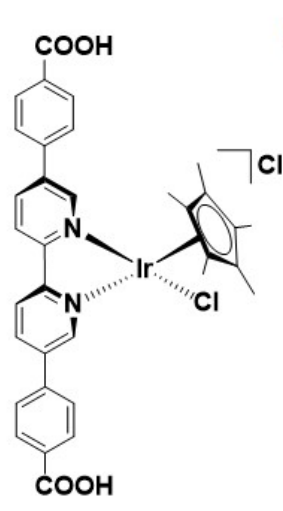

L9

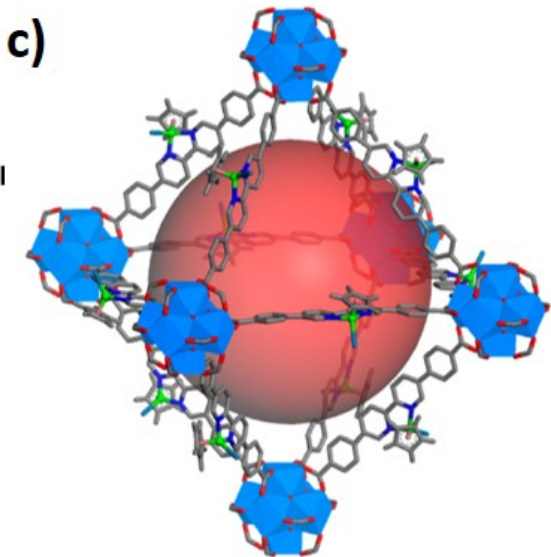

Figure 27. a) Chemical structures of the Ir(III) metalloligands L5, L6 and L7. b) Chemical structures of the extended Ir(III) metalloligands L8 and L9. c) Structure model for MOF6 showing the octahedral cage of $1 \mathrm{~nm}$ in diameter. $\mathrm{Zr}$, blue polyhedron; Ir, green balls; $\mathrm{Cl}$, dark green, $\mathrm{C}$, grey; $\mathrm{N}$, blue. The red ball in the middle represents the cage cavity. Image c) is adapted with permission from Ref. [138]. Copyright 2012, American Chemical Society.

In a subsequent work, Pt nanoparticles of 2-3 $\mathrm{nm}$ and 5-6 $\mathrm{nm}$ in diameter were loaded into MOFs constructed with the metalloligands L10 and L11 (respectively in Figure 28a and 28b) and the $\mathrm{Zr}_{6}\left(\mu_{3} \mathrm{O}\right)_{4}\left(\mu_{3} \mathrm{OH}\right)_{4}(\text { carboxylate })_{12}$ secondary units (Pt-MOF7 and Pt-MOF8, respectively).[139] The resulting Pt-MOF7 and Pt-MOF8 MOFs were used as efficient photocatalysts for hydrogen evolution from water by synergistic photoexcitation of the MOF 
frameworks and electron-injection into the Pt-nanoparticles. The larger channels of Pt-MOF8, resulting from the use of the elongated ancillary ligand on L11, promoted enhanced catalytic efficiency of Pt-MOF8 compared to Pt-MOF7 under visible light irradiation, with triethylamine (TEA) serving as a sacrificial reducing agent. Over 48h, Pt-MOF8 and PtMOF7 exhibited, respectively, TONs of 2400 and $7000 \mathrm{~h}^{-1}$. The MOF materials proved to be very stable and could be collected back after catalytic experiments and recycled for use at least three further times without loss of activity.

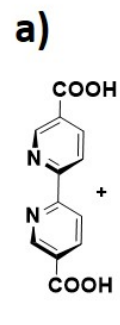

bpy-dc

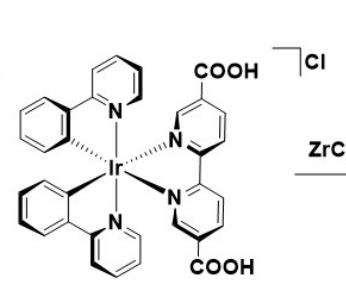

L10

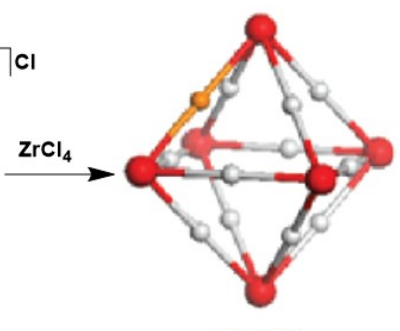

MOF7

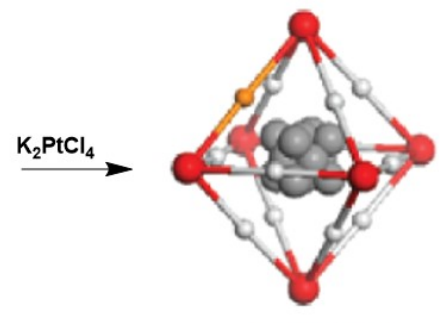

Pt-MOF7

b)

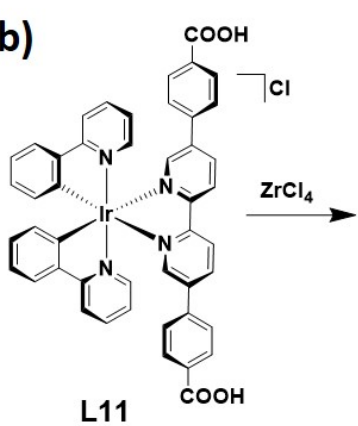

L11

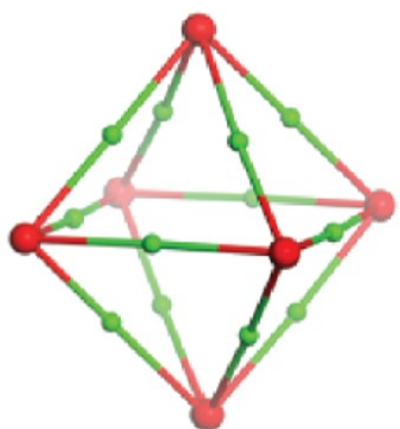

MOF8

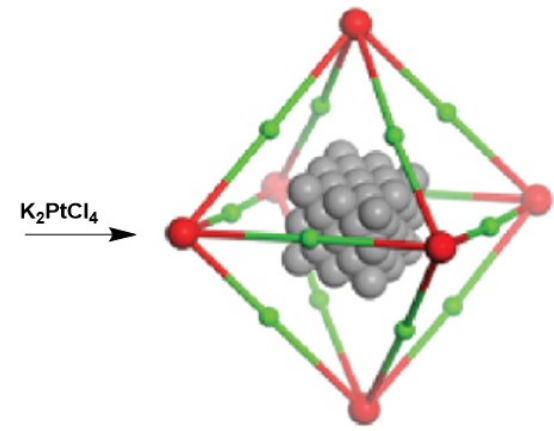

Pt-MOF8

Figure 28. Schematic representation of the formation of: a) Pt-MOF7 and b) Pt-MOF8. Red balls are $\mathrm{Zr}$ atoms, white linkers are bpy-dc, yellow linkers are L10, green linkers are $\mathbf{L 1 1}$ and in grey are Pt nanoparticles. Adapted with permission from Ref. [139]. Copyright 2012, American Chemical Society.

A supramolecular system composed of the iridium complex $\left[\operatorname{Ir}(p p y)_{2}(\right.$ pytl- $\left.\beta C D)\right] C l$ (pytl$\beta C D$ is 1 -substituted-1H-1,2,3-triazol-4-yl)pyridine functionalised with a $\beta$-cyclodextrin unit) 
as the photosensitiser, viologen functionalised with two adamantyl moieties as the electronrelay and cyclodextrin coated platinum nanoparticles as the catalyst, was also tested for photoinduced hydrogen evolution from water.[140] The system was designed to assemble through adamantane - cyclodextrin non-covalent interactions and therefore to give rise to photoinduced electron transfer from the iridium chromophore to the Pt nanoparticle via the viologen bridge (Figure 29). Interestingly, with ethylendiaminetetra-acetic acid (EDTA) serving as a sacrificial donor, this supramolecular system could produce almost $32 \mu$ moles (approximately $0.75 \mathrm{ml}$ ) of $\mathrm{H}_{2}$ per hour from $10 \mathrm{ml}$ of $\mathrm{H}_{2} \mathrm{O}$, which was a higher yield than the analogous supramolecular system involving a ruthenium chromophore in Rubpy/viologen/Pt.[141]

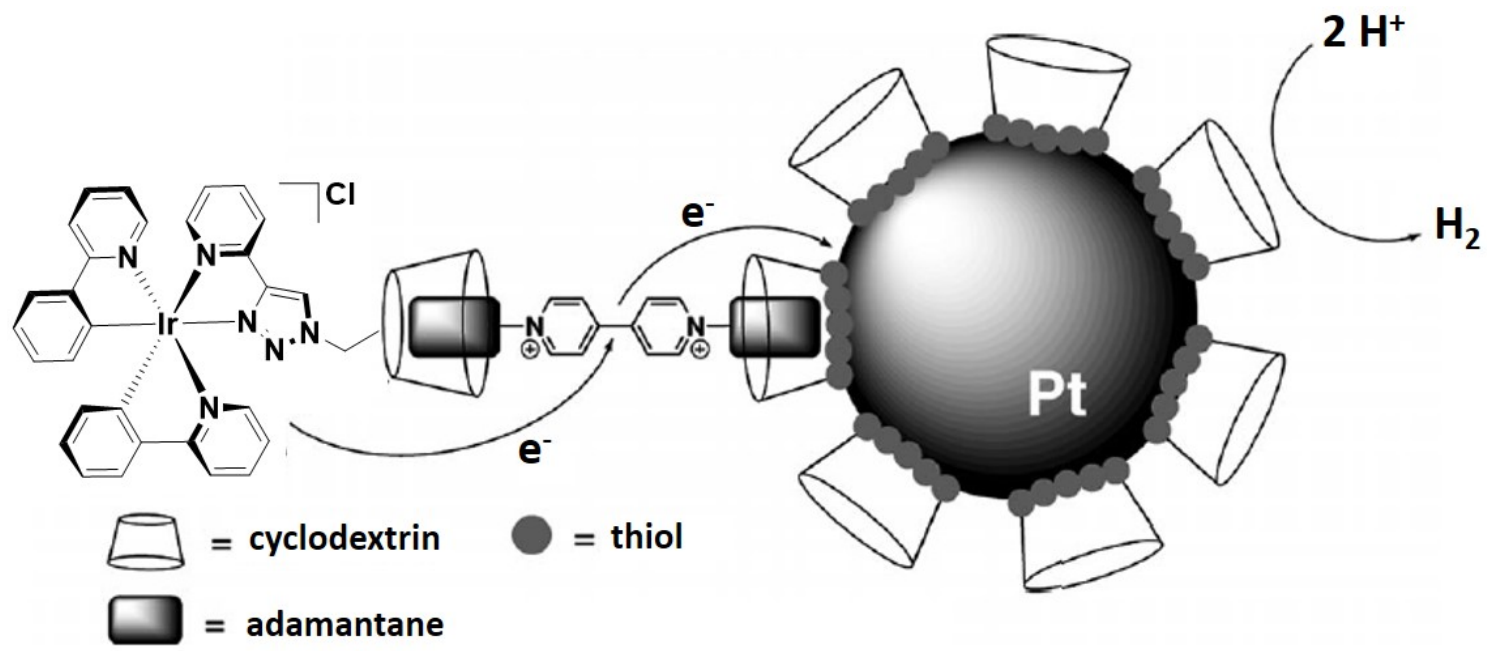

Figure 29. Illustration of the supramolecular assembly $\mathrm{Ir} /$ viologen/Pt used for photoproduction of $\mathrm{H}_{2}$. Adapted with permission. Copyright 2012, Wiley-VCH.[140]

Two Ir(III) metalloligands containing six carboxylic acid groups appended at the 4,4'positions of both the ppy and bpy ligands in the homoleptic complex $f a c-\left[\operatorname{Ir}(\mathrm{ppy}-\mathrm{dc})_{3}\right](\mathbf{L 1 2})$ (ppy-dc is 2-(3-carboxyphenyl)isonicotinic acid) and the heteroleptic complex [Ir(ppydc $)_{2}($ bpy-dc) $]\left(\mathbf{L 1 3}\right.$, Figure 30a,b), have been recently assembled with $[\mathrm{Ni}($ cyclam $)]\left(\mathrm{ClO}_{4}\right)_{2}$ 
(cyclam is 1,4,8,11-tetraazacyclotetradecane), forming two networks of cubic topologies (MOF9 and MOF10).[142] MOF9 and MOF10 both crystallized in trigonal space groups (R3 and $\mathrm{R}-3 \mathrm{c}$, respectively) where the $\mathrm{Ni}(\mathrm{II})$ cations are in octahedral coordination environments bound to four nitrogen atoms of the cyclam ligand and to two carboxylate groups from two L12 and L13 metalloligands, respectively, along the z-axis. As illustrated in Figure 30c, the crystal packing of MOF9 and MOF10 gave rise to two sets of interlocked primitive cubic networks. The materials exhibited small pore sizes and therefore poor ability to absorb $\mathrm{CO}_{2}$ and $\mathrm{N}_{2}$. For example, at $298 \mathrm{~K}$ and 1 atm, the sorption capacity of MOF9 for $\mathrm{CO}_{2}$ was 13.2 $\mathrm{cm}^{3} \mathrm{~g}^{-1}$, while that of MOF10 was $29.6 \mathrm{~cm}^{3} \cdot \mathrm{g}^{-1}$. The luminescence properties of MOF9 and MOF10 were not investigated.

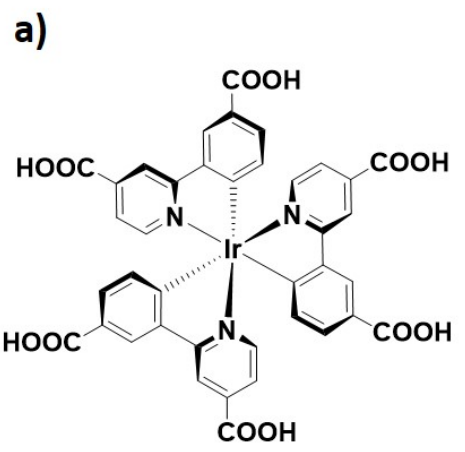

L12 b)

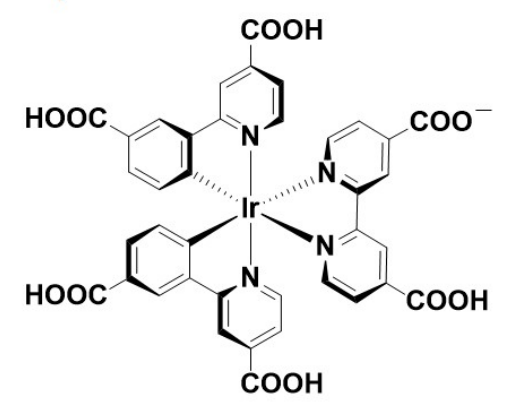

L13

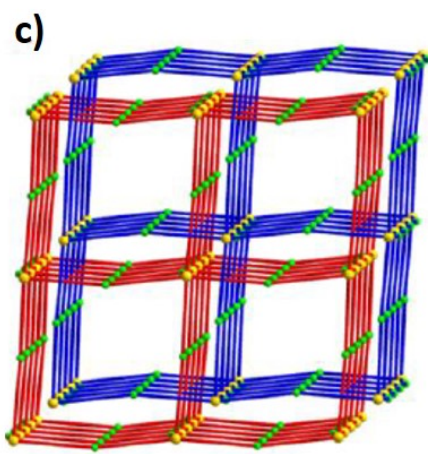

MOF9

Figure 30. a) Chemical structure of $\mathbf{L 1 2}$; b) chemical structure of $\mathbf{L 1 3}$ and c) illustration of the interlocked cubic topology exhibited by the crystal structures of MOF9 and MOF10.[142] Image c) is adapted with permission. Copyright 2017, Wiley-VCH.[142]

Three iridium-based MOFs of composition $\left.\left[\mathrm{Cd}_{3}(\mathbf{L 1})_{3}\right]_{2}(\mathrm{DMF})_{2}\left(\mathrm{H}_{2} \mathrm{O}\right)_{4}\right] \cdot 6 \mathrm{H}_{2} \mathrm{O} \cdot 2 \mathrm{DMF}$ (MOF11), $\left.\quad\left[\mathrm{Cd}_{3}(\mathbf{L 1})_{3}\right]_{2}(\mathrm{DMA})_{2}\left(\mathrm{H}_{2} \mathrm{O}\right)_{2}\right] \cdot 0.5 \mathrm{H}_{2} \mathrm{O} \cdot 2 \mathrm{DMA} \quad$ (MOF12) and $\left.\left[\mathrm{Cd}_{3}(\mathbf{L 1})_{3}\right]_{2}(\mathrm{DEF})_{2}\left(\mathrm{H}_{2} \mathrm{O}\right)_{2}\right] \cdot 8 \mathrm{H}_{2} \mathrm{O} \cdot 2 \mathrm{DEF}(\mathbf{M O F 1 3})(\mathbf{L 1}$ is reported in Figure 22, DMA is $N, N$ - 
dimethylacetamide and DEF is $N, N$-diethylformamide) were recently reported by Zheng and co-workers.[143] X-ray single-crystal structure analyses revealed that MOF11, MOF12 and MOF13 are isostructural and crystallized in the monoclinic space group $\mathrm{P} 2 / n$, showing a three dimensional framework where complex $\mathbf{L} \mathbf{1}$ bridges three $\mathrm{Cd}^{2+}$ ions through its six carboxylate oxygen atoms (Figure 31).

a)

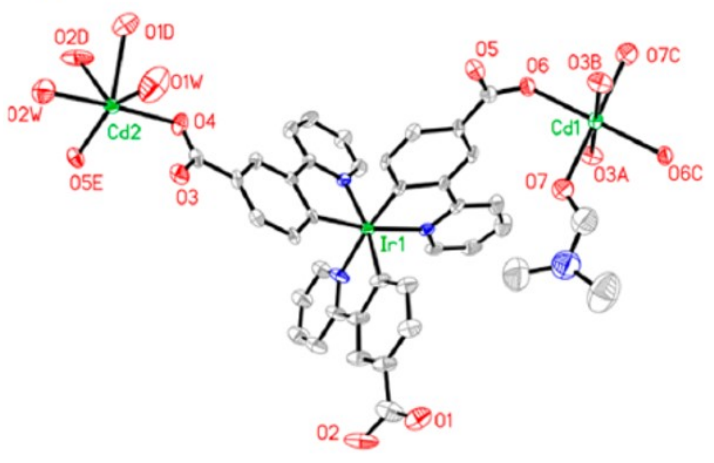

b)

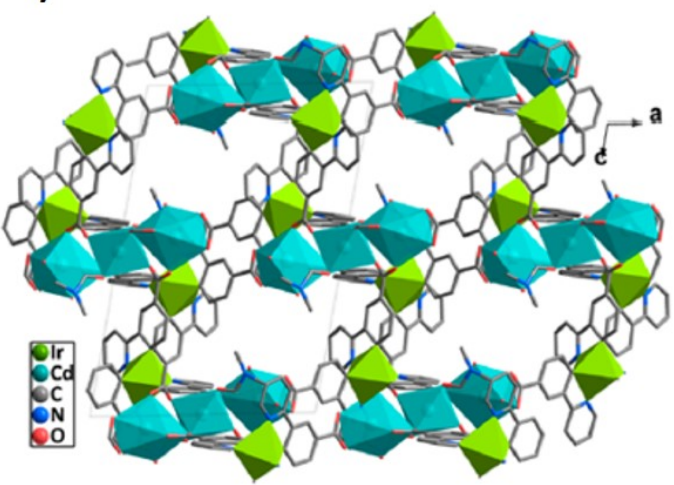

Figure 31. a) Building units of MOF11 and b) View of the 3D structure of MOF11, showing the channels along the $b$-axes. Solvent molecules are removed for clarity. Image is adapted with permission from Ref. [143]. Copyright 2018, American Chemical Society.

The powder emission of MOF11 was broad, originating from a ${ }^{3}$ MLCT state, and red-shifted at $\lambda_{\mathrm{PL}}=519 \mathrm{~nm}$ with longer $\tau_{\mathrm{PL}}$ of $2.95 \mu$ s (Table $\mathbf{1}$ ) compared to the powder emission exhibited by complex $\mathbf{L 1}\left(\lambda_{\mathrm{PL}}=488,510 \mathrm{~nm}, \tau_{\mathrm{PL}}\right.$ of $\left.1.93 \mu \mathrm{s}\right)$. The red-shifted emission observed for MOF11 is due to coordination of the $\mathrm{Cd}^{2+}$ ions to the iridium complex, which decrease the LUMO thereby giving rise to a smaller optical gap, while the increased rigidity reduces nonradiative decay and accounts for the longer $\tau_{\mathrm{PL}}$ in MOF11 compared to that of L1. MOF11 was found to be soluble in water and emissive at $515 \mathrm{~nm}$. The sensing ability of MOF11 towards metal cations $\left(\mathrm{Na}^{+}, \mathrm{Mg}^{2+}, \mathrm{K}^{+}, \mathrm{Ca}^{2+}, \mathrm{Cr}^{3+}, \mathrm{Mn}^{2+}, \mathrm{Fe}^{3+}, \mathrm{Co}^{2+}, \mathrm{Ni}^{2+}, \mathrm{Cu}^{2+}\right.$ and $\left.\mathrm{Zn}^{2+}\right)$ and various anions $\left(\mathrm{F}^{-}, \mathrm{Cl}^{-}, \mathrm{Br}^{-}, \mathrm{I}^{-}, \mathrm{BrO}_{3}^{-}, \mathrm{IO}_{3}{ }^{-}, \mathrm{NO}_{3}{ }^{-}, \mathrm{CO}_{3}{ }^{2-}, \mathrm{SO}_{4}{ }^{2-}, \mathrm{PF}_{6}^{-}, \mathrm{HPO}_{4}{ }^{2-}\right.$ and $\left.\mathrm{Cr}_{2} \mathrm{O}_{7}{ }^{2-}\right)$ were investigated by emission spectroscopy both in water and in PMMA-doped films. Among this series of 
analytes, MOF11 exhibited selective sensing for the cation $\mathrm{Fe}^{3+}$ and the anion $\mathrm{Cr}_{2} \mathrm{O}_{7}{ }^{2-}$ with detection limits of 67.8 and $145.1 \mathrm{ppb}$ for $\mathrm{Fe}^{3+}$ and $\mathrm{Cr}_{2} \mathrm{O}_{7}{ }^{2-}$, respectively. MOF11 also exhibited selective sensing of adenosine triphosphate $\left(\mathrm{ATP}^{2-}\right)$ over both adenosine diphosphate $\left(\mathrm{ADP}^{2-}\right)$ and adenosine monophosphate $\left(\mathrm{AMP}^{2-}\right)$. Indeed, following gradual addition of $\mathrm{ATP}^{2-}$ to an aqueous solution MOF11 or exposing a PMMA-doped film of MOF11 to vapors of ATP $^{2-}$ a significant phosphorescent quenching of MOF11 was observed; no emission quenching was observed when either $\mathrm{ADP}^{2-}$ and $\mathrm{ATP}^{2-}$ were added to MOF11.

An example of a heterometallic paddlewheel structure (P5) was reported by Hosseini and coworkers[144] by assembling an Ir(III) dipyrrin derivative bearing an appended carboxylic acid (L14) with $\mathrm{Cu}(\mathrm{II})$ ions (Figure 32). Single crystals of $\mathbf{P 5}$ suitable for x-ray diffraction were obtained by slow diffusion of a $\mathrm{MeOH}$ solution of $\mathrm{Cu}(\mathrm{OAc})_{2}$ into a DMF solution of $\mathbf{L 1 4}$, leading to the formation after two weeks of dark red crystals of composition of $\left[(\mathbf{L 1 4})_{4} \mathrm{Cu}_{2}(\mathrm{DMF})\left(\mathrm{H}_{2} \mathrm{O}\right)\right] . \mathbf{P 5}$ crystallized in a in a triclinic P$\overline{1}$ space group where two $\mathrm{Cu}(\mathrm{II})$ cations form the paddlewheel motif bridged by the carboxylate groups of four L14 molecules, and one DMF molecule and one water molecule occupy the remaining two axial positions (Figure 32). Complex L14 exhibited a weak emission at $\lambda_{\mathrm{PL}}=710 \mathrm{~nm}$ in degassed DCM (Table 1). However, complex P5 was rather insoluble or unstable in common organic solvents and therefore, its emission properties could not be investigated. 


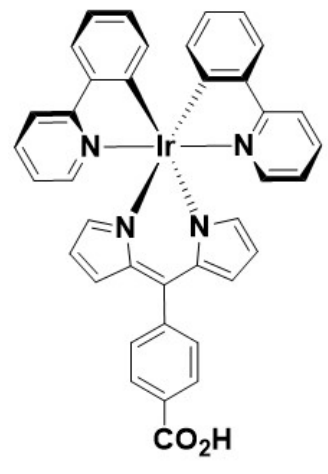

L14

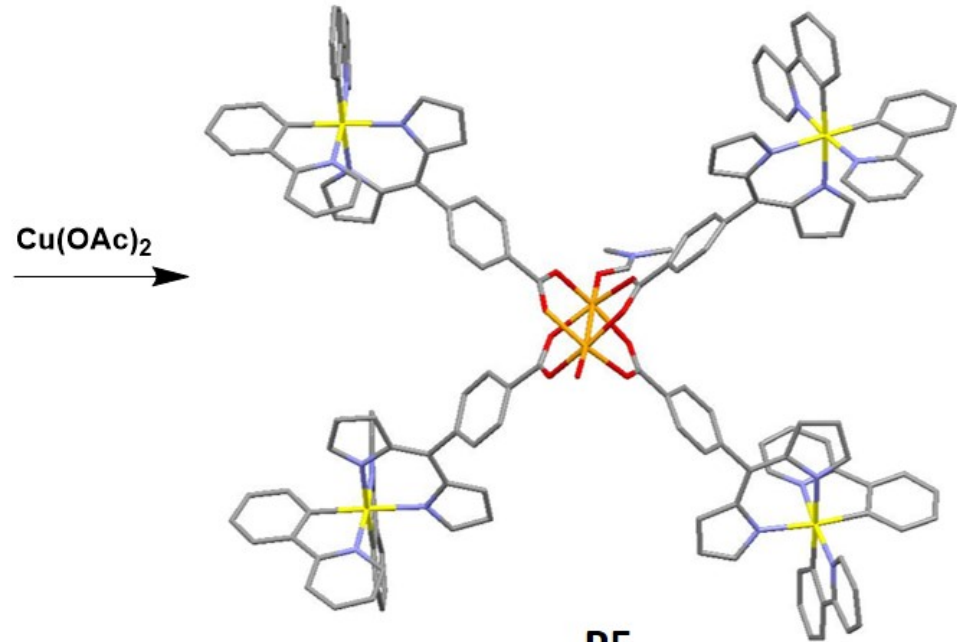

P5

Figure 32. Formation of the paddlewheel structure P5 by reacting the iridium complex L14 with $\mathrm{Cu}(\mathrm{II})$ ions. The $\mathrm{x}$-ray structure of $\mathbf{P 5}$ is shown (carbon, oxygen, copper and iridium atoms are shown respectively in grey, red, orange and yellow).

More recently the same group reported two homochiral heterometallic coordination networks involving cyclometalated $\operatorname{Ir}(\mathrm{III})$ chiral metallotectons.[145, 146] Enantiopure $\Delta$ - and racemic $r a c$ - $\operatorname{Ir}(\mathrm{III})$ complexes, $\Delta^{-}, r a c-\mathbf{L 1 5}$ and $\Delta^{-}, r a c-\mathbf{L 1 6}$, of composition of $\Delta^{-}, r a c-\left[\operatorname{Ir}\left(\mathrm{C}^{\wedge} \mathrm{N}\right)_{2}(\mathrm{py}-\right.$ alk-bpy)]PF${ }_{6}$ (where $\mathrm{C}^{\wedge} \mathrm{N}$ is ppy in $\mathbf{L 1 5}$ and dFppy in $\mathbf{L 1 6}$ and py-alk-bpy is 5,5'-bis(pyridine4-ylethynyl)-2,2'-bipyridine) were assembled, respectively, with $\mathrm{Cu}(\mathrm{I})[145]$ and $\mathrm{Cd}(\mathrm{II})[146]$ ions (Figure 33a and 33b, respectively). When an $\mathrm{EtOH}$ solution of $\left[\mathrm{Cu}(\mathrm{NCMe})_{4}\right] \mathrm{BF}_{4}$ was left to slowly diffuse into an $\mathrm{MeCN}$ solution of $\mathrm{rac}$-L15, single crystals suitable for $\mathrm{x}$-ray diffraction were obtained. The structural investigation of these crystals revealed the formation of a grid-type network (Figure 33a), where $\mathrm{Cu}(\mathrm{II})$ ions, formed during the crystallization process from oxidation of $\mathrm{Cu}(\mathrm{I})$ under ambient conditions, adopted a slightly distorted octahedral geometry, with four pyridyl units of four L15 molecules occupying the square base of the octahedron and two $\mathrm{BF}_{4}^{-}$ions occupying the axial positions. Interestingly, each grid was intrinsically chiral as only one enantiomer of L15 was present. However, consecutive homochiral sheets were packed with alternation of $\Delta$-L15 and $\Lambda$-L15 leading thus to achiral 
crystal. No single crystals were obtained when the enantiopure $\Delta$-L15 was used in the assembly. Metalloligand $r a c$-L15 exhibited a mixed ${ }^{3} \mathrm{MLCT} /{ }^{3} \mathrm{LLCT}$ emission in the solid state at $\lambda_{\mathrm{PL}}=677 \mathrm{~nm}$ with a $\Phi_{\mathrm{PL}}$ of $3 \%$ (Table 1), while no emission could be detected from the gridtype network.
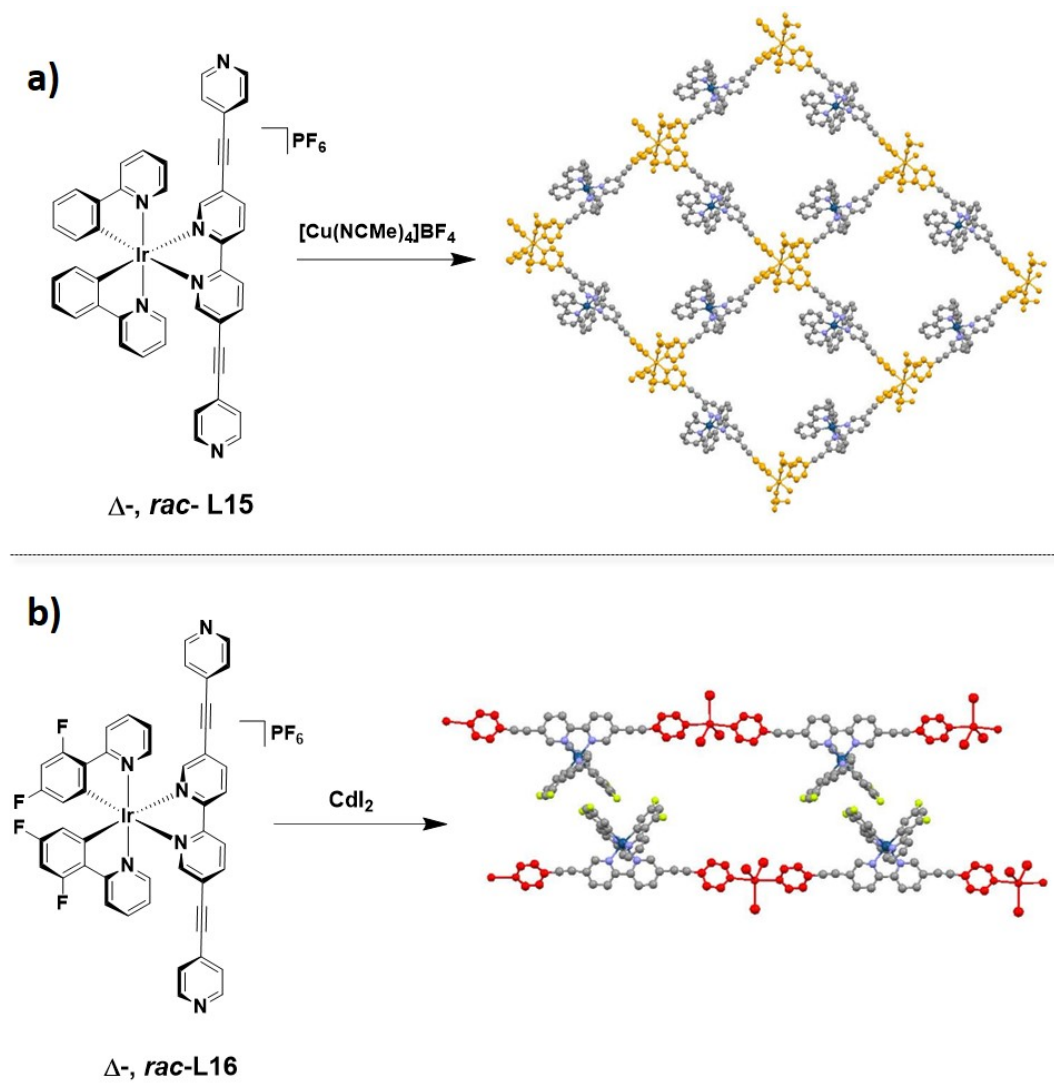

Figure 33. a) Self-assembly between metalloligands $\Delta$-, $r a c-\mathbf{L 1 5}$ and $\mathrm{Cu}(\mathrm{I})$ ions yielding the $\mathrm{Ir}-\mathrm{Cu}$ grid-type network. In orange is illustrated the coordination around the $\mathrm{Cu}(\mathrm{I})$ ions.[145] b) Self-assembly between metalloligands $\Delta$-, rac-L16 and Cd(II) ions yielding the Ir-Cd linear network. In red is illustrated the coordination around the $\mathrm{Cd}(\mathrm{II})$ ions.

Diffusion of an EtOH solution of $\mathrm{CdI}_{2}$ through an $\mathrm{EtOH} / \mathrm{Cl}_{2} \mathrm{CHCHCl}_{2}$ buffer layer containing two drops of trifluoroethanol and 4,4,4-trifluorobutanol into a solution of either $\Delta$ - and racL16 in 1,1,2,2-tetrachloroethane led to the slow formation of orange single crystals. X-ray analyses of the crystals obtained by the assembly of both complexes $\Delta$-L16 and rac-L16 and 
$\mathrm{CdI}_{2}$ demonstrated the formation identical structures. These resembled infinite 1D networks where the Cd centers adopted a trigonal bipyramidal coordination geometry with the two terminal pyridine moieties of $\Delta$-L16 and rac-L16 occupying the apical positions, and three iodine atoms located at the trigonal base (Figure 33b). In the case of the network involving rac-L16, consecutive homochiral planes of opposite chirality were packed in a parallel fashion, resulting in the formation of non-chiral crystals. By contrast, the assembly of enantiopure $\Delta$ L16 with $\mathrm{CdI}_{2}$ resulted in the formation of a chiral 1D network. Metalloligand rac-L16 exhibited structured emission in both degassed THF and in the solid state with two maxima at $\lambda_{\mathrm{PL}}=570,605 \mathrm{~nm}$, but with divergent $\Phi_{\mathrm{PL}}$ of $19 \%\left(\tau_{\mathrm{PL}}\right.$ of $\left.1.47 \mu \mathrm{s}\right)$ and $2 \%$, respectively (Table 1); no lifetime data were reported in the solid state. The racemic and enantiopure $\operatorname{Ir}(\mathrm{III})-\mathrm{Cd}(\mathrm{II})$ coordination networks exhibited structured emission in the solid state with two emission maxima red-shifted at $\lambda_{\mathrm{PL}}=575,620 \mathrm{~nm}$ and with lower $\Phi_{\mathrm{PL}}<1 \%$ compared to $r a c$-L16. The red-shifted emissions of the Ir-Cd networks are attributed to the lowering of their LUMO energy levels as a result of the binding of the Lewis-acidic $\mathrm{Cd}(\mathrm{II})$ ions to the pyridine moieties of L16.

Table 1. Relevant photophysical properties at $298 \mathrm{~K}$ of $\operatorname{Ir}(\mathrm{III})$ metalloligands, CPs and MOFs

\begin{tabular}{|c|c|c|c|c|c|}
\hline & medium & $\lambda_{\mathrm{PL}}(\mathbf{n m})$ & $\Phi_{\mathrm{PL}}(\%)$ & $\tau_{\mathrm{PL}}(\mu \mathrm{s})$ & reference \\
\hline L1 & powder & 520 & - & 1.9 & 128,143 \\
\hline L2 & powder & 575 & - & - & 128 \\
\hline $\mathbf{L 3}$ & powder & 613 & 17.8 & 7.8 & $\begin{array}{c}129,131,132, \\
135,136\end{array}$ \\
\hline $\mathbf{L 4}$ & powder & 538 & - & - & 133 \\
\hline L14 & DCM & 710 & - & - & 144 \\
\hline rac-L15 & powder & 677 & 3 & & 145 \\
\hline rac-L16 & $\begin{array}{l}\text { powder, } \\
\text { (THF) }\end{array}$ & 570,605 & 2 & (1.5) & 146 \\
\hline P1 & powder & 540 & - & - & 128 \\
\hline $\mathbf{P 2}$ & powder & 550 & - & - & 128 \\
\hline P3a & crystal & 613 & 27.4 & - & 129 \\
\hline P3b & crystal & 595 & 19.3 & - & 129 \\
\hline P3c & crystal & 587 & 0.1 & - & 129 \\
\hline
\end{tabular}




\begin{tabular}{|c|c|c|c|c|c|}
\hline P3d & crystal & 600 & 0.2 & - & 129 \\
\hline P3e & powder & 544 & 14.6 & 7.7 & 131 \\
\hline P3f & powder & 554 & 18.1 & 13.3 & 131 \\
\hline P3g & powder & 570 & 2.4 & 7.7 & 131 \\
\hline P3h & crystal & 592 & - & 29.0 & 135 \\
\hline P4 & powder & 531 & - & - & 133 \\
\hline MOF1 & powder & 602 & 23.6 & 14.3 & 136 \\
\hline MOF11 & powder & 519 & & 2.9 & 143 \\
\hline
\end{tabular}

\subsection{Macrocycles, capsules and cages}

In the previous section, we documented extended structures incorporating iridium metalloligands. Here, we summarize discrete cage-like structure incorporating iridium. Coordination capsules and cages, formed through the self-assembly of arrays of metal ions and bridging ligands, have been areas of great interest in supramolecular chemistry during the last two decades.[147-149] Small guest molecules have been shown to be sequestered within the cavities of these cages and their host-guest interactions have been exploited in the context of sensing, gas storage and purification, and for catalysis.[150, 151] In recent years a small number of photophysically active capsules and cages that include $\operatorname{Ir}(\mathrm{III})$ metalloligands as luminescent units have been reported. In addition, iridium half-sandwich complexes of Cp*Ir ( $\mathrm{Cp} *$ is penthamethylcyclopentadienyl) have been extensively used in macrocyclic chemistry to form a wide range of 2D-assemblies, including molecular squares, rectangles and triangles, with application in catalysis.[152-154] As these macrocycles have been already reported in pertinent review articles, they are not included herein.

A luminescent tetranuclear square-like macrocycle was reported by Baranoff and coworkers.[155] This macrocycle (M1, Figure 34a) was synthetized in one step by reacting the 
dimeric complex $\left[\operatorname{Ir}(\mathrm{ppy})_{2} \mathrm{Cl}\right]_{2}$ with two equivalents of tetrabutyl ammonium cyanide (TBACN) in the presence of a small excess of AgOTf in DCM. The geometry of M1 was identified by x-ray diffraction (Figure 34a). M1 could be defined as a cyclic tetramer where the four Ir(III) centers and the bridging ambidentate cyano ligands form a chiral structure. Interestingly, while each iridium unit could be either the $\Lambda$ - or $\Delta$-isomer, giving a total of nine possible optical isomers, only two isomers were observed in the crystal structure, namely the $[-\Delta-\Lambda-\Delta-\Lambda]$ and the mirror image $[-\Lambda-\Delta-\Lambda-\Delta]$. M1 exhibited a bright green structured luminescence with maxima at $496 \mathrm{~nm}$ and $521 \mathrm{~nm}$ in degassed $\mathrm{MeCN}$, with a $\Phi_{\mathrm{PL}}$ of $66 \%$ and a bi-exponential $\tau_{\mathrm{PL}}$ of $40 \mathrm{~ns}, 2320 \mathrm{~ns}$ (Table 2). The emission of M1 was red-shifted and slightly quenched when compared to the reference $\operatorname{TBA}\left[\operatorname{Ir}(\mathrm{ppy})_{2}(\mathrm{CN})_{2}\right]$, which likewise showed structured emission in degassed $\mathrm{MeCN}$ at $\lambda_{\mathrm{PL}}=470,502 \mathrm{~nm}$, with $\Phi_{\mathrm{PL}}$ of $79 \%$. Solution-processed OLEDs fabricated by using M1 as the emitter achieving a maximum external quantum efficiency (EQE) of $10.2 \%\left(\lambda_{\mathrm{EL}}=497 \mathrm{~nm}\right)$.

Shiu and co-workers[156] reported the self-assembly of the $\operatorname{Ir}(\mathrm{III})$ complex $\left[\operatorname{Ir}(\mathrm{ppy})_{2}(4-\right.$ pyCO $\left.\mathrm{CO}_{2} \mathrm{H}\right)_{2} \mathrm{NO}_{3}$ (4-pyCO $\mathrm{CO}_{2} \mathrm{H}$ is 4-pyridine carboxylic acid), $\mathbf{L 1 7}$ with the Arrhenius base $\mathrm{Mg}(\mathrm{OH})_{2}$ in the presence of $\mathrm{KPF}_{6}$, yielding quantitatively the cage structure of composition $\left[(\mathbf{L 1 7})_{3}\left(\mathrm{Mg}\left(\mathrm{OH}_{2}\right)_{3}\right)_{2}\right] \mathrm{K}_{2}\left(\mathrm{PF}_{6}\right)_{3}, \mathbf{C 1}$ (Figure 34b). The x-ray crystal structure of $\mathbf{C 1}$ comprised of a cationic coordination cage exhibiting a large trigonal bipyramidal geometry that encapsulated the quintuple ionic aggregate $\mathrm{K}_{2}\left(\mathrm{PF}_{6}\right)_{3}^{-}$formed in solution from $\mathrm{KPF}_{6}$ (Figure 34b). The neutralization of $\mathbf{C 1}$ with $\mathrm{KOH}$ and $\mathrm{Mg}(\mathrm{OH})_{2}$ in $\mathrm{MeOH}$ or EtOH promoted the degradation of the coordination cage and the subsequent formation of a zig-zag coordination polymer of composition $\left[(\mathbf{L 1 7})_{4} \mathrm{MgK}_{2}\right]_{\mathrm{n}}$, which was itself also characterised by $\mathrm{x}$-ray diffraction. The 
emission properties of the coordination cage $\mathbf{C 1}$ and the related coordination polymer were not investigated.

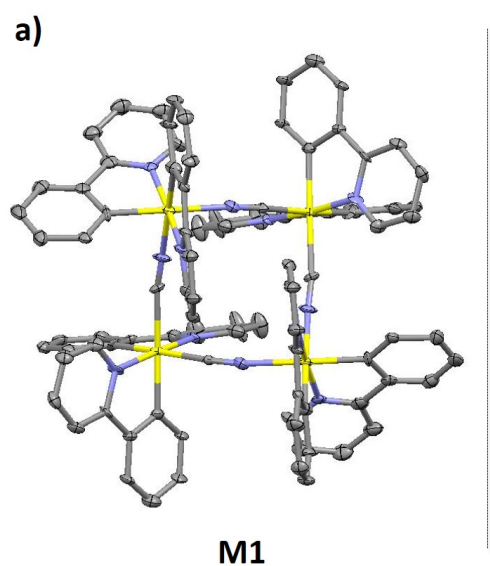

b)

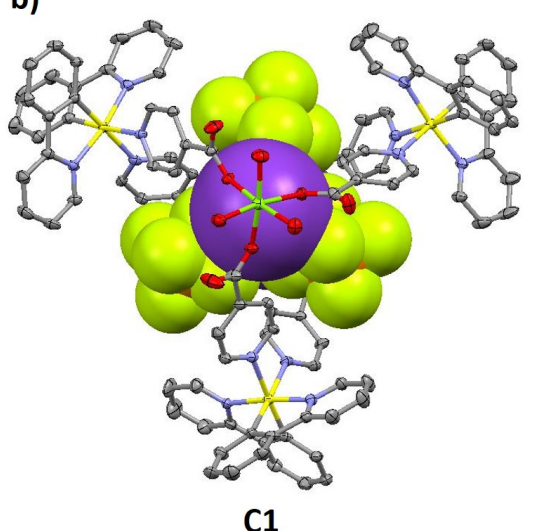

c)

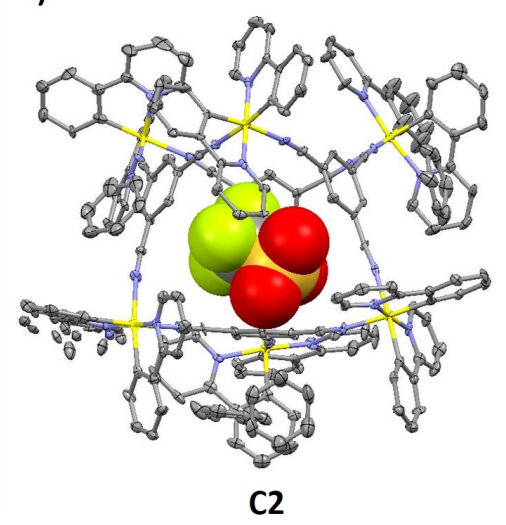

Figure 34. X-ray crystal structures of: a) $\mathbf{M 1}$ and b) $\mathbf{C 1}$ and c) $\mathbf{C 2}$. C, N and Ir atoms are respectively shown in grey, blue and yellow. The guests $\mathrm{K}_{2}\left(\mathrm{PF}_{6}\right)_{3}$ in b) and OTf molecule in c) are illustrated in space-fill mode.

Lusby and co-workers[157] reported the first example of a 3D luminescent $\operatorname{Ir}(\mathrm{III})$ capsule of composition of $\left[\left(\operatorname{Ir}(\mathrm{ppy})_{2}\right)_{6}(\mathrm{tcb})_{4}\right](\mathrm{OTf})_{6}(\mathrm{tbc}$ is 1,3,5-tricyanobenzene) $(\mathbf{C 2}$, Figure 34c). To eliminate the problem of mixed stereoisomer formation during the self-assembly, the rac$\left[\operatorname{Ir}(\mathrm{ppy}){ }_{2} \mathrm{Cl}\right]_{2}$ dimer was firstly resolved into its enantiopure $\Lambda, \Lambda$ - and $\Delta, \Delta$-stereoisomers through chromatographic resolution of serine-based complexes, the amino acid acting as a chiral ancillary ligand thereby forming a diastereomeric mixture of products. Reaction of either $\Lambda, \Lambda$ - and $\Delta, \Delta-\left[\operatorname{Ir}(\mathrm{ppy})_{2} \mathrm{Cl}\right]_{2}$ with tcb quantitatively yielded the enantiopure $\Lambda_{6^{-}}$and $\Delta_{6}-\mathbf{C 2}$. Vapor diffusion of benzene into a saturated DCM solution of $\Delta_{6}-\mathbf{C 2}$ afforded suitable crystals for x-ray diffractions. Within the crystal structure of $\Delta_{6}-\mathbf{C 2}$ a triflate anion is encapsulated within the octahedral cavity of $\mathbf{C 2}$ (Figure 34c). Interestingly, despite the weak emission $\left(\Phi_{\mathrm{PL}}\right.$ $<1 \%$ ) observed for the bis(benzonitrile) reference complex $\left[\operatorname{Ir}(\mathrm{ppy})_{2}(\mathrm{NCPh})_{2}\right] \mathrm{OTf}$ at $\lambda_{\mathrm{PL}}=525$ $\mathrm{nm}$, a broad and red-shifted emission at $575 \mathrm{~nm}$ with an unusually enhanced $\Phi_{\mathrm{PL}}$ of $4 \%$ was 
detected for $\mathbf{C 2}$ in deareated tetrachloroethane (Table 2). The capsule exhibited an affinity for the encapsulation of perfluorinated anions following the sequence: $\mathrm{PF}_{6}^{-}>\mathrm{OTf}^{-} \sim \mathrm{CF}_{3} \mathrm{BF}_{3}^{-}>$ $\mathrm{BF}_{4}^{-}$.

The self-assembly between square planar palladium(II) or platinum(II) metal ions and complementary bent ligands containing specifically positioned distal pyridine moieties, first demonstrated by Fujita and co-workers,[158] has been used as a technology to prepare myriad molecular capsules and cages.[124, 149] Recently, our group[159] has reported the first examples or metallocages through $\mathrm{N}_{\text {(pyridine) }}$-Pd coordination. $\operatorname{Ir}(\mathrm{III})$ homochiral supramolecular cages of composition $\Lambda_{8^{-}}, \Delta_{8^{-}}$, and $\mathrm{rac}$ - $\left[\mathrm{Ir}_{8} \mathrm{Pd}_{4}\right]^{16+}$ were obtained through the self-assembly between two families of $\operatorname{Ir}(\mathrm{III})$ metalloligands of the form of $\left.\operatorname{Ir}\left(\mathrm{C}^{\wedge} \mathrm{N}\right)_{2}(\mathrm{qpy})\right] \mathrm{BF}_{4}$ and $\mathrm{Pd}^{2+}$ ions (Figure 35a,b; $\mathrm{C}^{\wedge} \mathrm{N}$ is mesppy $=$ 2-phenyl-4-mesitylpyridinato in $\mathbf{L 1 8}$, and dFmesppy $=2-(4,6-$ difluorophenyl)-4-mesitylpyridinato in L19).[160] The metalloligands $\mathbf{L 1 8}$ and $\mathbf{L 1 9}$ were prepared in their racemic forms and also as their $\Lambda$ - and $\Delta$-enantiomers.[161] The assembly of rac-L18 and $\boldsymbol{r a c}$-L19 with $\mathrm{Pd}^{2+}$ ions yielded racemic cages $r a c-\left[\operatorname{Ir}_{8} \mathrm{Pd}_{4}\right]^{16+}(\boldsymbol{r a c}-\mathbf{C} 3$ and $\boldsymbol{r a c}$ C4, respectively), while when $\Lambda$ - and $\Delta$-L18 and $\Lambda$ - and $\Delta$-L19 were assembled with Pd(II) ions, enantiopure cages $\Lambda_{8^{-}}$and $\Delta_{8^{-}}\left[\operatorname{Ir}_{8} \mathrm{Pd}_{4}\right]^{16+}$ were obtained $\left(\Lambda_{-}^{-}, \Delta_{-} \mathbf{C} 3\right.$ and $\Lambda_{-}^{-}, \Delta_{-} \mathbf{C 4}$, respectively).[159] The enantiopurity of metalloligands $\Lambda^{-}, \Delta-\mathbf{L 1 8}$ and $\Lambda_{-}^{-}, \Delta-\mathbf{L 1 9}$, and metallocages $\Lambda_{-}^{-}, \Delta-\mathbf{C 3}$ and $\Lambda_{-}^{-}, \Delta-\mathbf{C 4}$ were confirmed by CD spectroscopy. As the chirality of the iridium metal did not impact the overall self-assembly process, metalloligand exchange was observed when either of the homochiral cages $\Lambda$ - or $\Delta-\mathbf{C} 3$ were mixed with the homochiral cage $\Delta-\mathbf{C} 4$ at $85^{\circ} \mathrm{C}$ for $12 \mathrm{~h}$, promoting the formation of a statistical mixture of heteronuclear cages of composition $\left[(\Lambda, \Delta-\mathbf{L} 18)_{\mathrm{n}}(\Delta-\mathbf{L} 19)_{\mathrm{m}} \mathrm{Pd}_{4}\right]\left(\mathrm{BF}_{4}\right)_{16}(\mathrm{n}+\mathrm{m}=8$, from $\Lambda$-, $\Delta$-L18 : $\Delta$-L19 $=$ $7: 1$ to $\Lambda$-, $\Delta-\mathbf{L 1 8}: \Delta-\mathbf{L 1 9}=1: 7)$. 


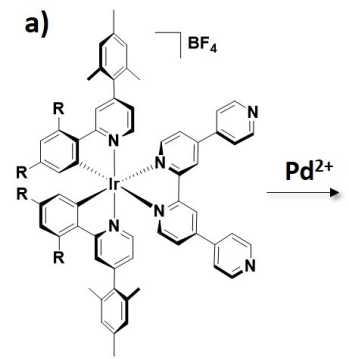

R: H, rac-, $\Lambda$-, $\Delta$-L18

R: F, rac-, $\Lambda-, \Delta-$ L19

b)

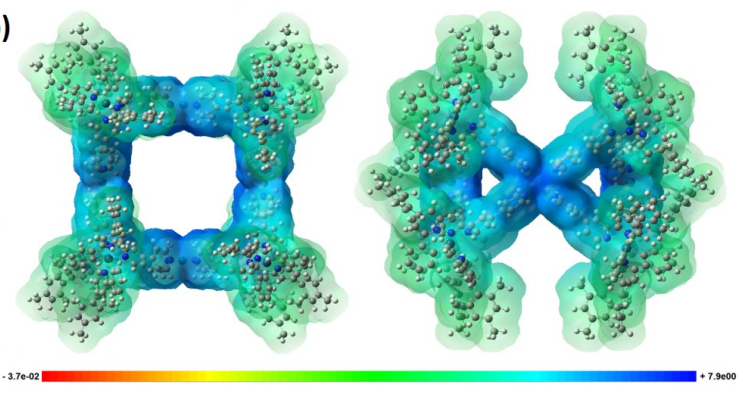

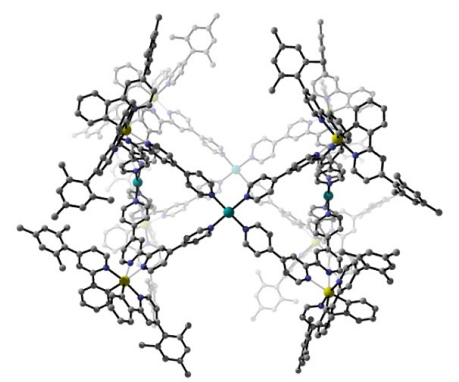

rac-, $\Lambda-, \Delta-C 3$
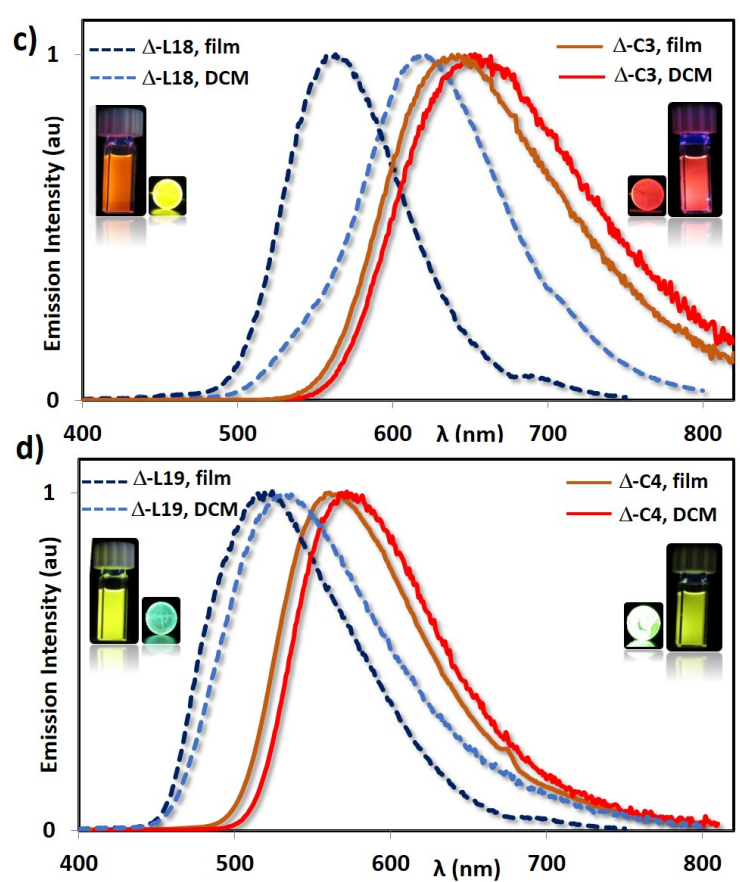

Figure 35. a) Self-assembly between the metalloligands rac-, $\Lambda-, \Delta-\mathbf{L 1 8}$ and rac- $^{-}, \Lambda-, \Delta-\mathbf{L} 19$ and $\mathrm{Pd}^{2+}$ ions yielding cages rac-, $\Lambda-, \Delta-\mathbf{C 3}$ and $\mathbf{r a c}-, \Lambda_{-}^{-}, \Delta-\mathbf{C 4}$. For clarity, only the calculated structure of $\Delta-\mathbf{C 3}$ obtained is shown. b) Molecular electrostatic potential [HF/6-31G(d)] map of $\Delta-\mathbf{C} 3$ with front (left) and central (right) views. The most positive potential regions are shown in deep blue. Normalized emission spectra of: c) $\Delta$-L18 and $\Delta$-C3 and d) $\Delta$-ML19 and $\Delta$-C4. Dotted dark-blue lines: PMMA-doped film with $5 \mathrm{wt} \%$ of metalloligands $\Delta$-L18 and $\Delta$ L19 spin-coated on quartz substrates; Dotted light-blue lines: deareated DCM solution of $\Delta^{-}$ L18 and $\Delta$-L19; Solid orange lines: PMMA-doped film with 5 wt $\%$ of $\Delta-\mathbf{C 3}$ and $\Delta$-C4 spincoated on quartz substrates; Solid red lines: deaerated DCM solution of $\Delta-\mathbf{C 3}$ and $\Delta-\mathbf{C 4}$.[159]

The photophysical properties of the metalloligands rac-, $\Lambda_{-}^{-}, \Delta-\mathbf{L 1 8}$ and $\mathbf{r a c}_{-}, \Lambda_{-}^{-}, \Delta-\mathbf{L} \mathbf{1 9}$, and metallocages rac-, $\Lambda_{-}^{-}, \Delta-\mathbf{C 3}$ and $\boldsymbol{r a c}-, \Lambda_{-}^{-}, \Delta-\mathbf{C 4}$ were investigated both in DCM solution and in polymethyl methacrylate (PMMA) doped films (Figure 35c,d) (Table 2). In deaerated DCM, 
cages $\mathbf{r a c}-, \Lambda_{-}^{-}, \Delta_{-}^{-} \mathbf{C 3}$ and $\mathbf{r a c}-, \Lambda_{-}^{-}, \Delta_{-}^{-} \mathbf{C 4}$ exhibited red-shifted emissions, respectively, at 655 nm and $561 \mathrm{~nm}$, with lower $\Phi_{\mathrm{PL}}$ of $5 \%$ and $14 \%$, and shorter $\tau_{\mathrm{PL}}$ of $202 \mathrm{~ns}$ and $825 \mathrm{~ns}$, compared to those of the corresponding metalloligands rac-, $\Lambda$-, $\Delta$-L18 and rac-, $\Lambda$-, $\Delta-\mathbf{L 1 9}$ (e.g., racL18: $\lambda_{\mathrm{PL}}=620 \mathrm{~nm}, \Phi_{\mathrm{PL}}=14 \%, \tau_{\mathrm{PL}}=300 \mathrm{~ns} ; \boldsymbol{r a c}-\mathbf{L 1 9}: \lambda_{\mathrm{PL}}=527 \mathrm{~nm}, \Phi_{\mathrm{PL}}=34 \%, \tau_{\mathrm{PL}}=1000$ ns). As a result of the less polar environment and the rigidification conferred by the PMMA host polymer, the emissions of L18, L19, C3 and C4 in the thin films were blue-shifted, respectively, at $564 \mathrm{~nm}, 518 \mathrm{~nm}, 643 \mathrm{~nm}$ and $531 \mathrm{~nm}$ (Figures 35c,d), with enhanced $\Phi_{\mathrm{PL}}$ of $28 \%, 41 \%, 10 \%$ and $16 \%$ and longer multi-exponential $\tau_{\mathrm{e}}$ compared to their photophysical behavior in DCM. The red-shifted emissions of the cages $\mathbf{C 3}$ and $\mathbf{C 4}$ in both DCM and PMMAdoped films compared to the corresponding metalloligands was interpreted to be the result of coordination of the Lewis acidic $\mathrm{Pd}^{\mathrm{II}}$ to the iridium complex thereby lowering the LUMO energies of $\mathbf{L 1 8}$ and $\mathbf{L 1 9}$ localized on the qpy ligand, [160] [159] [158] [158] [157] [156] [155] [152] [136] [136] [138] [137] [136] [135] [134] [133] [133] [132] [131] [130] [130] [129] [128] [128] [127] [126] [125] [124] [123] [122] [121] [120] [119] [118] [117] [116] [115] and giving rise to smaller optical gaps. Interestingly, cage $\mathbf{C 3}$ could encapsulate within its cavity large anionic guests including the blue-emitting complex $\mathrm{NBu}_{4}\left[\operatorname{Ir}(\mathrm{dFppy})_{2}(\mathrm{CN})_{2}\right]$, giving rise to host-guest photoinduced interactions. These results will be discussed in the following chapter.

Hardie, Zysman-Colman and co-workers[162] reported the assembly of CTV-type ligands (CTV is cyclotriveratrylene), ( \pm )-tris(isonicotinoyl)-cyclotriguaiacylene (L20), or ( \pm )-tris(4pyridyl-methyl)-cyclotriguaiacylene $\quad(\mathbf{L 2 1})$, with $\quad\left[\operatorname{Ir}(\mathrm{ppy})_{2}(\mathrm{NC})_{2}\right]^{+}, \quad$ forming metallocryptophane cages of compositions of $\left[\left(\operatorname{Ir}(\mathrm{ppy})_{3}\right)_{3}\left(\mathbf{L 2 0}_{2}\right]\left(\mathrm{BF}_{4}\right)_{3} \quad(\mathbf{C 5})\right.$ and $\left[\left(\operatorname{Ir}(\mathrm{ppy})_{3}\right)_{3}(\mathbf{L 2 1})_{2}\right]\left(\mathrm{BF}_{4}\right)_{3}(\mathbf{C 6}$, Figure 36a). The geometry of $\mathbf{C 5}$ was revealed by $\mathrm{x}$-ray crystallography (Figure 36b). The cage has three pseudo-octahedrally coordinated Ir(III) 
centers, each bearing two ppy ligands and two pyridyl groups from two L20 ligands in a cisarrangements. The two L20 ligands are bridged between three Ir(III) centers, acting as vertices. Interestingly, despite iridium-centred $\Lambda$ - and $\Delta$-enantiomers and the $\mathrm{M}$ and $\mathrm{P}$ enantiomers of the CTV ligands that were present in the reaction mixture, and thus twelve possible stereoisomeric cages, the cage exhibited homochiral self-sorting, and only the enantiomeric $\mathrm{MM}-\Lambda \Lambda \Lambda$ and PP- $\Delta \Delta \Delta$ cages were observed, both in the $\mathrm{x}$-ray structure of $\mathbf{C 5}$ and by NMR in solution after several months, where the self-sorting was found to be very slow. The self-sorting in solution was found to be accelerated by the presence of R-camphor or S-camphor as chiral guests.

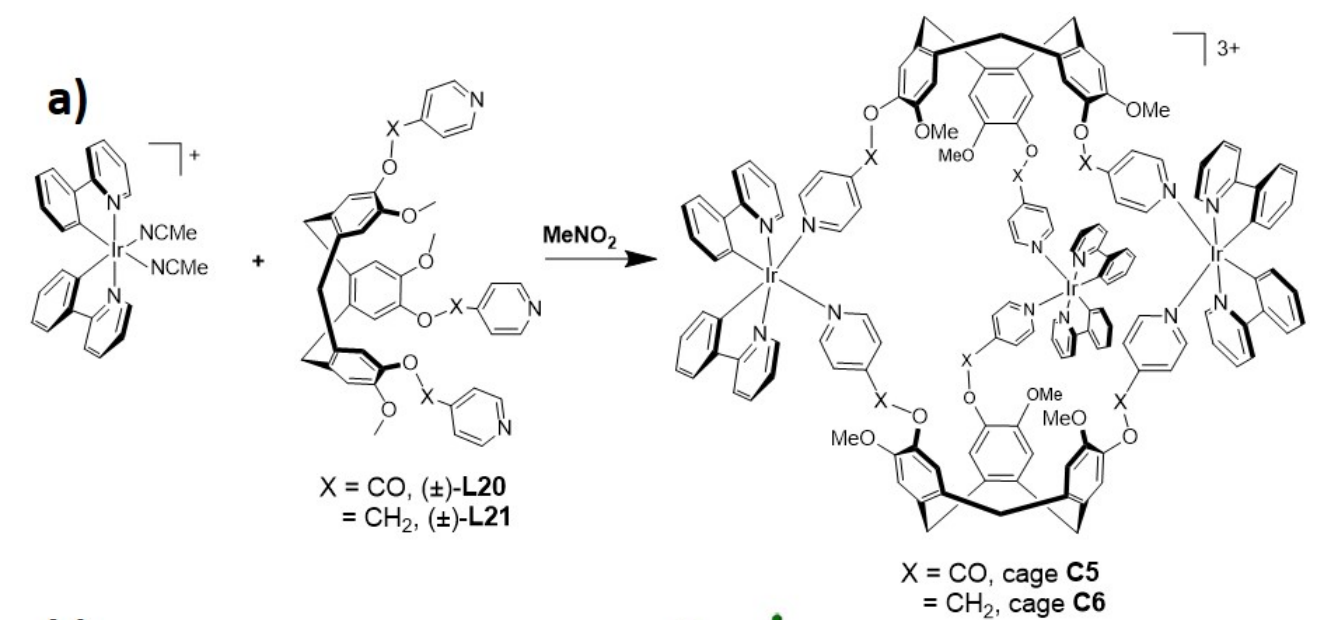

b)

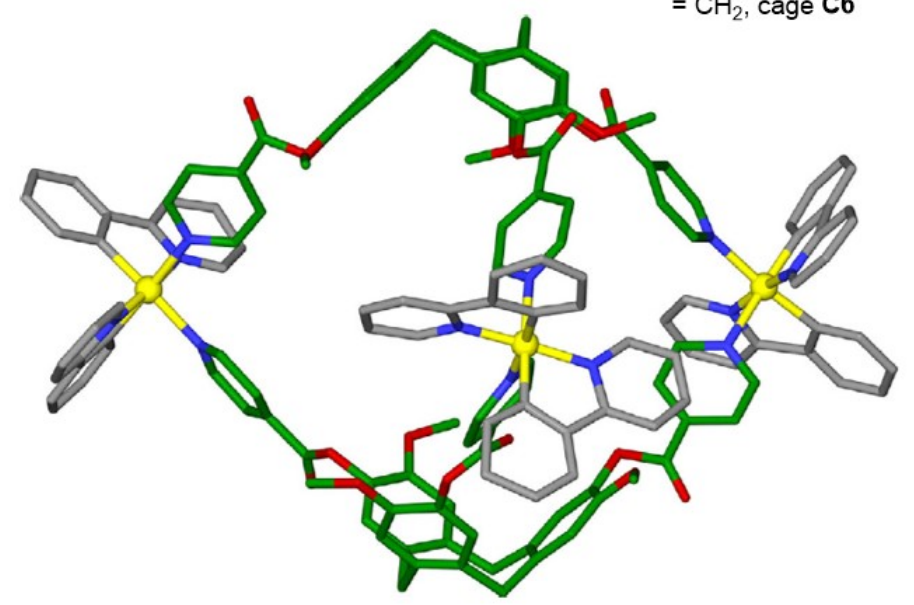

C5

Figure 36. a) Chemicals structures of ligands L20 and L21 and cages C5 and C6. b) X-ray structure of cage C5.[162] 
Cages $\mathbf{C 5}$ and $\mathbf{C 6}$ are emissive in solution, as bulk powders and in PMMA-doped films (Figure 37a,b) (Table 2). The emission of $\mathbf{C 5}$ in the powder was red-shifted $\left(\lambda_{\mathrm{PL}}=648 \mathrm{~nm}\right)$ compared to that in $\operatorname{DCM}\left(\lambda_{\mathrm{PL}}=604 \mathrm{~nm}\right)$. In both media low $\Phi_{\mathrm{PL}}$ of $1 \%$ and short bi-exponential emission decays were observed. Due to the increased conjugation into the CTV scaffold as a result of the carbonyl linker to the distal pyridine, $\mathbf{C 5}$ exhibited red-shifted emission compared to $\mathbf{C 6}$ but with similar though red-shifted photophysical behavior compared to the monomeric $\left[\operatorname{Ir}(\mathrm{ppy})_{2}\left(4-\mathrm{pyCO}_{2} \mathrm{Et}\right)_{2}\right]^{+}\left(4-\mathrm{pyCO} \mathrm{Ct}_{2}=4\right.$-ethyl isonicotinate $)\left(\lambda_{\mathrm{PL}}=560 \mathrm{~nm} ; \Phi_{\mathrm{PL}}=2 \%\right)$. As a result of the reduction of non-radiative vibrational motion in PMMA-doped thin films, the emission of C5 was blue-shifted and more structured at $\lambda_{\mathrm{PL}}=514 \mathrm{~nm}$ with an enhanced emission and longer photoluminescence decays $\left(\Phi_{\mathrm{PL}}=5.5 \%, \tau_{\mathrm{PL}}=634 \mathrm{~ns}, 2319 \mathrm{~ns}\right)$ compared to the emission in DCM. The photoluminescence of $\mathbf{C 6}$ in DCM was found to be structured and blue-shifted at $\lambda_{\mathrm{PL}}=516 \mathrm{~nm}$ with higher $\Phi_{\mathrm{PL}}$ of $15 \%$ and longer $\tau_{\mathrm{PL}}=523,887 \mathrm{~ns}$ compared to C5. Unlike that observed for $\mathbf{C 5}$, the emissions of $\mathbf{C 6}$ as a powder and in PMMA-doped films were similar to that in DCM (in powder: $\lambda_{\mathrm{PL}}=519 \mathrm{~nm}, \Phi_{\mathrm{PL}}=1.6 \%, \tau_{\mathrm{PL}}=141,1175 \mathrm{~ns}$; in thin film: $\left.\lambda_{\mathrm{PL}}=515 \mathrm{~nm}, \Phi_{\mathrm{PL}}=10 \%, \tau_{\mathrm{PL}}=688,3042 \mathrm{~ns}\right)$.
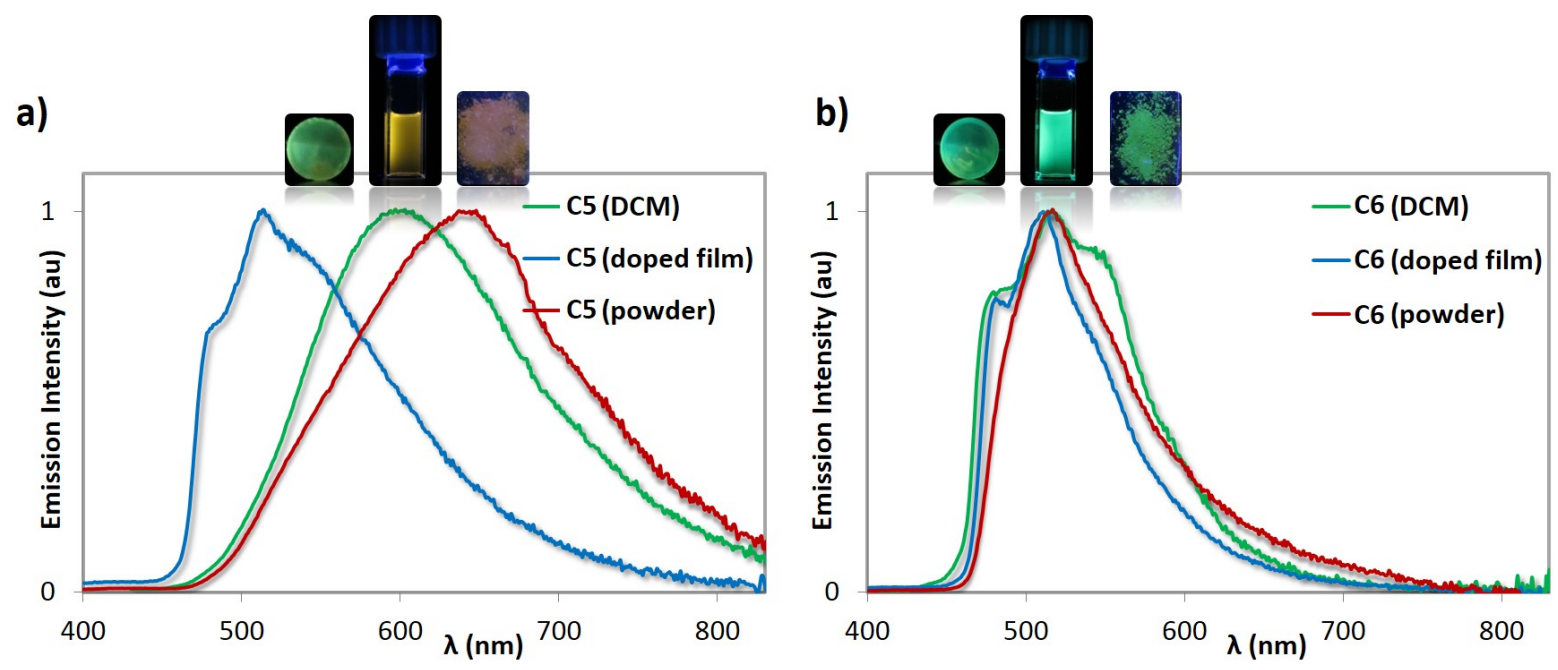

Figure 37. Normalized photoluminescence spectra of a) C5 and b) C6. Green lines are deaerated DCM solutions, light-blue lines are PMMA-doped films with 5wt $\%$ of cages spin- 
coated on a quartz substrate; red lines are bulk powders. Insets are images of the samples under UV irradiation.[162]

By functionalizing the three arms of the CTV core with three bipyridines instead of pyridines as in the preceding example, emissive polynuclear systems composed of cationic $\operatorname{Ir}(\mathrm{III})$ complexes bearing core fragments of $\left[\operatorname{Ir}(\mathrm{ppy})_{2}\right]^{+}$and/or $\left[\operatorname{Ir}(\mathrm{dFppy})_{2}\right]^{+}$coordinated to the CTV through the bpy ligands were also reported (Figure 38).[163] In mixed systems containing both the $\left[\operatorname{Ir}(\text { ppy })_{2}\right]^{+}$and the $\left[\operatorname{Ir}(\mathrm{dFppy})_{2}\right]^{+}$luminescent units linked to a single CTV core, the $\operatorname{Ir}(\mathrm{III})$ chromophores behaved as isolated centers, with no optoelectronic communication between them. This is an unusual behavior for multimetallic $\operatorname{Ir}(\mathrm{III})$-chromophoric complexes, since energy transfer between metal centers is commonly observed.
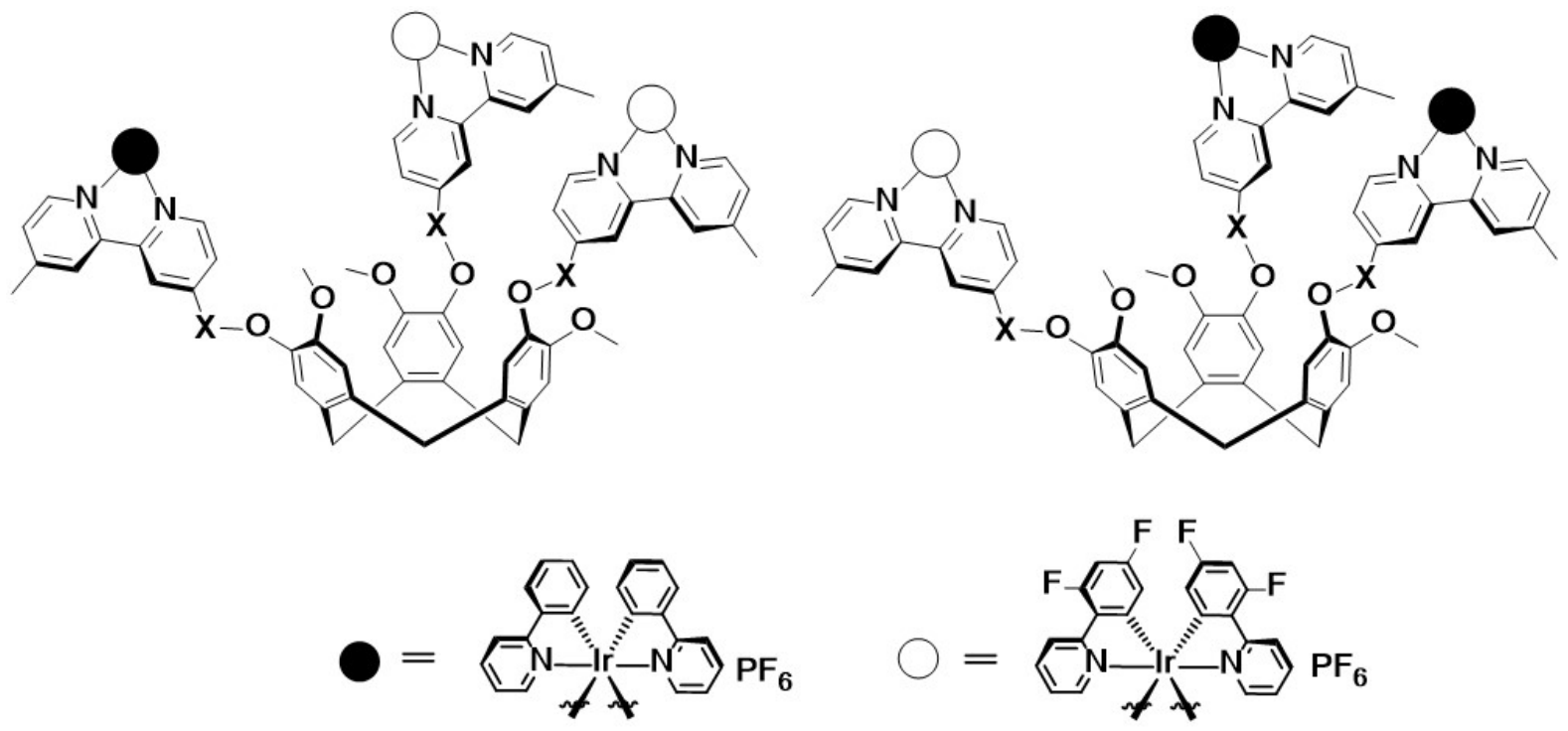

Figure 36. Illustration of the chemical structures of the multimetallic Ir(III)-luminophoric complexes.[163]

Duan and co-workers recently reported the multicomponent self-assembly of two pentanuclears $\operatorname{Ir}(\mathrm{III})-\mathrm{Zn}(\mathrm{II})[164]$ (C7a) and $\operatorname{Ir}(\mathrm{III})-\mathrm{Co}(\mathrm{II})[165]$ (C7b) heterometal-organic polyhedrons. Polyhedron C7a was obtained by the reaction of fac-tris(4-(2pyridinyl)phenylpyridinato)iridium (L22) and 2-formylpyridine, via a subcomponent self- 
assembly in the presence of $\mathrm{Zn}\left(\mathrm{BF}_{4}\right)_{2} \cdot 6 \mathrm{H}_{2} \mathrm{O}$ in acetonitrile under nitrogen (Figure 39a). Similarly, polyhedron C7b was formed by mixing $\mathbf{L 2 2}$ with 2-formylpyridine in the presence of $\mathrm{Co}\left(\mathrm{ClO}_{4}\right) \cdot 6 \mathrm{H}_{2} \mathrm{O}$ in a 2:6:3 ratio in acetonitrile (Figure 40a). Suitable single crystals for $\mathrm{x}-$ ray diffraction of both $\mathbf{C 7 a}$ and $\mathbf{C 7 b}$ were obtained through slow vapor diffusion of diethyl ether into $\mathrm{MeCN}$ solutions of the polyhedrons. X-ray crystallography analyses revealed the formation of discrete cages of composition of $\operatorname{Ir}_{2} \mathrm{M}_{3}$ (where $\mathrm{M}$ is $\mathrm{Zn}$ in $\mathbf{C 7 a}$ and $\mathrm{Co}$ in $\mathbf{C 7 b}$ ) that exhibited a trigonal bipyramidal geometry. In both structures, the three $\mathrm{M}$ atoms form the equatorial plane and the two iridium atoms occupied the axial positions.

a)

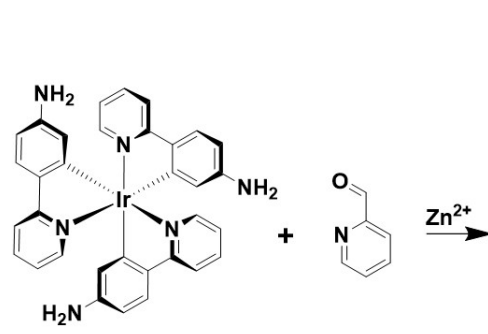

L22

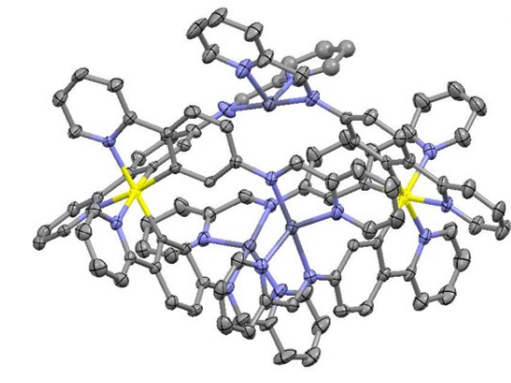

C7a b)

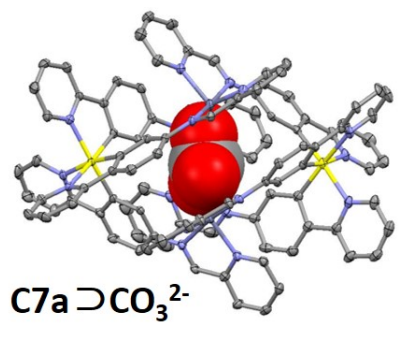

$\mathrm{SO}_{2} / \mathrm{SO}_{3}^{2-}$

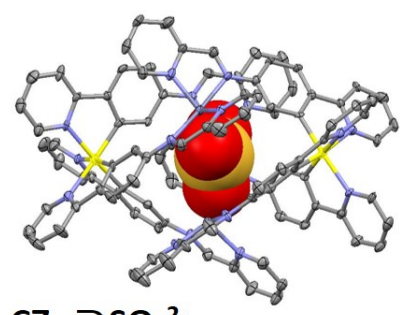

$\mathrm{C} 7 \mathrm{a} \supset \mathrm{SO}_{3}{ }^{2-}$

Figure 39. a) formation of polyhedron C7a from the assembly of $\mathbf{L 2 2}$. b) X-ray structures of C7a encapsulating $\mathrm{CO}_{3}{ }^{2-}$ and $\mathrm{SO}_{3}{ }^{2-}$ shown with space-fill representations.

In Nature, carbon anhydrases (CAs) are common enzymes that contain active $\mathrm{Zn}^{2+}$ sites that are coordinated by three histidine residues and a water or hydroxide molecule and catalyze the reversible hydration of $\mathrm{CO}_{2}$ to $\mathrm{CO}_{3}{ }^{2-}$.[166] Interestingly, $\mathbf{C 7 a}$ exhibits an adequate hydrophobic cavity and coordination geometry around the $\mathrm{Zn}$ atoms to mimic the active site of natural CAs. Vapor diffusion of diethyl ether into a $\mathrm{MeCN}$ solution of $\mathbf{C 7 a}$ under a $\mathrm{CO}_{2}$ atmosphere, yielded single crystals suitable for x-ray diffraction. The crystallographic analyses revealed that $\mathrm{CO}_{2}$ 
was converted into $\mathrm{CO}_{3}{ }^{2-}$ and encapsulated into the cavity of $\mathbf{C 7 a}\left(\mathbf{C 7 a} \supset \mathbf{C O}_{3}{ }^{2-}\right.$, Figure 39b). $\mathbf{C 7 a}_{\mathbf{a}} \mathbf{C O}_{\mathbf{3}}{ }^{2-}$ exhibited the same polyhedral structure as $\mathbf{C 7 a}$ with each of the three $\mathrm{Zn}$ atoms coordinating to one mono-dentate oxygen atom from $\mathrm{CO}_{3}{ }^{2-}$ forming a $\left[\mathrm{Zn}_{3}\left(\mu_{3}-\mathrm{CO}_{3}{ }^{2-}\right)\right]$ core, which was protected inside the cavity of the polyhedron. Similarly, C7a was found to be able to capture $\mathrm{SO}_{2}$ and convert it into $\mathrm{SO}_{3}^{-}$. The x-ray crystal structure of $\mathbf{C 7 a}$ encapsulating $\mathbf{S O}_{\mathbf{3}}{ }^{2-}$ $\left(\mathbf{C 7 a} \supset \mathrm{SO}_{3}{ }^{2-}\right.$, Figure 39b) was also obtained. The formation of the host-guest systems $\mathbf{C 7 a} \supset$ $\mathbf{C O}_{3}{ }^{2-}$ and $\mathbf{C 7 a} \supset \mathrm{SO}_{3}{ }^{2-}$ was observed not only in the solid state but also in MeCN solution by ${ }^{1} \mathrm{H}$ NMR spectroscopy and ESI-MS spectrometry. Emission spectroscopy provided further evidence of the encapsulation of $\mathrm{CO}_{3}{ }^{2-}$ within $\mathbf{C 7 a}$. The weak $\operatorname{Ir}(\mathrm{III})$-centered emission exhibited by C7a at $508 \mathrm{~nm}$ (Table 2) was gradually quenched within 18 minutes as a result of the formation of $\mathbf{C 7 a} \supset \mathbf{C O}_{\mathbf{3}}{ }^{2-}$ upon pumping gaseous $\mathrm{CO}_{2}$ into the $\mathrm{MeCN}$ solution of $\mathbf{C 7 a}$.

When treatment of capsule $\mathbf{C 7 b}$ with one equivalent of carbonate dianions in $\mathrm{MeCN}$ solution, the formation of the host-guest assembly $\mathbf{C 7 b} \supset \mathbf{C O}_{3}{ }^{2-}$ was observed both by x-ray diffraction (Figure 40) and ESI-MS spectrometry. Interestingly, the empty cage $\mathbf{C 7 b}$ was able to convert in high yield (86-96\%) 2-aylpyridines to their $\alpha$-trichloromethylated products when the system was photoirradiated with a $26 \mathrm{~W}$ fluorescent lamp (Figure 40b). However, when $\mathbf{C 7 b} \supset \mathbf{C O}_{\mathbf{3}}{ }^{2-}$ or only the single components $\mathbf{L 2 2}$ or $\mathrm{Co}\left(\mathrm{ClO}_{4}\right) \cdot 6 \mathrm{H}_{2} \mathrm{O}$ were tested as photocatalysts, no conversion was observed (Figure 40c). These results unequivocally demonstrate that in order to photocatalyze the conversion of 2-aylpyridines, it is necessary to combine the photoactivity of the Ir(III) chromophores with the coordinatively unsaturated Co(II) centers. C7b offers a rigid platform to keep the $\operatorname{Ir}(\mathrm{III})$ complexes in close proximity to the $\mathrm{Co}$ (II) metal ions, 
increasing the effective reaction concentration within the local micro-environment, and thus promoting high photoconversion of the substrates.

b)

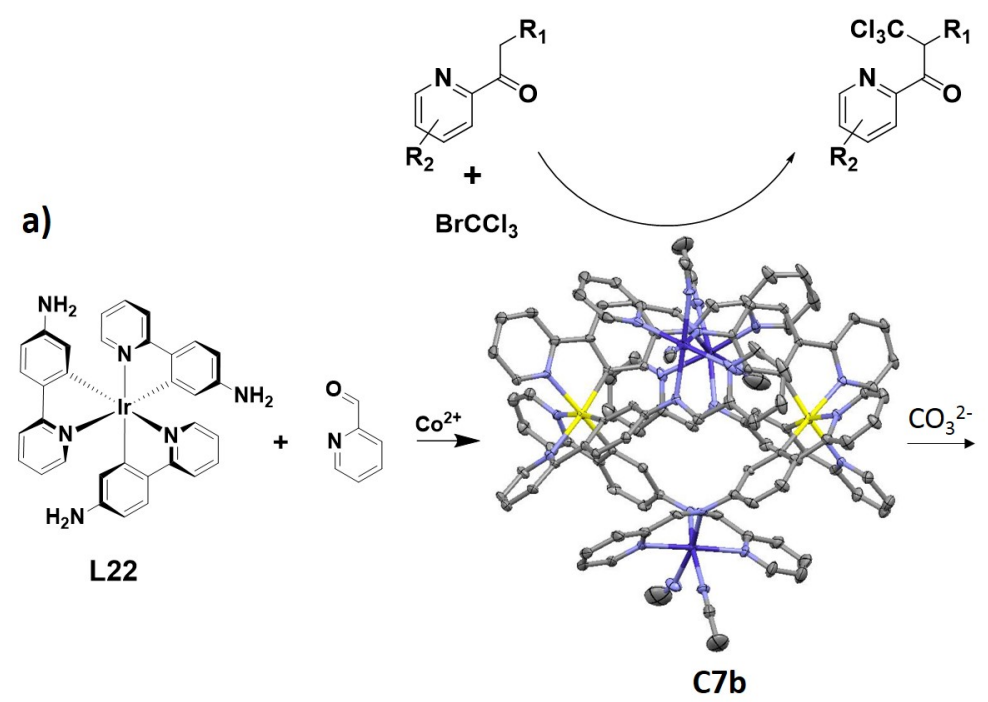

c)
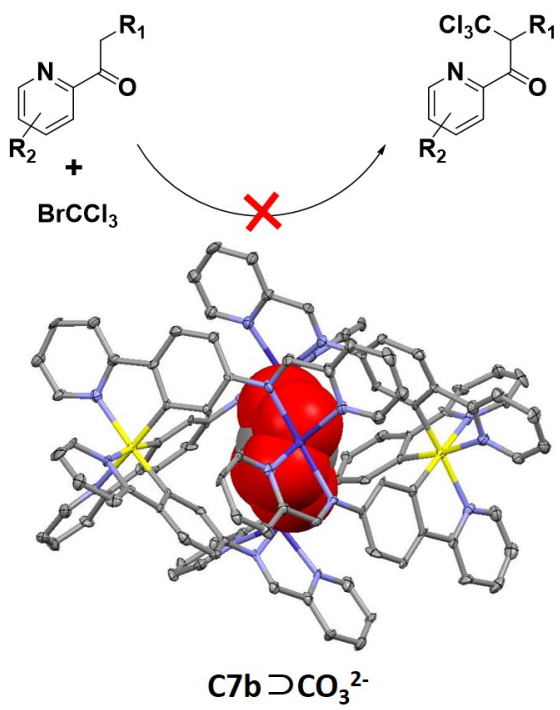

Figure 40. a) Synthesis and x-ray crystal structure of polyhedral C7b. b) illustration of the photocatalyzed $\alpha$-trichloromethylation of acylpyridine promoted by $\mathbf{C 7 b}(1 \mathrm{wt} \%)$. c) no photoreaction occurred when $\mathrm{CO}_{3}^{2-}$ ions was encapsulated into the cavity of $\mathbf{C 7 b}$.

Table 2. Relevant photophysical properties at $298 \mathrm{~K}$ of $\operatorname{Ir}(\mathrm{III})$ metalloligands, capsules, cages and macrocycles

\begin{tabular}{|c|c|c|c|c|c|}
\hline & medium & $\lambda_{\mathrm{PL}}(\mathrm{nm})$ & $\Phi_{P L}(\%)$ & $\tau_{\mathrm{PL}}(\mu \mathrm{s})$ & reference \\
\hline $\mathrm{C2}$ & TCE & 575 & 4 & - & 157 \\
\hline rac-,$\Lambda-, \Delta-\mathrm{C3}$ & DCM, (film) $)^{\mathrm{a}}$ & $655(643)$ & $5(10)$ & $\begin{array}{c}0.20(0.27 \\
0.72)\end{array}$ & 159 \\
\hline$r a c-, \Lambda-, \Delta-C 4$ & DCM, (film) $)^{\mathrm{a}}$ & $561(531)$ & $14(16)$ & $\begin{array}{c}0.83(0.24, \\
1.19)\end{array}$ & 159 \\
\hline C5 & $\begin{array}{l}\text { DCM, (film) }{ }^{\mathrm{a}}, \\
\text { [powder] }\end{array}$ & $\begin{array}{c}604(514) \\
{[648]}\end{array}$ & $\begin{array}{c}1(5.5) \\
{[1.0]}\end{array}$ & $\begin{array}{c}0.06,0.13 \\
(0.63,2.31) \\
{[0.06,0.20]}\end{array}$ & 162 \\
\hline C6 & $\begin{array}{l}\text { DCM, (film) }{ }^{\mathrm{a}} \text {, } \\
\text { [powder] }\end{array}$ & $\begin{array}{c}516(515) \\
{[519]}\end{array}$ & $\begin{array}{c}15(10) \\
{[1.6]}\end{array}$ & $\begin{array}{c}0.52,0.89 \\
(0.69,3.09) \\
{[0.14,1.18]}\end{array}$ & 162 \\
\hline $\mathbf{C 7 a}$ & $\mathrm{MeCN}$ & 508 & - & - & 164 \\
\hline rac-, $\Lambda$-, $\Delta-\mathrm{L} 18$ & DCM, (film) $)^{\mathrm{a}}$ & $620(564)$ & $14(28)$ & $\begin{array}{c}0.30(0.34, \\
1.04)\end{array}$ & 159 \\
\hline rac-, $\Lambda$-, $\Delta$-L19 & DCM, (film) $)^{\mathrm{a}}$ & $527(518)$ & $34(41)$ & $\begin{array}{c}1.00(0.24, \\
1.18)\end{array}$ & 159 \\
\hline M1 & $\mathrm{MeCN}$ & 496,521 & 66 & $0.04,2.32$ & 155 \\
\hline
\end{tabular}




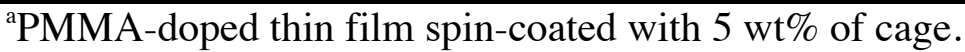

\section{Encapsulation of $\operatorname{Ir}($ III) chromophores}

Several studies have demonstrated that the photophysical properties of luminescent $\operatorname{Ir}(\mathrm{III})$ metal complexes emitting from CT states strongly depend on the local environment.[101, 107, $111,167]$ In this context, the encapsulation of iridium complexes into the cavities of photoactive cages, capsules or MOFs has been demonstrated to be an efficient approach to tuning of the emission properties of the assembly as a function of host-guest energy transfer.

Umakoshi and co-workers[168]. encapsulated $\left[\operatorname{Ir}(\text { ppy })_{2}(\mathrm{bpy})\right] \mathrm{Cl}(\mathbf{L 2 3})$ within a hexameric resorcinarene hydrogen-bonded capsule (Figure 41a) and observed that the capsule provided a hydrophobic environment and also effectively hampered non-radiative decay, thereby inducing a change in the emission of $\mathbf{L 2 3}$ from orange $\left(\lambda_{\mathrm{PL}}=609 \mathrm{~nm}\right)$ to yellow $\left(\lambda_{\mathrm{PL}}=582 \mathrm{~nm}\right)$ while enhancing both the $\Phi_{\mathrm{PL}}$ and the $\tau_{\mathrm{PL}}$ of the encapsulated iridium guest in degassed chloroform (encapsulated L23: $\Phi_{\mathrm{PL}}=32 \%, \tau_{\mathrm{PL}}=860 \mathrm{~ns}$; free L23: $\Phi_{\mathrm{PL}}=20 \%, \tau_{\mathrm{PL}}=420 \mathrm{~ns}$ ) (Figure 41b).

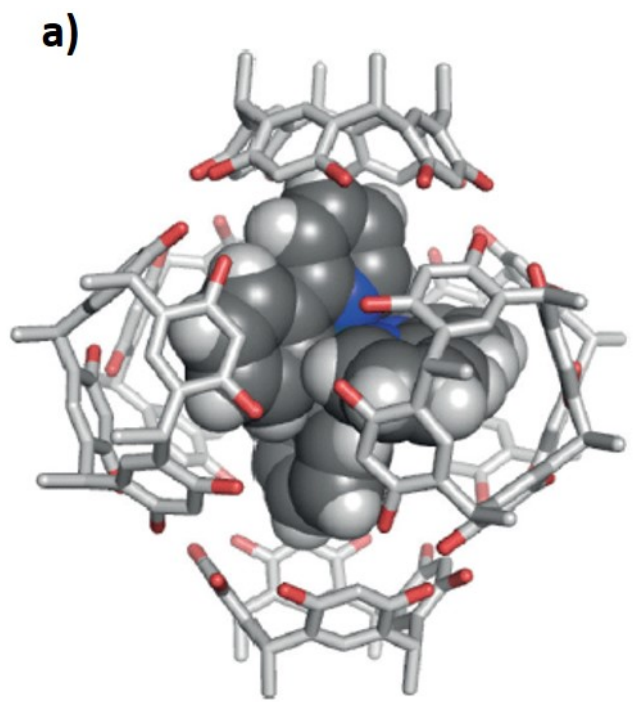

b)

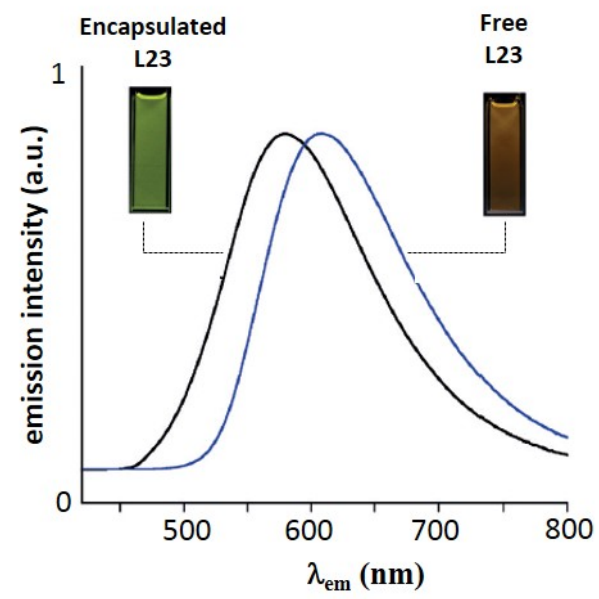


Figure 41. a) Molecular model of the resorcinarene capsule encapsulating L23 (space-fill representation). b) normalized emission spectra of free $\mathbf{L 2 3}$ (blue line) and encapsulated L23 (black line) collected at $298 \mathrm{~K}$ in $\mathrm{CHCl}_{3}\left(\lambda_{\text {exc }}=400 \mathrm{~nm}\right)$. Image b) is adapted with permission. Copyright 2016, Wiley-VCH.[168]

Similarly, the emission of the $\operatorname{Ir}(\mathrm{III})$ complex $\left[\operatorname{Ir}(\mathrm{ppy}-\mathrm{CHO})_{2}(\mathrm{bpy})\right]^{+}(\mathbf{L} \mathbf{2 4}$, where ppy-CHO is 4-(2-pyridylbenzaldehyde), Figure 42a) was remarkably enhanced and blue-shifted upon its encapsulation into the cavity of the cucurbituril [Q10] host (Figure 42b,c).[169] Indeed, in aqueous buffer solution ( $\mathrm{pH} 4.7$ ), complex $\mathbf{L 2 4}$ exhibited a weak emission at $593 \mathrm{~nm}$, which was enhanced 80-fold and blue-shifted to $543 \mathrm{~nm}$ after its encapsulation (Figure 42b). The temperature had a strong effect on the binding equilibrium; at $40{ }^{\circ} \mathrm{C}$ the host-guest assembly was found to be partially dissociated and thus its emission intensity and emission lifetime were, respectively, lower and shorter compared to those collected at $6{ }^{\circ} \mathrm{C}$ (at $40{ }^{\circ} \mathrm{C}: \tau_{\mathrm{PL}}=100,1750$ $\mathrm{ns} ;$ at $\left.6{ }^{\circ} \mathrm{C}: \tau_{\mathrm{PL}}=230,3260 \mathrm{~ns}\right)$.

a)

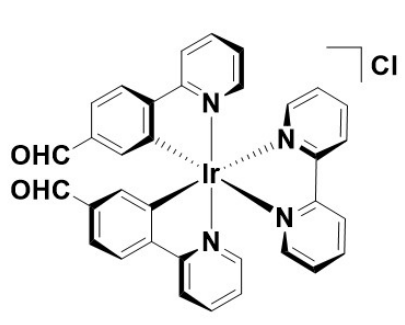

L24 b)

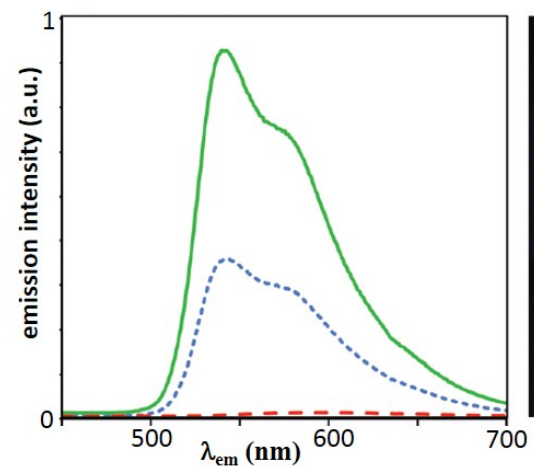

c)
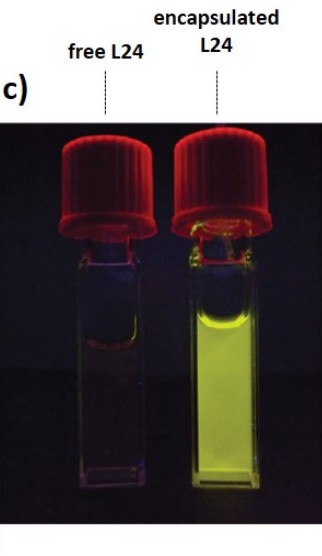

Figure 42. a) chemical structure of L24. b) Emission spectra in aqueous buffer solution ( $\mathrm{pH}$ 4.7) at $22{ }^{\circ} \mathrm{C}$ of $\mathbf{L 2 4}$ (dashed red line), with added [Q10] in 1:1 molar ratio (dotted blue line) and with excess of [Q10] (solid green line). c) Emission from free L24 (left) and L24 
encapsulated into [Q10] host (right). Adapted from Ref. [169] with permission from The Royal Society of Chemistry.

The introduction of $\operatorname{Ir}(\mathrm{III})$ luminophores into the nanospace of inorganic host materials have also been explored. Wada and co-workers[170] introduced mixtures of the homoleptic $f a c$ - and $m e r-\left[\operatorname{Ir}(\mathrm{ppy})_{3}\right](\mathbf{L 2 5})$ and $f a c$ - and $m e r-\left[\operatorname{Ir}(\mathrm{dFppy})_{3}\right](\mathbf{L 2 6})$, into the cavity of a zeolite (Figure 43). Depending on the Ir(III) species introduced into the zeolite, different emission colours were observed from the solid materials. Structured blue emission at $\lambda_{\mathrm{PL}}=465,488 \mathrm{~nm}$ was observed when $\mathbf{L 2 6}$ was encapsulated, while green emission at $\lambda_{\mathrm{PL}}=524 \mathrm{~nm}$ was observed from the zeolite encapsulating L25 (Figure 43). These emission profiles were consistent with those exhibited by the free complexes $\mathbf{L 2 5}\left(\lambda_{\mathrm{PL}}=510 \mathrm{~nm}\right)$ and $\mathbf{L 2 6}\left(\lambda_{\mathrm{PL}}=468,482 \mathrm{~nm}\right)$ in $\mathrm{MeCN}$.

a)
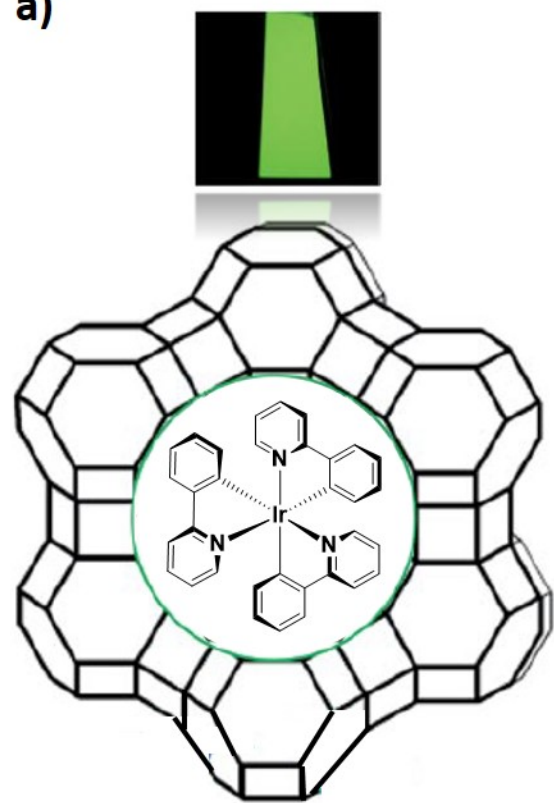

b)
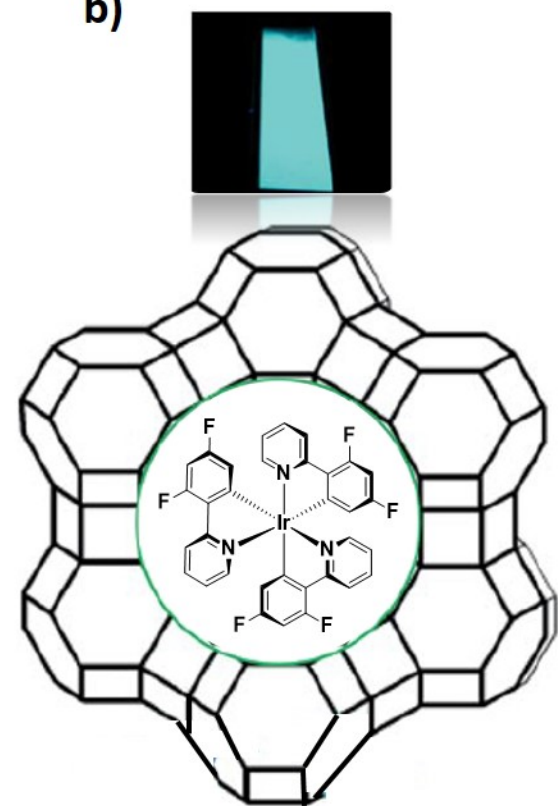
Figure 43. Illustration of the encapsulation of the $\operatorname{Ir}(\mathrm{III})$ chromophores $\left[\operatorname{Ir}(\mathrm{ppy})_{3}\right]$, a) and $\left.\left[\operatorname{Ir}(\mathrm{dFppy})_{3}\right], \mathbf{b}\right)$ into the cavity of the zeolite cage. Insets are images of their emission colours. Adapted with permission. Copyright 2012, Wiley-VCH.[170]

In a subsequent work, the same group investigated the photoinduced electron transfer (PeT) processes from L25 つZeolite to propyl viologen sulfonate (PVS) in solution by using 1,1'ethylene-2,2'-bipyridilynium $\left(2 \mathrm{DQ}^{2+}\right)$, also incorporated into the zeolite cage, as an electronrelay molecule.[171] Their results demonstrated that upon photoirradiation, electron transfer from $\mathbf{L 2 5}$ to $2 \mathrm{DQ}^{2+}$ occurred in the zeolite framework, forming the $2 \mathrm{DQ}{ }^{+}$radical cation and the $\mathbf{L 2 5}^{-}$radical anion. 2DQ + ${ }^{+}$transferred subsequently the electron to PVS is solution through a dark reaction, forming the PVS - radical anion. The regeneration of $\mathbf{L 2 5}$ in its ground state was achieved through the addition of triethanolamine as a sacrificial reductant. The encapsulation of both $\mathbf{L 2 5}$ and 2DQ ${ }^{+}$in the cavity of the zeolite was found to be pivotal for promoting the PeT. Indeed, when the free species L25, $2 \mathrm{DQ}^{2+}$ and PVS were irradiated in solution, no PeT was observed.

A Periodic Mesoporous Organosilica derivative (PMO) bearing high density of the homoleptic $\operatorname{Ir}(\mathrm{III})$ complex $\left[\operatorname{Ir}(\mathrm{ppy})_{3}\right](\mathbf{4 b}$ in Figure $\mathbf{2})$ on the pore surface was investigated by Inagaki and co-workers.[167, 172] The PMO material was prepared by the polycondensation reaction between the ppy-bridge alkoxysilane precursor, 2-(4-triethoxysilylphenyl)-5triethoxysilylpyridine and the cationic surfactant octadecyltrimethylammonium chloride $\left(\mathrm{C}_{18} \mathrm{TMACl}\right)$. The subsequent cyclometalation reaction of $\left[\operatorname{Ir}(\mathrm{ppy})_{2} \mathrm{Cl}\right]_{2}$ with the ppy ligands of 
PMO in an ethylene glycol solution in the presence of $\mathrm{K}_{2} \mathrm{CO}_{3}$ at $120{ }^{\circ} \mathrm{C}$ for $24 \mathrm{~h}$ yielded the PMO material with the $\operatorname{Ir}(\mathrm{III})$ complex $\left[\operatorname{Ir}(\mathrm{ppy})_{3}\right]$ included in its pores (Ir-PMO). Ir-PMO exhibited a broad phosphorescence at $\lambda_{\mathrm{PL}}=550 \mathrm{~nm}$ with a $\Phi_{\mathrm{PL}}$ of $3 \%$ and a bi-exponential emission lifetime of $\tau_{\mathrm{PL}}=250 \mathrm{~ns}, 1000 \mathrm{~ns}$. These emission properties are characteristic for the meridional isomer mer-[ $\left.\operatorname{Ir}(\mathrm{ppy})_{3}\right]$, which is typically formed when cyclometalation reactions are conducted at relatively low temperature $\left(<140{ }^{\circ} \mathrm{C}\right)$.[173] Ir-PMO also acted as a lightharvesting antennae as the energy absorbed by the PMO framework upon photoexcitation at $300 \mathrm{~nm}$ was efficiently transferred to the Ir(III) complex following a Förster mechanism. Indeed, the emission of mer-[Ir(ppy $\left.)_{3}\right]$ in Ir-PMO was enhanced when excited at $300 \mathrm{~nm}$ (instead of at $380 \mathrm{~nm}$ ) and the characteristic emission of the PMO framework at $\lambda_{\mathrm{PL}}=420 \mathrm{~nm}$ was completely quenched.

The phosphorescence properties of PMO derivatives functionalized with the heteroleptic $\operatorname{Ir}(\mathrm{III})$ complex $\left[\operatorname{Ir}(\mathrm{ppy})_{2}(\mathrm{bpy}] \mathrm{Cl}\right.$ (4b, Figure 2) were also investigated.[174] Depending on the amount of $\mathbf{4 b}$ loaded into the pores of the PMO, the emission properties of $\mathbf{4 b}-\mathrm{PMO}$ in the solid state were found to differ only slightly. With a low, medium and high $\mathbf{4 b}$ loading, respectively, of $3.47 \mu \mathrm{mol} \mathrm{g} \mathrm{g}^{-1}, 20.4 \mu \mathrm{mol} \mathrm{g} \mathrm{g}^{-1}$ and $59.9 \mu \mathrm{mol} \mathrm{g} \mathrm{g}^{-1}$, 4b-PMO exhibited broad emission, respectively, at $\lambda_{\mathrm{PL}}=527 \mathrm{~nm}, \lambda_{\mathrm{PL}}=530 \mathrm{~nm}$ and $\lambda_{\mathrm{PL}}=535 \mathrm{~nm}$ with $\Phi_{\mathrm{PL}}$ of $13 \%, 14 \%$ and $13 \%$ and $\tau_{\mathrm{PL}}$ of $405 \mathrm{~ns}, 462 \mathrm{~ns}$ and $438 \mathrm{~ns}$. In MeCN the emission of $\mathbf{4 b}$-PMO was red-shifted at $\lambda_{\mathrm{PL}}$ $=560 \mathrm{~nm}$ with $\Phi_{\mathrm{PL}}$ of $7.0 \%$ and $\tau_{\mathrm{PL}}$ of $784 \mathrm{~ns}$. When a MeCN solution of tetracene was gradually added (from 0 to $0.4 \mathrm{mM}$ ) to a $\mathrm{MeCN}$ solution of $\mathbf{4 b}-\mathrm{PMO}$, the emission intensity of $\mathbf{4 b}$-PMO at $\lambda_{\mathrm{PL}}=527 \mathrm{~nm}$ was correspondingly quenched together with a shortenning of its emission lifetime from 784 ns to 107 ns. Förster energy transfer was therefore promoted from $\mathbf{4 b}$-PMO donor to the tetracene acceptor upon photoexcitation at $340 \mathrm{~nm}$. 
By encapsulating the yellow-emitting $\left[\operatorname{Ir}(\mathrm{ppy})_{2}(\mathrm{bpy})\right] \mathrm{PF}_{6}(\mathbf{L 2 7})$ chromophore into the cavities of the blue-emitting fluorescent MOF $\left[\left(\mathrm{CH}_{3}\right)_{2} \mathrm{NH}_{2}\right]_{15}\left[\left(\mathrm{Cd}_{2} \mathrm{Cl}\right)_{3}(\mathrm{TATPT})_{4}\right] \cdot 12 \mathrm{DMF} \cdot 18 \mathrm{H}_{2} \mathrm{O}$ (MOF-H, TATPT is a hexadentate carboxylate triazine ligand, 2,4,6-tris(2,5-dicarboxyphenylamino)-1,3,5-triazine), an efficient white-emitting assembly was obtained as reported by Li and co-workers.[175] The $\operatorname{Ir}(\mathrm{III})$ complex L27 exhibited an adequate molecular size of approximately of $10 \times 11 \AA^{2}$ to be encapsulated into the aperture of the pore windows of MOF-H $\left(11 \times 11 \AA^{2}\right)$. L27 showed a broad emission at $\lambda_{\mathrm{PL}}=570 \mathrm{~nm}$ in degassed DMF, while MOF-H exhibited bright blue emission at $\lambda_{\mathrm{PL}}=425 \mathrm{~nm}$ attributed to the emissive TATPT linker. When complex $\mathbf{L 2 7}$ was loaded into the pores of MOF-H at various concentrations from $0.52 \mathrm{wt} \%$ to $8.8 \mathrm{wt} \%$, the hostguest MOF-H $\supset \mathbf{L 2 7}$ exhibited two emission maxima with various intensities at $\lambda_{\mathrm{PL}}=425 \mathrm{~nm}$ and $\lambda_{\mathrm{PL}}=530 \mathrm{~nm}$ (Figure 44a), attributed, respectively, to the emissions of MOF-H and L27 without energy transfer between the two. Due to the rigid confinement of $\mathbf{L 2 7}$ into the cavities of MOF-H, the emission of L27 in MOF-H $2 \mathbf{L 2 7}$ was blue-shifted by ca. $40 \mathrm{~nm}$ compared to that observed for the free complex in solution. Interestingly, at a concentration of $3.5 \mathrm{wt} \%$ of L27, MOF-HつL27 exhibited pure white light emission with a high $\Phi_{\mathrm{PL}}$ of $20.4 \%$ corresponding to CIE coordinates of x: 0.31, y: 0.33 (Figure 44b,c). A WOLED (white organiclight emitting diode) of CIE coordinates of $\mathrm{x}$ : 0.30, y: 0.35 using this material and an InGaAsN ultraviolet chip were both successfully fabricated. 
a)

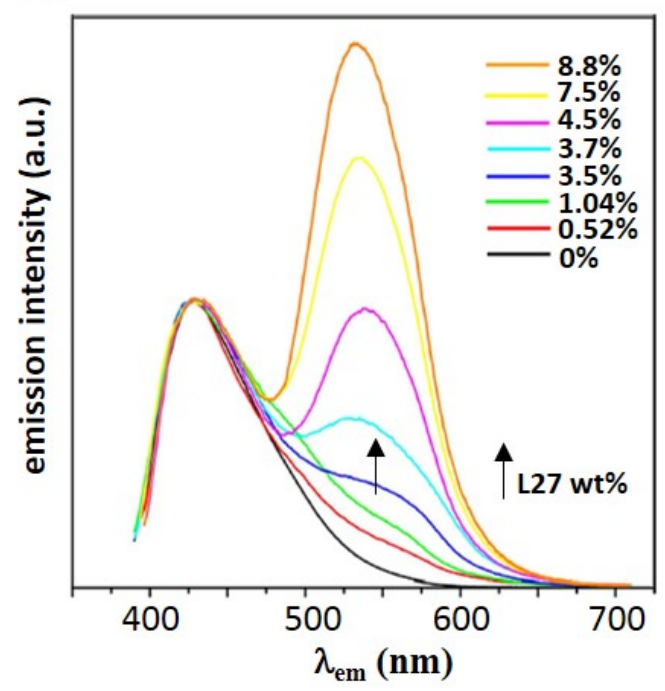

b)

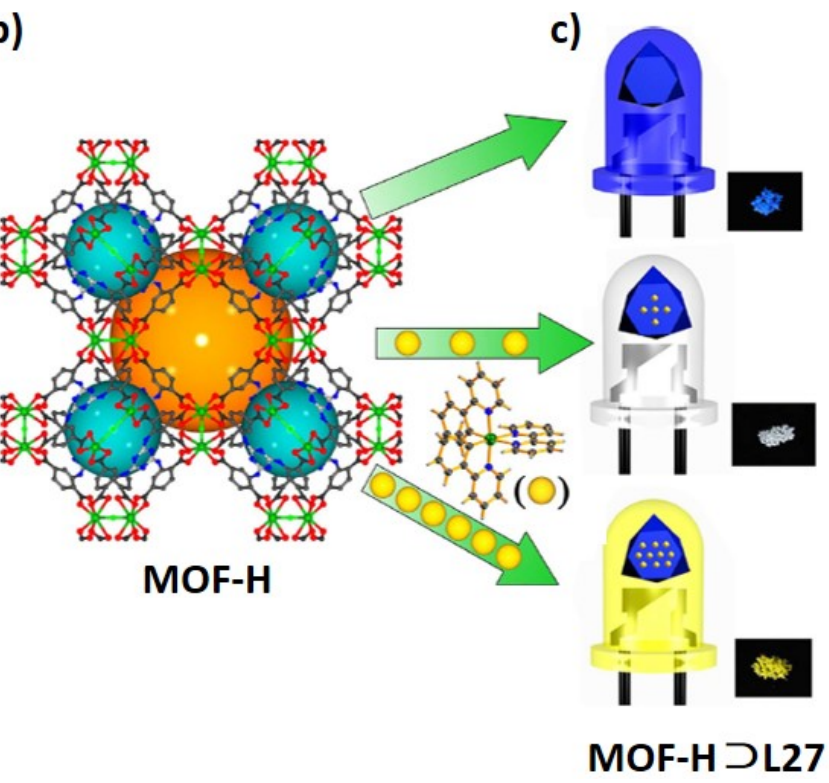

Figure 44. a) Emission spectra of MOF-H and MOF-H $\supset$ L27 with different concentrations of $\mathbf{L 2 7}$ (from $0.52 \mathrm{wt} \%$ to $8.8 \mathrm{wt} \%, \lambda_{\text {ect }}=370 \mathrm{~nm}, 298 \mathrm{~K}$ ); b) ball and stick representation of the 3D structure of MOF-H (orange and cyan spheres represent the void spaces); c) illustration of the blue, white and yellow emissions exhibited by MOF-HつL27 with a concentration of L27 respectively of 0\%, 3.5\% and $8.8 \mathrm{wt} \%$. Adapted from Ref. [175], Springer Nature.

The red-emitting cage $\mathbf{C 3}$ (Figure 35a,b) we recently reported exhibited a diameter of approximately $18.8 \AA$ (corresponding to the Pd $\cdots$ Pd distance) with an internal pocket volume of approximately $3480 \AA^{3}$, which was of sufficient size to include mononuclear Ir(III) complexes.[159] We thus targeted the encapsulation of the anionic blue-emitting $\mathrm{NBu}_{4}\left[\operatorname{Ir}(\mathrm{dFppy})_{2}(\mathrm{CN})_{2}\right]$ complex (L28) to study the nature of the energy transfer between the donor blue-emitting guest and the acceptor red-emitting cage $\mathbf{C 3}$ (Figure 45).[159] ${ }^{1} \mathrm{H},{ }^{1} \mathrm{H}$ DOSY and ${ }^{19} \mathrm{~F}$ NMR investigations along with computational calculations revealed a strong binding of $\mathbf{L 2 8}$ within the cavity of $\mathbf{C 3}$ in $\mathbf{C 3} \supset \mathbf{L} 28$ with an association constant $K$ of $3.9 \times 10^{6}$ $\pm 0.2 \mathrm{M}^{-1}$. 

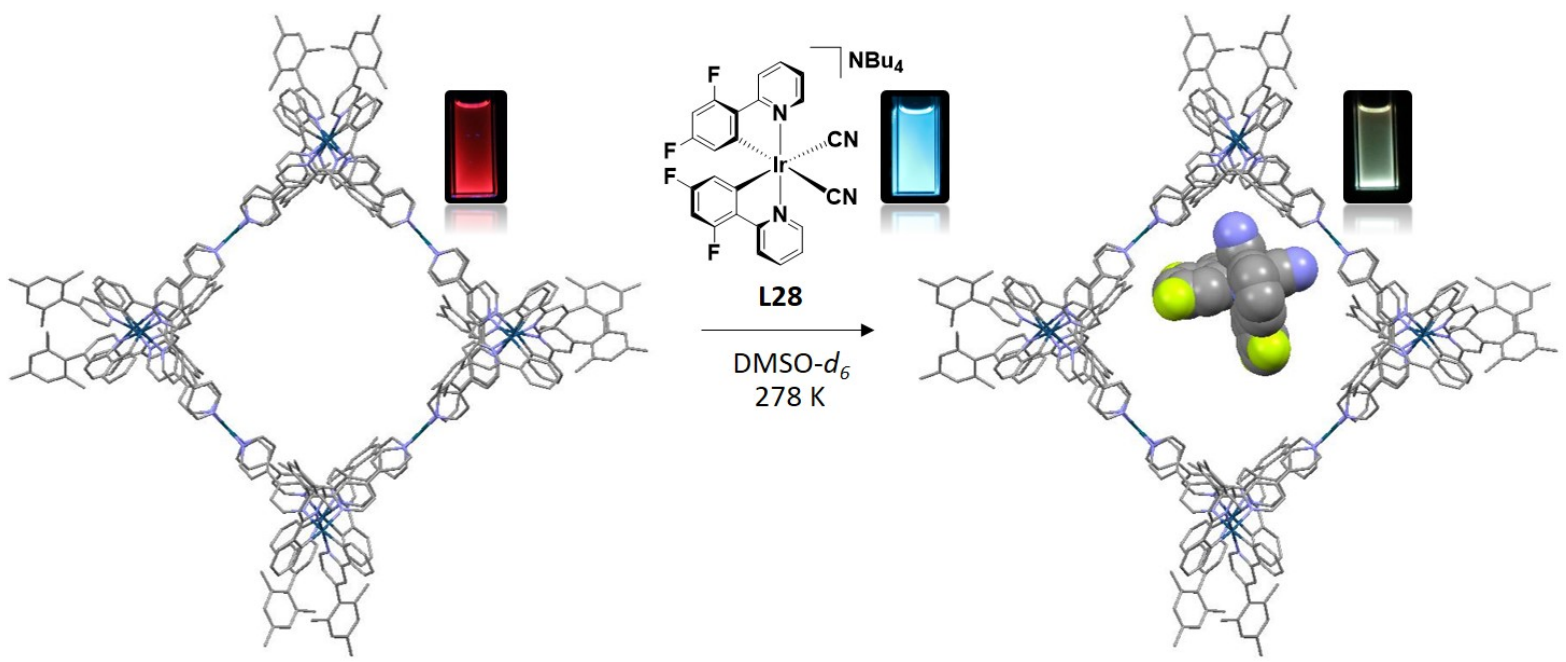

Figure 45. Illustration of encapsulation of $\mathbf{L 2 8}$ (space-fill representation) within the cavity of C3. The HF/6-31G(d) optimized host-guest structure C3 $\supset \mathbf{L 2 8}$ is shown. Insets are the emissions of the species under UV irradiation.[159]

The anionic complex $\mathbf{L 2 8}$ exhibited a blue ${ }^{3} \mathrm{LC}$ emission in DMSO, with two maxima at 458 and $483 \mathrm{~nm}$ and a shoulder at $515 \mathrm{~nm}$ (blue line in Figure 46a), a $\Phi_{\mathrm{PL}}$ of $52 \%$, and a $\tau_{\mathrm{PL}}$ of 2915 ns. Titration of cage $\mathbf{C 3}$ (from 0 to $120 \mu \mathrm{M}$ ) into a $100 \mu \mathrm{M}$ degassed DMSO solution of $\mathbf{L 2 8}$ at $298 \mathrm{~K}$ resulted in a gradual quenching of the blue emission of the donor $\mathbf{L} \mathbf{2 8}$ together with a gradual enhancement of the emission of the red-emitting cage at $666 \mathrm{~nm}$, with an isosbestic point observed at $565 \mathrm{~nm}$ (Figure 46a). Upon photoexcitation of C3 つL28 at $360 \mathrm{~nm}$, Dexter energy transfer from the blue-emitting $\mathbf{L} 28$ to the red-emitting $\mathbf{C 3}$ was therefore promoted. 

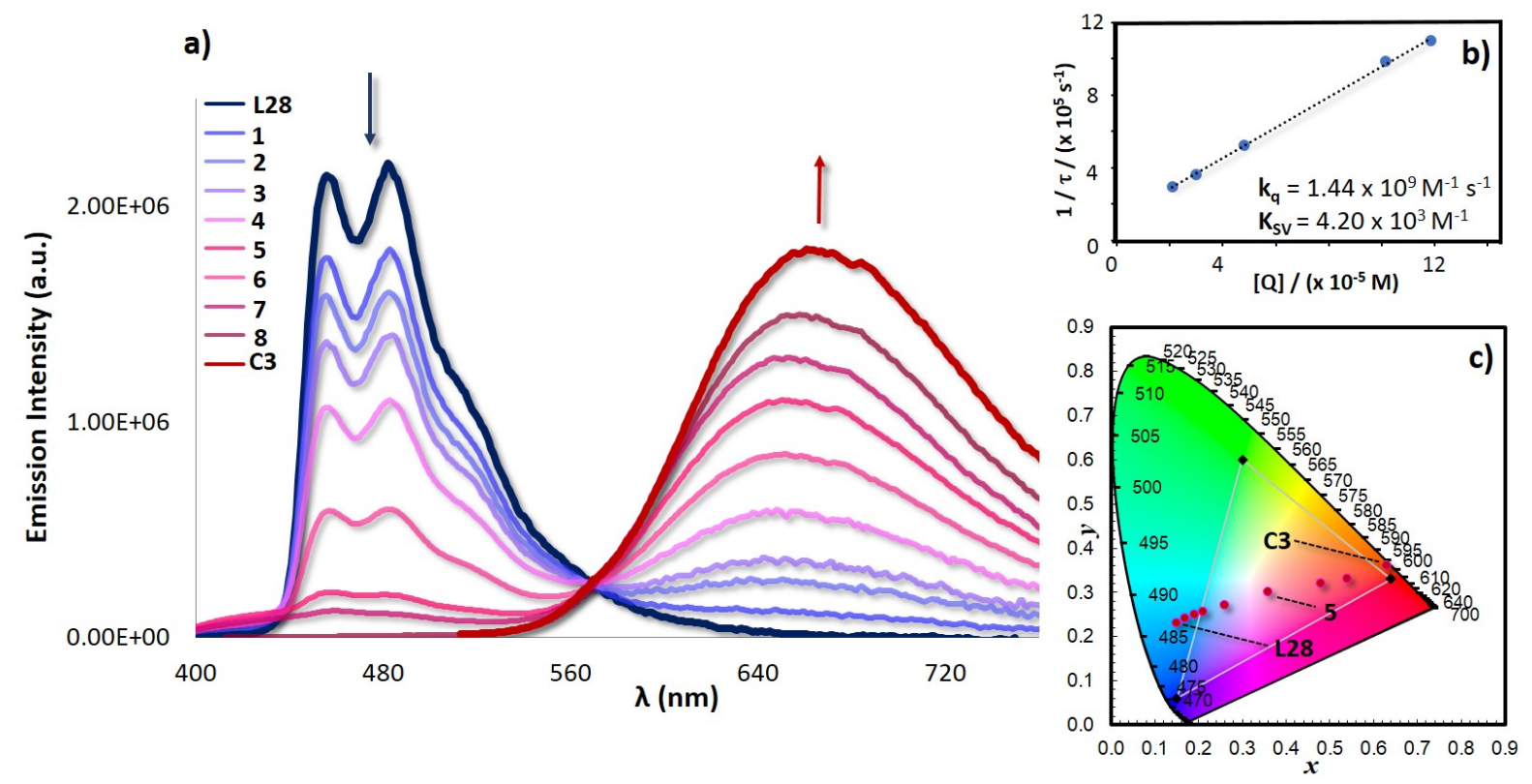

Figure 46. a) Emission titrations of $\mathbf{C 3}$ into a $100 \mu \mathrm{M}$ solution of $\mathbf{L 2 8}$ at $298 \mathrm{~K}$ in degassed DMSO; b) Stern-Volmer plot of the quenching study between L28 and C3; c) CIE diagram indicating the change of emission colors during the emission titration.[159]

Stern-Volmer analysis (Figure 46b) demonstrated that the energy transfer/quenching process in $\mathbf{C 3} \supset \mathbf{L 2 8}$ was very efficient with a calculated quenching rate constant $\left(\mathrm{k}_{\mathrm{q}}\right)$ of $1.44 \times 10^{9} \mathrm{M}^{-}$ ${ }^{1} \mathrm{~S}^{-1}$ and a Stern-Volmer constant $\left(\mathrm{K}_{\mathrm{SV}}\right)$ of $4.20 \times 10^{3} \mathrm{M}^{-1}$. The CIE diagram shown in Figure 46c illustrates the change in the emission colors observed during the emission titration. Titration 5 (Figure 46c) shows CIE coordinates of $(0.36,0.30)$, which are close to coordinates of pure white light (x: 0.31, y: 0.33).

\section{Conclusions}

The self-assembly of $\operatorname{Ir}(\mathrm{III})$ luminophores into supramolecular materials clearly offers possibilities for tuning the physical and optoelectronic properties of $\operatorname{Ir}(\mathrm{III})$ complexes and opens up opportunities for exploiting these materials in many applications, ranging from 
catalysis to electroluminescent devices. Iridium-based soft materials generally exhibit highly organized structures with enhanced emission when compared to their mononuclear counterparts. Three-dimensional iridium-based polymers and MOFs are still in their infancy. However, it appears clear that the combination of the luminescent properties of $\operatorname{Ir}(\mathrm{III})$ chromophores and the large channel sizes exhibited by these classes of porous materials is of great interest for sensing and for solar-driven chemical transformations. Photoactive coordination cages and capsules incorporating Ir(III) chromophores are promising candidates as photoactive containers capable of photophysically interacting with guest molecules. On the other hand, stability, ligand design and control of the luminescent properties of the materials in the solid state are the major challenges to meet in order to expand the use and number of supramolecular Ir(III) assemblies. The relatively small number of examples included in this review article shows, however, that the field is relatively new, with most of the articles published only in the last decade. However, given the demonstrated functionality of these systems, their importance is sure to grow rapidly.

Acknowledgements. EZ-C acknowledges the University of St Andrews for financial support and the Engineering and Physical Sciences Research Council for financial support (EP/M02105X/1).

\section{References}

[1] D. Philp, J.F. Stoddart, Angew. Chem. Int. Ed. Engl., 35 (1996) 1154-1196.

[2] J.M. Grimes, J.N. Burroughs, P. Gouet, J.M. Diprose, R. Malby, S. Zientara, P.P.C. Mertens, D.I. Stuart, Nature, 395 (1998) 470-478.

[3] A.W. Roszak, T.D. Howard, J. Southall, A.T. Gardiner, C.J. Law, N.W. Isaacs, R.J. Cogdell, Science, 302 (2003) 1969-1972. 
[4] L. Yang, A. Liu, S. Cao, R.M. Putri, P. Jonkheijm, J.J.L.M. Cornelissen, Chem. Eur. J., 22 (2016) 15570-15582.

[5] G.M. Whitesides, B. Grzybowski, Science, 295 (2002) 2418-2421.

[6] W.R. Wikoff, L. Liljas, R.L. Duda, H. Tsuruta, R.W. Hendrix, J.E. Johnson, Science, 289 (2000) 2129-2133.

[7] G. McDermott, S.M. Prince, A.A. Freer, A.M. Hawthornthwaite-Lawless, M.Z. Papiz, R.J. Cogdell, N.W. Isaacs, Nature, 374 (1995) 517-521.

[8] S. Bahatyrova, R.N. Frese, C.A. Siebert, J.D. Olsen, K.O. van der Werf, R. van Grondelle, R.A. Niederman, P.A. Bullough, C. Otto, C.N. Hunter, Nature, 430 (2004) 1058-1062.

[9] K. Goossens, K. Lava, C.W. Bielawski, K. Binnemans, Chem Rev, 116 (2016) 4643-4807. [10] T. Wohrle, I. Wurzbach, J. Kirres, A. Kostidou, N. Kapernaum, J. Litterscheidt, J.C. Haenle, P. Staffeld, A. Baro, F. Giesselmann, S. Laschat, Chem Rev, 116 (2016) 1139-1241. [11] D. Kim, S. Cheong, Y.G. Ahn, S.W. Ryu, J.K. Kim, J. Cho, Nanoscale, 8 (2016) 70007016.

[12] P.-P. Yang, X.-X. Zhao, A.-P. Xu, L. Wang, H. Wang, J. Mater. Chem. B, 4 (2016) 26622668.

[13] S.S. Babu, V.K. Praveen, A. Ajayaghosh, Chem Rev, 114 (2014) 1973-2129.

[14] Z. Qi, C.A. Schalley, Acc Chem Res, 47 (2014) 2222-2233.

[15] A. Winter, U.S. Schubert, Chem Soc Rev, 45 (2016) 5311-5357.

[16] L. Yang, X. Tan, Z. Wang, X. Zhang, Chem Rev, 115 (2015) 7196-7239.

[17] M.C. Das, S. Xiang, Z. Zhang, B. Chen, Angew Chem Int Ed Engl, 50 (2011) 1051010520.

[18] D. Fujita, Y. Ueda, S. Sato, N. Mizuno, T. Kumasaka, M. Fujita, Nature, 540 (2016) $563-$ 566.

[19] D. Fujita, H. Yokoyama, Y. Ueda, S. Sato, M. Fujita, Angew Chem Int Ed Engl, 54 (2015) 155-158.

[20] H.K. Bisoyi, Q. Li, Acc Chem Res, 47 (2014) 3184-3195.

[21] M. Antonietti, C. Göltner, Angew. Chem. Int. Ed. Engl., 36 (1997) 910-928.

[22] C.F. Faul, Acc Chem Res, 47 (2014) 3428-3438.

[23] E. Caló, V.V. Khutoryanskiy, Eur. Polym. J., 65 (2015) 252-267.

[24] A.S. Hoffman, Advanced Drug Delivery Reviews, 64 (2012) 18-23.

[25] V.K. Thakur, M.R. Kessler, Polymer, 69 (2015) 369-383.

[26] L. Sun, M.G. Campbell, M. Dinca, Angew Chem Int Ed Engl, 55 (2016) 3566-3579.

[27] J.-L. Wang, C. Wang, W. Lin, ACS Catalysis, 2 (2012) 2630-2640.

[28] T.H. Noh, O.-S. Jung, Acc. Chem. Res., 49 (2016) 1835-1843.

[29] Z. Hu, B.J. Deibert, J. Li, Chem Soc Rev, 43 (2014) 5815-5840.

[30] L. Xu, Y.X. Wang, H.B. Yang, Dalton Trans, 44 (2015) 867-890.

[31] M.W. Cooke, D. Chartrand, G.S. Hanan, Coord. Chem. Rev., 252 (2008) 903-921.

[32] S. Durot, J. Taesch, V. Heitz, Chem Rev, 114 (2014) 8542-8578.

[33] D.B. Amabilino, D.K. Smith, J.W. Steed, Chem Soc Rev, 46 (2017) 2404-2420.

[34] H. Xu, R. Chen, Q. Sun, W. Lai, Q. Su, W. Huang, X. Liu, Chem. Soc. Rev., 43 (2014) 3259-3302.

[35] T. Zhang, W. Lin, Chem. Soc. Rev., 43 (2014) 5982-5993.

[36] A.F. Henwood, E. Zysman-Colman, Chem. Commun., 53 (2017) 807-826.

[37] A.F. Henwood, E. Zysman-Colman, Top. Curr. Chem., 374 (2016) 36.

[38] D. Ma, T. Tsuboi, Y. Qiu, L. Duan, Adv Mater, 29 (2017) 1603253.

[39] J.C. Deaton, F.N. Castellano, Archetypal Iridium(III) Compounds for Optoelectronic and Photonic Applications, in: Iridium(III) in Optoelectronic and Photonics Applications, John Wiley \& Sons, Ltd, 2017, pp. 1-69. 
[40] Z. Liu, Z. Bian, C. Huang, Luminescent Iridium Complexes and Their Applications, in: H. Bozec, V. Guerchais (Eds.) Molecular Organometallic Materials for Optics, Springer Berlin Heidelberg, Berlin, Heidelberg, 2010, pp. 113-142.

[41] Y. You, S. Cho, W. Nam, Inorg Chem, 53 (2014) 1804-1815.

[42] D.-L. Ma, S. Lin, W. Wang, C. Yang, C.-H. Leung, Chem. Sci., 8 (2017) 878-889.

[43] K.K.-W. Lo, K.K.-S. Tso, Inorganic Chemistry Frontiers, 2 (2015) 510-524.

[44] C.K. Prier, D.A. Rankic, D.W.C. MacMillan, Chem. Rev., 113 (2013) 5322-5363.

[45] N.D. McDaniel, S. Bernhard, Dalton Trans., 39 (2010) 10021-10030.

[46] J.M. Thomsen, D.L. Huang, R.H. Crabtree, G.W. Brudvig, Dalton Trans., 44 (2015) $12452-12472$.

[47] A.F. Henwood, E. Zysman-Colman, A Comprehensive Review of Luminescent Iridium Complexes Used in Light-Emitting Electrochemical Cells (LEECs), in: Iridium(III) in Optoelectronic and Photonics Applications, John Wiley \& Sons, Ltd, 2017, pp. 275-357.

[48] E. Longhi, L. De Cola, Iridium(III) Complexes for OLED Application, in: Iridium(III) in Optoelectronic and Photonics Applications, John Wiley \& Sons, Ltd, 2017, pp. 205-274.

[49] L. Flamigni, J.-P. Collin, J.-P. Sauvage, Acc. Chem. Res., 41 (2008) 857-871.

[50] V.L. Whittle, J.A.G. Williams, Dalton Trans., (2009) 3929-3940.

[51] A.M. Soliman, D. Fortin, P.D. Harvey, E. Zysman-Colman, Dalton Trans., 41 (2012) 9382-9393.

[52] A. Winter, U.S. Schubert, Polymeric Architectures Containing Phosphorescent Iridium(III) Complexes, in: Iridium(III) in Optoelectronic and Photonics Applications, John Wiley \& Sons, Ltd, 2017, pp. 145-203.

[53] Q. Zhao, S.-J. Liu, W. Huang, Macromol. Rapid Commun., 31 (2010) 794-807.

[54] F. Xu, H.U. Kim, J.-H. Kim, B.J. Jung, A.C. Grimsdale, D.-H. Hwang, Prog. Polym. Sci., 47 (2015) 92-121.

[55] C. Wu, H.-F. Chen, K.-T. Wong, M.E. Thompson, J. Am. Chem. Soc., 132 (2010) 31333139.

[56] M. Mauro, K.C. Schuermann, R. Prétôt, A. Hafner, P. Mercandelli, A. Sironi, L. De Cola, Angew. Chem. Int. Ed., 49 (2010) 1222-1226.

[57] M. Sandroni, E. Zysman-Colman, Dalton Trans., 43 (2014) 3676-3680.

[58] K.N. Swanick, M. Sandroni, Z. Ding, E. Zysman-Colman, Chem. Eur. J., 21 (2015) 74357440.

[59] E.H. Doeven, E.M. Zammit, G.J. Barbante, C.F. Hogan, N.W. Barnett, P.S. Francis, Angew. Chem. Int. Ed., 51 (2012) 4354-4357.

[60] G.J. Barbante, N. Kebede, C.M. Hindson, E.H. Doeven, E.M. Zammit, G.R. Hanson, C.F. Hogan, P.S. Francis, Chem. Eur. J., 20 (2014) 14026-14031.

[61] E.H. Doeven, E.M. Zammit, G.J. Barbante, P.S. Francis, N.W. Barnett, C.F. Hogan, Chem. Sci., 4 (2013) 977-982.

[62] A. Ionescu, E.I. Szerb, Y.J. Yadav, A.M. Talarico, M. Ghedini, N. Godbert, Dalton Trans., 43 (2014) 784-789.

[63] V. Fiorini, A. D'Ignazio, K.D. Magee, M.I. Ogden, M. Massi, S. Stagni, Dalton Trans, 45 (2016) 3256-3259.

[64] S. Lamansky, P. Djurovich, D. Murphy, F. Abdel-Razzaq, R. Kwong, I. Tsyba, M. Bortz, B. Mui, R. Bau, M.E. Thompson, Inorg. Chem., 40 (2001) 1704-1711.

[65] S. Lamansky, P. Djurovich, D. Murphy, F. Abdel-Razzaq, H.-E. Lee, C. Adachi, P.E. Burrows, S.R. Forrest, M.E. Thompson, J. Am. Chem. Soc., 123 (2001) 4304-4312.

[66] Y. Chi, P.-T. Chou, Chem. Soc. Rev., 39 (2010) 638-655.

[67] C.E. Housecroft, E.C. Constable, Coord. Chem. Rev., 350 (2017) 155-177.

[68] R.D. Costa, G. Fernández, L. Sánchez, N. Martín, E. Ortí, H.J. Bolink, Chem. Eur. J., 16 (2010) 9855-9863. 
[69] E.A. Plummer, A. van Dijken, J.W. Hofstraat, L. De Cola, K. Brunner, Adv. Funct. Mater., 15 (2005) 281-289.

[70] X. Yang, X. Xu, J.S. Dang, G. Zhou, C.L. Ho, W.Y. Wong, Inorg Chem, 55 (2016) 17201727.

[71] X. Yang, Z. Feng, J. Zhao, J.S. Dang, B. Liu, K. Zhang, G. Zhou, ACS Appl Mater Interfaces, 8 (2016) 33874-33887.

[72] A. M'Hamedi, A.S. Batsanov, M.A. Fox, M.R. Bryce, K. Abdullah, H.A. Al-Attar, A.P. Monkman, J. Mater. Chem., 22 (2012) 13529-13540.

[73] Y. Zheng, A.S. Batsanov, M.A. Fox, H.A. Al-Attar, K. Abdullah, V. Jankus, M.R. Bryce, A.P. Monkman, Angew Chem Int Ed Engl, 53 (2014) 11616-11619.

[74] M.Y. Wong, G. Xie, C. Tourbillon, M. Sandroni, D.B. Cordes, A.M.Z. Slawin, I.D.W. Samuel, E. Zysman-Colman, Dalton Trans., (2015) DOI: 10.1039/C1034DT03127J

[75] K. He, N. Su, Y. Junting, Y. Liu, W. Xiong, Z. Hao, D. Ma, W. Zhu, Tetrahedron, 72 (2016) 7164-7169.

[76] F. Dumur, G. Nasr, G. Wantz, C.R. Mayer, E. Dumas, A. Guerlin, F. Miomandre, G. Clavier, D. Bertin, D. Gigmes, Org. Electron., 12 (2011) 1683-1694.

[77] G. Nasr, A. Guerlin, F. Dumur, L. Beouch, E. Dumas, G. Clavier, F. Miomandre, F. Goubard, D. Gigmes, D. Bertin, G. Wantz, C.R. Mayer, Chem. Commun., 47 (2011) 1069810700.

[78] C. He, K. Lu, W. Lin, J Am Chem Soc, 136 (2014) 12253-12256.

[79] H. Izumi, T. Torigoe, H. Ishiguchi, H. Uramoto, Y. Yoshida, M. Tanabe, T. Ise, T. Murakami, T. Yoshida, M. Nomoto, K. Kohno, Cancer Treatment Reviews, 29 (2003) 541549.

[80] S. Chen, Y. Hong, Y. Liu, J. Liu, C.W. Leung, M. Li, R.T. Kwok, E. Zhao, J.W. Lam, Y. Yu, B.Z. Tang, J Am Chem Soc, 135 (2013) 4926-4929.

[81] Y. Ma, H. Liang, Y. Zeng, H. Yang, C.-L. Ho, W. Xu, Q. Zhao, W. Huang, W.-Y. Wong, Chem. Sci., 7 (2016) 3338-3346.

[82] S. Liu, A. Xu, Z. Chen, Y. Ma, H. Yang, Z. Shi, Q. Zhao, Opt Express, 24 (2016) 2824728255.

[83] J.H. Vella, A. Parthasarathy, K.S. Schanze, J Phys Chem A, 117 (2013) 7818-7822.

[84] K. Binnemans, Chem. Rev., 105 (2005) 4148-4204.

[85] S.A. Hudson, P.M. Maitlis, Chem. Rev., 93 (1993) 861-885.

[86] P. Berdague, J. Courtieu, P.M. Maitlis, J. Chem. Soc., Chem. Commun., (1994) 13131314.

[87] M.A. Esteruelas, L.A. Oro, E. Sola, M.B. Ros, J.L. Serrano, J. Chem. Soc., Chem. Commun., (1989) 55-56.

[88] D.W. Bruce, D.A. Dunmur, M.A. Esteruelas, S.E. Hunt, R.L. Lagadec, P.M. Maitlis, J.R. Marsden, E. Sola, J.M. Stacey, J. Mater. Chem., 1 (1991) 251-254.

[89] S.T. Trzaska, T.M. Swager, Chem. Mater., 10 (1998) 438-443.

[90] E.I. Szerb, A.M. Talarico, I. Aiello, A. Crispini, N. Godbert, D. Pucci, T. Pugliese, M. Ghedini, Eur. J. Inorg. Chem., 2010 (2010) 3270-3277.

[91] A. Santoro, A.M. Prokhorov, V.N. Kozhevnikov, A.C. Whitwood, B. Donnio, J.A.G. Williams, D.W. Bruce, J. Am. Chem. Soc., 133 (2011) 5248-5251.

[92] A.M. Prokhorov, A. Santoro, J.A.G. Williams, D.W. Bruce, Angew. Chem. Int. Ed., 51 (2012) 95-98.

[93] Y. Wang, C.P. Cabry, M. Xiao, L. Male, S.J. Cowling, D.W. Bruce, J. Shi, W. Zhu, E. Baranoff, Chem. Eur. J., 22 (2016) 1618-1621.

[94] N.S. Kumar, M.Z. Shafikov, A.C. Whitwood, B. Donnio, P.B. Karadakov, V.N. Kozhevnikov, D.W. Bruce, Chemistry, 22 (2016) 8215-8233. 
[95] V.N. Kozhevnikov, B. Donnio, D.W. Bruce, Angew. Chem. Int. Ed., 47 (2008) 62866289.

[96] J.W. Steed, Chem. Soc. Rev., 39 (2010).

[97] N.M. Sangeetha, U. Maitra, Chem Soc Rev, 34 (2005) 821-836.

[98] X. Du, J. Zhou, J. Shi, B. Xu, Chem Rev, 115 (2015) 13165-13307.

[99] C.D. Jones, J.W. Steed, Chem. Soc. Rev., 45 (2016) 6546-6596.

[100] M.-O.M. Piepenbrock, G.O. Lloyd, N. Clarke, J.W. Steed, Chem. Rev., 110 (2010) 19602004.

[101] X. Cao, Y. Wu, K. Liu, X. Yu, B. Wu, H. Wu, Z. Gong, T. Yi, J. Mater. Chem., 22 (2012) 2650.

[102] L. Xiong, Q. Zhao, H. Chen, Y. Wu, Z. Dong, Z. Zhou, F. Li, Inorg Chem, 49 (2010) 6402-6408.

[103] Y.J. Yadav, B. Heinrich, G. De Luca, A.M. Talarico, T.F. Mastropietro, M. Ghedini, B. Donnio, E.I. Szerb, Adv. Optical Mater., 1 (2013) 844-854.

[104] M. Mauro, A. Aliprandi, D. Septiadi, N.S. Kehr, L. De Cola, Chem Soc Rev, 43 (2014) 4144-4166.

[105] A. Aliprandi, D. Genovese, M. Mauro, L. De Cola, Chem. Lett., 44 (2015) 1152-1169.

[106] N. Vogel, M. Retsch, C.A. Fustin, A. Del Campo, U. Jonas, Chem Rev, 115 (2015) 62656311.

[107] A. Guerrero-Martínez, Y. Vida, D. Domínguez-Gutiérrez, R.Q. Albuquerque, L. De Cola, Inorg. Chem., 47 (2008) 9131-9133.

[108] A.M. Talarico, M. Ghedini, C.O. Rossi, E.I. Szerb, Soft Matter, 8 (2012) 11661-11669. [109] M. Mauro, G. De Paoli, M. Otter, D. Donghi, G. D'Alfonso, L. De Cola, Dalton Trans., 40 (2011) 12106-12116.

[110] D. Aiello, A.M. Talarico, F. Teocoli, E.I. Szerb, I. Aiello, F. Testa, M. Ghedini, New J. Chem., 35 (2011) 141-148.

[111] M. de Barros e Silva Botelho, J.M. Fernandez-Hernandez, T.B. de Queiroz, H. Eckert, L. De Cola, A.S.S. de Camargo, J. Mater. Chem., 21 (2011) 8829-8834.

[112] U.M. Tefashe, K.L. Metera, H.F. Sleiman, J. Mauzeroll, Langmuir, 29 (2013) 1286612873.

[113] K.L. Metera, K.D. Hänni, G. Zhou, M.K. Nayak, H.S. Bazzi, D. Juncker, H.F. Sleiman, ACS Macro Letters, 1 (2012) 954-959.

[114] A.-H. Liang, K. Zhang, J. Zhang, F. Huang, X.-H. Zhu, Y. Cao, Chem. Mater., 25 (2013) 1013-1019.

[115] A.-h. Liang, S. Dong, K. Zhang, X. Xiao, F. Huang, X.-H.Zhu, Y. Cao, Macromol. Rapid Commun., 34 (2013) 1301-1305.

[116] A.M. Talarico, E.I. Szerb, T.F. Mastropietro, I. Aiello, A. Crispini, M. Ghedini, Dalton Trans., 41 (2012) 4919-4926.

[117] L. Donato, P. Abel, E. Zysman-Colman, Dalton Trans., 42 (2013) 8402-8412.

[118] J.M. Rawson, L. Donato, E. Zysman-Colman, CrystEngComm, 16 (2014) 8531-8536.

[119] C.E. Welby, L. Gilmartin, R.R. Marriott, A. Zahid, C.R. Rice, E.A. Gibson, P.I. Elliott, Dalton Trans, 42 (2013) 13527-13536.

[120] S. Kammer, H. Müller, N. Grunwald, A. Bellin, A. Kelling, U. Schilde, W. Mickler, C. Dosche, H.-J. Holdt, Eur. J. Inorg. Chem., 2006 (2006) 1547-1551.

[121] S. Kammer, A. Kelling, H. Baier, W. Mickler, C. Dosche, K. Rurack, A. Kapp, F. Lisdat, H.-J. Holdt, Eur. J. Inorg. Chem., 2009 (2009) 4648-4659.

[122] S. Kammer, I. Starke, A. Pietrucha, A. Kelling, W. Mickler, U. Schilde, C. Dosche, E. Kleinpeter, H.-J. Holdt, Dalton Trans., 41 (2012) 10219-10227.

[123] L. Chen, Q. Chen, M. Wu, F. Jiang, M. Hong, Acc Chem Res, 48 (2015) 201-210.

[124] W. Wang, Y.X. Wang, H.B. Yang, Chem Soc Rev, 45 (2016) 2656-2693. 
[125] P.J. Stang, B. Olenyuk, Acc. Chem. Res., 30 (1997) 502-518.

[126] S. Kitagawa, R. Kitaura, S. Noro, Angew Chem Int Ed Engl, 43 (2004) 2334-2375.

[127] C. Wang, D. Liu, Z. Xie, W. Lin, Inorg Chem, 53 (2014) 1331-1338.

[128] Z. Xie, L. Ma, K.E. deKrafft, A. Jin, W. Lin, J. Am. Chem. Soc., 132 (2010) 922-923.

[129] M.-L. Ho, Y.-A. Chen, T.-C. Chen, P.-J. Chang, Y.-P. Yu, K.-Y. Cheng, C.-H. Shih, G.H. Lee, H.-S. Sheu, Dalton Trans., 41 (2012) 2592-2600.

[130] K.Y. Cheng, J.C. Wang, C.Y. Lin, W.R. Lin, Y.A. Chen, F.J. Tsai, Y.C. Chuang, G.Y. Lin, C.W. Ni, Y.T. Zeng, M.L. Ho, Dalton Trans, 43 (2014) 6536-6547.

[131] Y. Xu, L. Li, S. Zhang, S. Zhao, J. Luo, Crystal Growth \& Design, 16 (2016) 406-411.

[132] L. Li, S. Zhang, L. Xu, Z.-N. Chen, J. Luo, J. Mater. Chem. C, 2 (2014).

[133] D. Zeng, M. Ren, S.S. Bao, L. Li, L.M. Zheng, Chem. Commun., 50 (2014) 8356-8359.

[134] N.M. Ali, V.L. MacLeod, P. Jennison, I.V. Sazanovich, C.A. Hunter, J.A. Weinstein, M.D. Ward, Dalton Trans., 41 (2012) 2408-2419.

[135] L. Li, S. Zhang, L. Xu, J. Wang, L.-X. Shi, Z.-N. Chen, M. Hong, J. Luo, Chem. Sci., 5 (2014).

[136] L. Li, S. Zhang, L. Xu, L. Han, Z.N. Chen, J. Luo, Inorg Chem, 52 (2013) 12323-12325.

[137] C. Wang, Z. Xie, K.E. deKrafft, W. Lin, J. Am. Chem. Soc., 133 (2011) 13445-13454.

[138] C. Wang, J.-L. Wang, W. Lin, J. Am. Chem. Soc., 134 (2012) 19895-19908.

[139] C. Wang, K.E. deKrafft, W. Lin, J. Am. Chem. Soc., 134 (2012) 7211-7214.

[140] P. Contreras Carballada, N. Mourtzis, M. Felici, S. Bonnet, R.J.M. Nolte, R.M. Williams,

L. De Cola, M.C. Feiters, Eur. J. Org. Chem., 2012 (2012) 6729-6736.

[141] N. Mourtzis, P.C. Carballada, M. Felici, R.J. Nolte, R.M. Williams, L. de Cola, M.C. Feiters, Phys Chem Chem Phys, 13 (2011) 7903-7909.

[142] S.-L. Huang, N. Liu, Y. Ling, H.-K. Luo, Chem. Asian J., ASAP DOI: 10.1002/asia.201701339.

[143] K. Fan, S.-S. Bao, W.-X. Nie, C.-H. Liao, L.-M. Zheng, Inorg. Chem., 57 (2018) 10791089.

[144] C. Bronner, S.p.A. Baudron, M.W. Hosseini, Inorg. Chem., 49 (2010) 8659-8661.

[145] C. Xu, A. Guenet, N. Kyritsakas, J.-M. Planeix, M.W. Hosseini, Chem. Commun., 51 (2015) 14785-14788.

[146] C. Xu, A. Guenet, N. Kyritsakas, J.-M. Planeix, M.W. Hosseini, Inorg. Chem., 54 (2015) 10429-10439.

[147] M.D. Ward, P.R. Raithby, Chem. Soc. Rev., 42 (2013) 1619-1636.

[148] M.M.J. Smulders, I.A. Riddell, C. Browne, J.R. Nitschke, Chem. Soc. Rev., 42 (2013) $1728-1754$.

[149] R. Chakrabarty, P.S. Mukherjee, P.J. Stang, Chem. Rev., 111 (2011) 6810-6918.

[150] S. Zarra, D.M. Wood, D.A. Roberts, J.R. Nitschke, Chem Soc Rev, 44 (2015) 419-432.

[151] M. Yoshizawa, J.K. Klosterman, M. Fujita, Angew. Chem. Int. Ed., 48 (2009) 34183438.

[152] Y.F. Han, W.G. Jia, W.B. Yu, G.X. Jin, Chem Soc Rev, 38 (2009) 3419-3434.

[153] N. Singh, D. Kim, D.H. Kim, E.H. Kim, H. Kim, M.S. Lah, K.W. Chi, Dalton Trans, 46 (2017) 571-577.

[154] L. Yang, A. von Zelewsky, H. Stoeckli-Evans, Chem. Commun., (2005) 4155-4157.

[155] E. Baranoff, E. Orselli, L. Allouche, D. Di Censo, R. Scopelliti, M. Gratzel, M.K. Nazeeruddin, Chem. Commun., 47 (2011) 2799-2801.

[156] C.T. Wang, L.C. Shiu, K.B. Shiu, Chemistry, 21 (2015) 7026-7029.

[157] O. Chepelin, J. Ujma, X. Wu, A.M.Z. Slawin, M.B. Pitak, S.J. Coles, J. Michel, A.C. Jones, P.E. Barran, P.J. Lusby, J. Am. Chem. Soc., 134 (2012) 19334-19337.

[158] M. Fujita, D. Oguro, M. Miyazawa, H. Oka, K. Yamaguchi, K. Ogura, Nature, 378 (1995) 469-471. 
[159] D. Rota Martir, D. Escudero, D. Jacquemin, D.B. Cordes, A.M.Z. Slawin, H.A. Fruchtl, S.L. Warriner, E. Zysman-Colman, Chem. Eur. J., 23 (2017) 14358-14366.

[160] D. Rota Martir, G.J. Hedley, D.B. Cordes, A.M.Z. Slawin, D. Escudero, D. Jacquemin, T. Kosikova, D. Philp, D.M. Dawson, S.E. Ashbrook, I.D.W. Samuel, E. Zysman-Colman, Dalton Trans., 45 (2016) 17195-17205.

[161] D.R. Martir, C. Momblona, A. Pertegás, D.B. Cordes, A.M.Z. Slawin, H.J. Bolink, E. Zysman-Colman, ACS Applied Materials \& Interfaces, 8 (2016) 33907-33915.

[162] V.E. Pritchard, D. Rota Martir, S. Oldknow, S. Kai, S. Hiraoka, N.J. Cookson, E. Zysman-Colman, M.J. Hardie, Chem. Eur. J., 23 (2017) 6290-6294.

[163] V.E. Pritchard, D. Rota Martir, E. Zysman-Colman, M.J. Hardie, Chem. Eur. J., 23 (2017) 8839-8849.

[164] X. Li, J. Wu, C. He, R. Zhang, C. Duan, Chem. Commun., 52 (2016) 5104-5107.

[165] X. Li, J. Wu, L. Chen, X. Zhong, C. He, R. Zhang, C. Duan, Chem. Commun., 52 (2016) 9628-9631.

[166] C.D. Boone, S. Gill, A. Habibzadegan, R. McKenna, International Journal of Chemical Engineering, 2013 (2013) 1-6.

[167] M. Waki, N. Mizoshita, T. Tani, S. Inagaki, Angew. Chem. Int. Ed., 50 (2011) 1166711671.

[168] S. Horiuchi, H. Tanaka, E. Sakuda, Y. Arikawa, K. Umakoshi, Chem. Eur. J., 22 (2016) 17533-17537.

[169] L.R. Alrawashdeh, A.I. Day, L. Wallace, Dalton Trans, 42 (2013) 16478-16481.

[170] C. Xu, D. Mochizuki, Y. Hashimoto, T. Honda, Y. Tsukahara, T. Yamauchi, Y. Wada, Eur. J. Inorg. Chem., 2012 (2012) 3113-3120.

[171] C. Xu, D. Mochizuki, M.M. Maitani, Y. Wada, Eur. J. Inorg. Chem., 2014 (2014) 14701476.

[172] M. Waki, Y. Maegawa, K. Hara, Y. Goto, S. Shirai, Y. Yamada, N. Mizoshita, T. Tani, W.J. Chun, S. Muratsugu, M. Tada, A. Fukuoka, S. Inagaki, J Am Chem Soc, 136 (2014) 40034011.

[173] W.J. Finkenzeller, H. Yersin, Chem. Phys. Lett., 377 (2003) 299-305.

[174] D. Mochizuki, M. Sugiyama, M.M. Maitani, Y. Wada, Eur. J. Inorg. Chem., 2013 (2013) 2324-2329.

[175] C.-Y. Sun, X.-L. Wang, X. Zhang, C. Qin, P. Li, Z.-M. Su, D.-X. Zhu, G.-G. Shan, K.Z. Shao, H. Wu, J. Li, Nat Commun, 4 (2013) 1-8. 
TOC graphic

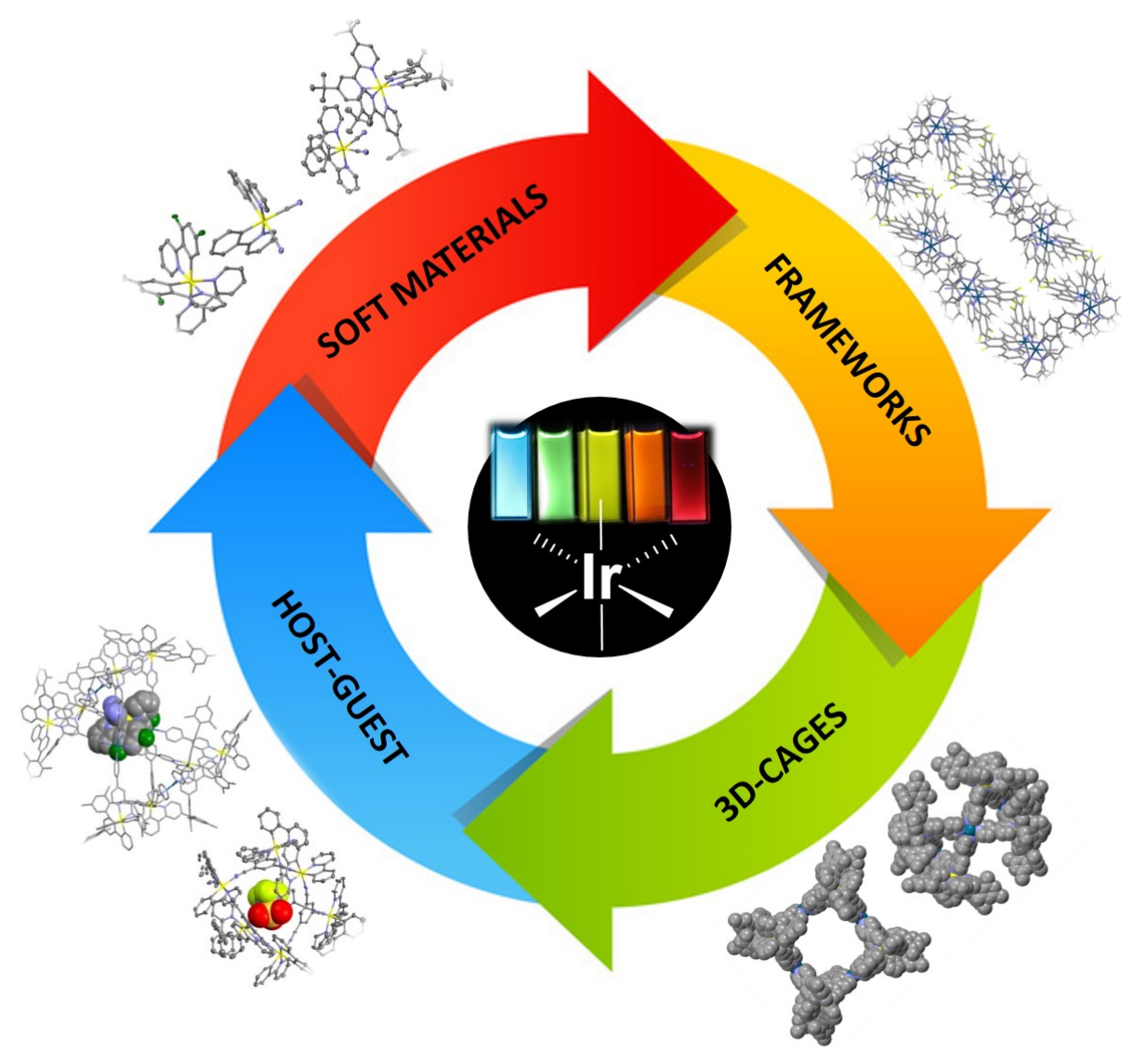

